United States Nuclear Regulatory Commission

Protecting People and the Environment

\title{
Validation of $\mathbf{k}_{\text {eff }}$ Calculations for Extended BWR Burnup Credit
}




\section{AVAILABILITY OF REFERENCE MATERIALS IN NRC PUBLICATIONS}

\section{NRC Reference Material}

As of November 1999, you may electronically access NUREG-series publications and other NRC records at NRC's Library at www.nrc.gov/reading-rm.html. Publicly released records include, to name a few, NUREG-series publications; Federal Register notices; applicant, licensee, and vendor documents and correspondence; NRC correspondence and internal memoranda; bulletins and information notices; inspection and investigative reports; licensee event reports; and Commission papers and their attachments.

NRC publications in the NUREG series, NRC regulations, and Title 10, "Energy," in the Code of Federal Regulations may also be purchased from one of these two sources.

1. The Superintendent of Documents

U.S. Government Publishing Office

Washington, DC 20402-0001

Internet: bookstore.gpo.gov

Telephone: (202) 512-1800

Fax: (202) 512-2104

2. The National Technical Information Service 5301 Shawnee Road

Alexandria, VA 22312-0002

www.ntis.gov

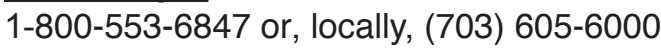

A single copy of each NRC draft report for comment is available free, to the extent of supply, upon written request as follows:

\section{Address: U.S. Nuclear Regulatory Commission}

Office of Administration

Multimedia, Graphics, and Storage \&

Distribution Branch

Washington, DC 20555-0001

E-mail: distribution.resource@nrc.gov

Facsimile: (301) 415-2289

Some publications in the NUREG series that are posted at NRC's Web site address www.nrc.gov/reading-rm/ doc-collections/nuregs are updated periodically and may differ from the last printed version. Although references to material found on a Web site bear the date the material was accessed, the material available on the date cited may subsequently be removed from the site.

\section{Non-NRC Reference Material}

Documents available from public and special technical libraries include all open literature items, such as books, journal articles, transactions, Federal Register notices, Federal and State legislation, and congressional reports. Such documents as theses, dissertations, foreign reports and translations, and non-NRC conference proceedings may be purchased from their sponsoring organization.

Copies of industry codes and standards used in a substantive manner in the NRC regulatory process are maintained at-

\section{The NRC Technical Library \\ Two White Flint North \\ 11545 Rockville Pike \\ Rockville, MD 20852-2738}

These standards are available in the library for reference use by the public. Codes and standards are usually copyrighted and may be purchased from the originating organization or, if they are American National Standards, from-
American National Standards Institute
11 West 42nd Street
New York, NY 10036-8002
www.ansi.org
(212) 642-4900

Legally binding regulatory requirements are stated only in laws; NRC regulations; licenses, including technical specifications; or orders, not in NUREG-series publications. The views expressed in contractor prepared publications in this series are not necessarily those of the NRC.

The NUREG series comprises (1) technical and administrative reports and books prepared by the staff (NUREG-XXXX) or agency contractors (NUREG/CR-XXXX), (2) proceedings of conferences (NUREG/CP-XXXX),

(3) reports resulting from international agreements

(NUREG/IA-XXXX),(4) brochures (NUREG/BR-XXXX), and

(5) compilations of legal decisions and orders of the Commission and Atomic and Safety Licensing Boards and of Directors' decisions under Section 2.206 of NRC's regulations (NUREG-0750).

DISCLAIMER: This report was prepared as an account of work sponsored by an agency of the U.S. Government. Neither the U.S. Government nor any agency thereof, nor any employee, makes any warranty, expressed or implied, or assumes any legal liability or responsibility for any third party's use, or the results of such use, of any information, apparatus, product, or process disclosed in this publication, or represents that its use by such third party would not infringe privately owned rights. 
United States Nuclear Regulatory Commission

Protecting People and the Environment

\section{Validation of $k_{\text {eff }}$ Calculations for Extended BWR Burnup Credit}

Manuscript Completed: July 2018

Date Published: December 2018

Prepared by:

W. J. Marshall

J. B. Clarity

S. M. Bowman

Oak Ridge National Laboratory

Managed by UT-Battelle, LLC

Oak Ridge, Tennessee 37831-6170

Mourad Aissa, NRC Project Manager

Office of Nuclear Regulatory Research 



\begin{abstract}
The US Nuclear Regulatory Commission and consensus standards recommend validation of the numerical methods used in criticality safety analyses. This validation requires the comparison of computational results with measurements of physical systems which are neutronically similar to those used in the safety analysis being performed. To this end, this document examines the methods available to generate sensitivity data to help identify systems similar to spent boilingwater reactor (BWR) fuel in a flooded spent nuclear fuel transportation or storage cask. A large number of critical benchmark experiments are surveyed using sensitivity/uncertainty $(S / U)$ techniques to assess their applicability to BWR burnup credit (BUC) beyond the burnup of peak reactivity. Multiple burnups of BWR assemblies are considered herein, as well as the actinide-only (AO) and actinide-and-major-fission-product (AFP) isotope sets. Sample validations are completed for representative application models to demonstrate that appropriate validation is possible and to indicate the bias and bias uncertainty values expected for related applications.
\end{abstract}





\section{TABLE OF CONTENTS}

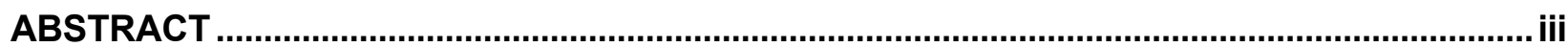

TABLE OF CONTENTS

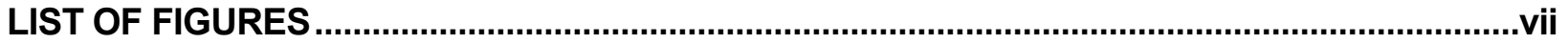

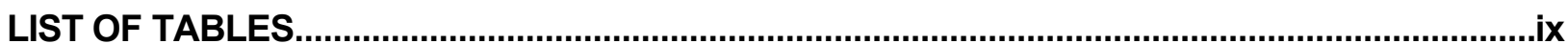

EXECUTIVE SUMMARY …….....................................................................................................

ABBREVIATIONS AND ACRONYMS .......................................................................................

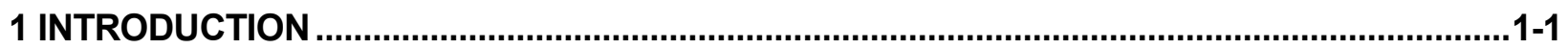

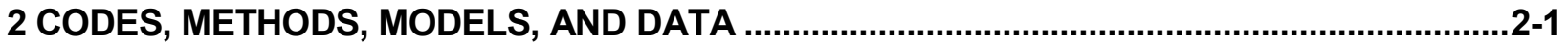

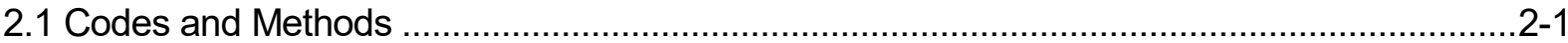

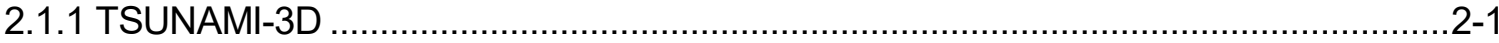

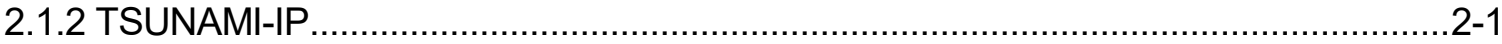

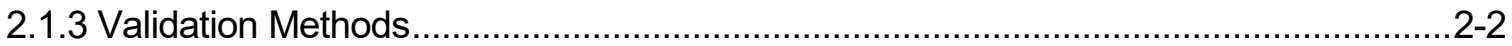

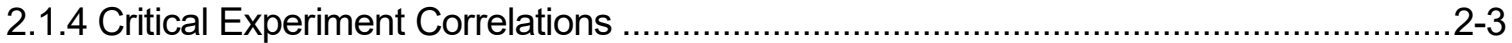

2.2 Models

2.3 Data.

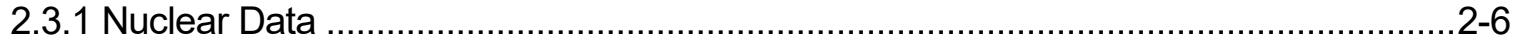

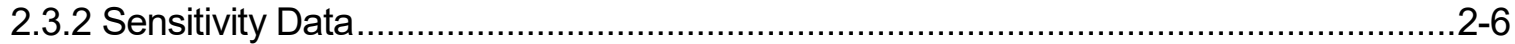

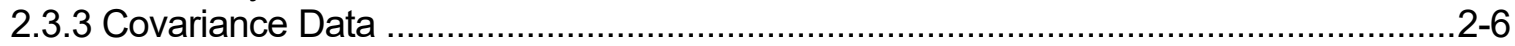

3 IMPACT OF NEW COVARIANCE DATA ON PEAK REACTIVITY VALIDATION.....................3-1

3.1 Potentially Applicable Experiments .............................................................................

3.2 Bias and Bias Uncertainty Determination........................................................................ $3-3$

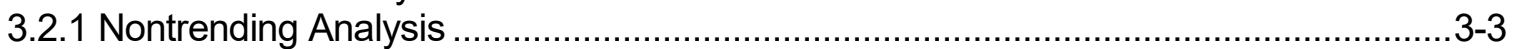

3.2.2 Traditional Trending Analysis............................................................................. $3-4$

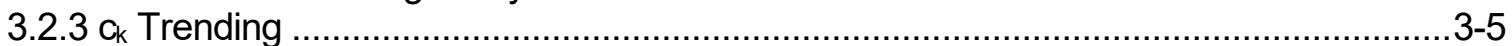

3.3 Reactivity Margins for Unvalidated Isotopes ..................................................................

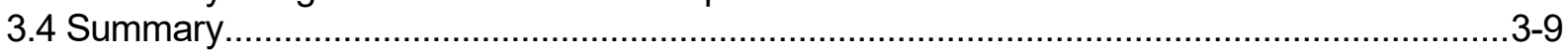

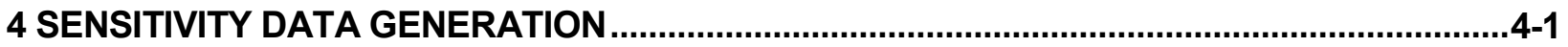

4.1 MG TSUNAMI-3D Models ......................................................................................

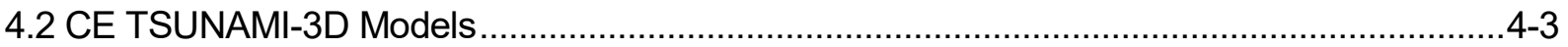

4.3 Comparison of MG and CE Sensitivities .................................................................... $4-5$

4.4 Comparison to GBC-32 ……………………………........................................

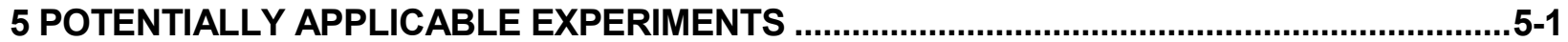

5.1 Application 1: $25 \mathrm{GWd} / \mathrm{MTU}$ and AO Isotope Set.......................................................

5.2 Application 2: $25 \mathrm{GWd} / \mathrm{MTU}$ and AFP Isotope Set......................................................5-2

5.3 Application 3: $50 \mathrm{GWd} / \mathrm{MTU}$ and AO Isotope Set..........................................................

5.4 Application 4: $50 \mathrm{GWd} / \mathrm{MTU}$ and AFP Isotope Set..................................................... $5-5$

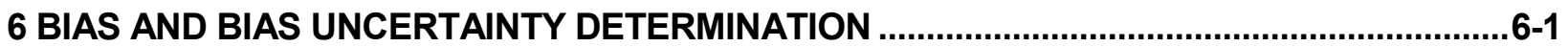

6.1 Application 1: $25 \mathrm{GWd} / \mathrm{MTU}$ and AO Isotope Set........................................................6-1

6.2 Application 2: $25 \mathrm{GWd} / \mathrm{MTU}$ and AFP Isotope Set......................................................6-3

6.3 Application 3: $50 \mathrm{GWd} / \mathrm{MTU}$ and AO Isotope Set.......................................................6-4

6.4 Application 4: $50 \mathrm{GWd} / \mathrm{MTU}$ and AFP Isotope Set .........................................................6-6 


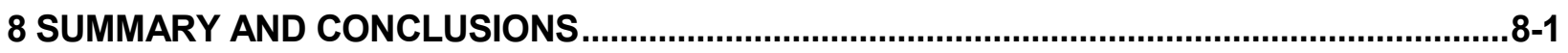

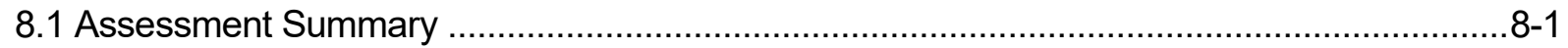

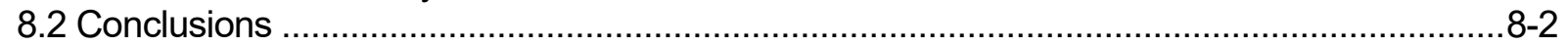

9 REFERENCES

APPENDIX A ASSESSMENT OF INTEGRAL PARAMETER E …........................................ A

APPENDIX B LIST OF CRITICAL BENCHMARK EXPERIMENTS CONSIDERED.................... B-1

APPENDIX $C$ EXPERIMENTS WITH $C_{K}$ VALUES OF AT LEAST 0.8 ......................................

APPENDIX D VALIDATION DATA FOR LCT EXPERIMENTS …......................................... D-1 


\section{LIST OF FIGURES}

Figure 2-1

Figure 2-2

Figure 3-1

Figure 3-2

Figure 3-3

Figure 3-4

Figure 3-5

Figure 3-6

Figure 4-1

Figure 4-2

Figure 4-3

Figure 4-4

Figure 4-5

Figure 5-1

Figure 5-2

Figure 5-3

Figure 5-4

Figure 5-5

Figure 5-6

Figure 5-7

Figure 5-8

Figure 6-1

Figure 6-2

Figure 6-3

Figure 6-4

Figure 6-5

Figure 6-6

Figure 6-7

Figure 6-8

Figure A-1

Figure A-2

Figure A-3

Figure A-4

Figure A-5

Figure A-6
Radial View of the GBC-68 Cask Model in KENO in the VAN Lattice. 2-4 Axial View of the GBC-68 Cask KENO Model.................................................. 2-5 $\mathrm{C}_{\mathrm{k}}$ Values for Critical Experiments Compared to GBC-68 with Vanished Lattice and AFP Isotope Set ................................................................................. 3-2

$\mathrm{C}_{\mathrm{k}}$ Values Greater than 0.8 with Vanished Lattice and AFP Isotope Set ............. 3-3

C/E Trend as a Function of Enrichment ........................................................ 3-5

$\mathrm{C} / \mathrm{E}$ Trend as a Function of EALF............................................................. 3-5

C/E Trend for the 103 experiment Set as a Function of $c_{k}$ Value ...................... 3-6

$\mathrm{C} / \mathrm{E}$ Trend for the 62 experiment Set as a Function of 56-group Covariance $c_{k}$

Value

${ }^{1} \mathrm{H}$ Total Sensitivity Profiles from MG and CE TSUNAMI-3D............................ 4-6

${ }^{10} \mathrm{~B}(\mathrm{n}, \alpha)$ Sensitivity Profiles from MG and CE TSUNAMI-3D ............................. 4-6

${ }^{235} \mathrm{U}$ Total Sensitivity Profiles from MG and CE TSUNAMI-3D .......................... 4-6

${ }^{239} \mathrm{Pu}$ Total Sensitivity Profiles from MG and CE TSUNAMI-3D .......................... 4-7

${ }^{56} \mathrm{Fe}$ Elastic Scattering Sensitivity Profiles from MG and CE TSUNAMI-3D ......... 4-8 $c_{k}$ Values for Critical Experiments Compared to GBC-68 with Fuel at a Burnup of $25 \mathrm{GWd} / \mathrm{MTU}$ and the AO Isotope Set .................................................... 5-2

$\mathrm{C}_{\mathrm{k}}$ Values Greater than 0.8 at $25 \mathrm{GWd} / \mathrm{MTU}$ Burnup with the AO Isotope Set ..... 5-2 $\mathrm{c}_{\mathrm{k}}$ Values for Critical Experiments Compared to GBC-68 with Fuel at a Burnup of $25 \mathrm{GWd} / \mathrm{MTU}$ and the AFP Isotope Set....

$c_{k}$ Values Not Less than 0.8 at 25 GWd/MTU Burnup with the AFP Isotope Set...5-4 $c_{k}$ Values for Critical Experiments Compared to GBC-68 with Fuel at a Burnup of $50 \mathrm{GWd} / \mathrm{MTU}$ and the AO Isotope Set....

$C_{k}$ Values Not Less than 0.8 at 50 GWd/MTU Burnup with the AO Isotope Set ....5-5 $c_{k}$ Values for Critical Experiments Compared to GBC-68 with Fuel at a Burnup of $50 \mathrm{GWd} / \mathrm{MTU}$ and the AFP Isotope Set ................................................... 5-6 $C_{k}$ Values Not Less than 0.8 at $50 \mathrm{GWd} / \mathrm{MTU}$ Burnup with the AFP Isotope Set..5-7 C/E vs EALF Trend for Experiments Applicable to the $25 \mathrm{GWd} / \mathrm{MTU}$ AO Case .. 6-2 C/E vs $C_{k}$ Trend for Experiments Applicable to the $25 \mathrm{GWd} / \mathrm{MTU}$ AO Case ....... 6-2 C/E vs EALF Trend for Experiments Applicable to the 25 GWd/MTU AFP Case..6-3 C/E vs $C_{k}$ Trend for Experiments Applicable to the $25 \mathrm{GWd} / \mathrm{MTU}$ AFP Case...... 6-4 C/E vs EALF Trend for Experiments Applicable to the $50 \mathrm{GWd} / \mathrm{MTU}$ AO Case .. 6-5 C/E vs $C_{k}$ Trend for Experiments Applicable to the $50 \mathrm{GWd} / \mathrm{MTU}$ AO Case ....... 6-5 $\mathrm{C} / \mathrm{E}$ vs EALF Trend for Experiments Applicable to the $50 \mathrm{GWd}$ /MTU AFP Case..6-6 C/E vs $C_{k}$ Trend for Experiments Applicable to the 50 GWd/MTU AFP Case...... 6-7 E Values for Critical Experiments Compared to GBC-68 with Fuel at a Burnup of $25 \mathrm{GWd} / \mathrm{MTU}$ and the $\mathrm{AO}$ Isotope Set ...............................................A-2 E Values for Critical Experiments Compared to GBC-68 with Fuel at a Burnup of $25 \mathrm{GWd} / \mathrm{MTU}$ and the AFP Isotope Set ............................................A-3 E Values for Critical Experiments Compared to GBC-68 with Fuel at a Burnup of $50 \mathrm{GWd} / \mathrm{MTU}$ and the $\mathrm{AO}$ Isotope Set .............................................. E Values for Critical Experiments Compared to GBC-68 with Fuel at a Burnup of $50 \mathrm{GWd} / \mathrm{MTU}$ and the AFP Isotope Set ...........................................A-4 E Values for Critical Experiments Compared to GBC-68 with Fuel at a Burnup of $50 \mathrm{GWd} / \mathrm{MTU}$ and the AFP Isotope Set ................................................ 5 Comparison of Energy Dependent ${ }^{1} \mathrm{H}$ Sensitivities for the $50 \mathrm{GWd} / \mathrm{MTU}$ AFP Case and the LCT, HTC, and MTC Experiments A-10 



\section{LIST OF TABLES}

Table 3-1

Table 3-2

Table 3-3

Table 3-4

Table 4-1

Table 4-2

Table 4-3

Table 4-4

Table 4-5

Table 4-6

Table 4-7

Table 4-8

Table 4-9

Table 6-1

Table 7-1

Table 7-2

Table 7-3

Table 7-4

Table 7-5

Table A-1

Table A-2

Table A-3

Table A-4

Table B-1

Table C-1

Table C-2

Table C-3

Table C-4

Table D-1
Bias, Bias Uncertainty, and Calculational Margin from Trending Analyses 3-4

$k_{\text {eff }}$ Uncertainty Contributions from Major Transuranic Nuclides ........................... 3-8

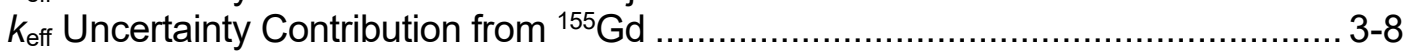

$k_{\text {eff }}$ Uncertainty Contribution from Major FPs and MAs .................................... 3-9

Summary of Comparisons of MG TSUNAMI-3D and Direct Perturbation

Sensitivities for 25 GWd/MTU Burnup and AO Isotope Set................................. 4-2

Summary of Comparisons of MG TSUNAMI-3D and Direct Perturbation

Sensitivities for $25 \mathrm{GWd} / \mathrm{MTU}$ Burnup and AFP Isotope Set.....

Summary of Comparisons of MG TSUNAMI-3D and Direct Perturbation

Sensitivities for $50 \mathrm{GWd} / \mathrm{MTU}$ Burnup and AO Isotope Set 4-3

Summary of Comparisons of MG TSUNAMI-3D and Direct Perturbation

Sensitivities for $50 \mathrm{GWd} / \mathrm{MTU}$ Burnup and AFP Isotope Set.....

Summary of Comparisons of CE TSUNAMI-3D and Direct Perturbation

Sensitivities for $25 \mathrm{GWd} / \mathrm{MTU}$ Burnup and AO Isotope Set

Summary of Comparisons of CE TSUNAMI-3D and Direct Perturbation

Sensitivities for $25 \mathrm{GWd} / \mathrm{MTU}$ Burnup and AFP Isotope Set.....

Summary of Comparisons of CE TSUNAMI-3D and Direct Perturbation

Sensitivities for $50 \mathrm{GWd} / \mathrm{MTU}$ Burnup and AO Isotope Set

Summary of Comparisons of CE TSUNAMI-3D and Direct Perturbation

Sensitivities for $50 \mathrm{GWd} / \mathrm{MTU}$ Burnup and AFP Isotope Set.....

Integral Parameters Ccomparing MG and CE TSUNAMI-3D

Bias and Bias Uncertainty Values for all 4 Applications

Uncertainty in $k_{\text {eff }}(\% \Delta \mathrm{k} / \mathrm{k})$ Due to Nuclear Data Uncertainty, Detailed

Application Models

Uncertainty in $k_{\text {eff }}(\% \Delta \mathrm{k} / \mathrm{k})$ Due to Nuclear Data Uncertainty, Non-BA Application..7-3 Reactivity Margin for Lack of Validation of FPs and MAs for Explicit Criticality

Safety Calculations

$7-4$

Reactivity Margin for Lack ofVvalidation of FPs and MAs for Non-BA Criticality

Safety Calculations.

7-4

Reactivity Margin for Lack of Validation of Residual BA ${ }^{155} \mathrm{Gd}$ in Explicit Criticality

Criticality Safety Calculations

7-4

Summary Statistics Associated with Difference Between $E$ and $c_{k}$ for the Four

Extended BUC Applications Examined in Sections 5-7....

A-4

Comparison of $E$ and $c_{k}$ Values for the Experiments Selected for Detailed

Analysis.

$A-7$

Comparison of Total Sensitivities for Major BUC Nuclear Applications and

Selected Experiments.

$A-7$

Comparison of Total Uncertainties for Major BUC Nuclear for Applications and

Selected Experiments.

A-8

Critical Benchmark Experiments Considered.

B-1

$c_{k}$ Values of at Least 0.8 for Application 1

$c_{k}$ Values of at Least 0.8 for Application 2

C-3

$c_{k}$ Values of at Least 0.8 for Application 3

C-4

$c_{k}$ Values of at Least 0.8 for Application 4

C-6

Critical Experiment Parameters Used for Validation

D-1 



\section{EXECUTIVE SUMMARY}

Applicants for certificates of compliance for spent nuclear fuel (SNF) transportation and dry storage systems perform analyses to demonstrate that these systems are adequately subcritical per the requirements of $10 \mathrm{CFR}$ Parts 71 and 72 . The credit for reactivity reduction during depletion is commonly referred to as burnup credit (BUC). BUC for boiling-water reactor (BWR) SNF is not addressed in the current interim staff guidance for pressurized-water reactor (PWR) BUC, but NUREG/CR-7194 provides a technical basis for peak reactivity BWR BUC methods. BWR BUC beyond the burnup of peak reactivity has not previously been evaluated. In this document, extended BWR BUC is defined as credit for the reduction in reactivity at burnups greater than the peak reactivity burnup.

Approaches for validation of $k_{\text {eff }}$ calculations for PWR BUC analyses are provided in NUREG/CR7109. While NUREG/CR-7194 addresses peak reactivity BUC analysis, including validation, this document presents an analysis for the validation of $k_{\text {eff }}$ calculations for extended BWR BUC. Validation is presented for the GBC-68 cask at burnups of 25 and $50 \mathrm{GWd} / \mathrm{MTU}$ using the actinide-only (AO) and actinide-and-major-fission-product (AFP) isotope sets. The results presented in this document include (1) the selection of potentially applicable benchmark experiments, (2) sample bias and bias uncertainty results, and (3) estimation of potential reactivity margins for unvalidated minor actinides (MAs) and fission products (FPs). The codes, methods, models, and nuclear data employed in this analysis are presented in Section 2.

Section 3 of this document reviews the impact of changes to covariance data used in the selection of applicable critical benchmark experiments for the validation of peak reactivity BUC analysis. The primary result from the updated covariance data is an increase in the number of benchmarks that may be applicable for validating the fully flooded, peak reactivity GBC-68 model. The bias and bias uncertainty values that result from this larger set of experiments could lead to a slightly larger total computational margin than that observed in NUREG/CR-7194. The reactivity margins for unvalidated isotopes in these results are significantly lower for actinides, somewhat higher for ${ }^{155} \mathrm{Gd}$, and unchanged for the remaining FPs. The total margin across all three of these factors is lower than that recommended in NUREG/CR-7194.

New sensitivity data were generated to allow critical experiment selection for three-dimensional (3D) models of the flooded GBC-68 cask containing fuel depleted beyond peak reactivity. The TSUNAMI-3D sequence was used to generate the sensitivity data, which were confirmed to contain accurate sensitivities by comparison to direct perturbation calculations. Section 4 discusses the generation of these sensitivity data files (SDFs). The SDFs were used in TSUNAMIIP calculations to assess the similarity of critical benchmark experiments for use in validation studies.

Four application cases were defined to examine the number of applicable benchmarks and to perform sample determinations of computational margin. All four cases included fuel stored in the flooded GBC-68 cask. The fuel was depleted to 25 or $50 \mathrm{GWd} / \mathrm{MTU}$, and the AO and AFP isotope sets were analyzed. Section 5 presents a discussion of potentially applicable experiments among 1,643 available critical benchmark experiments. For the two cases with the AO isotope set, 172 experiments were identified as applicable at a burnup of $25 \mathrm{GWd} / \mathrm{MTU}$, and 173 applicable experiments were identified as applicable at a burnup of $50 \mathrm{GWd} / \mathrm{MTU}$. A combination of LEUCOMP-THERM (LCT) and Haut Taux de Combustion (HTC) critical experiments are identified as applicable at both burnups with AO isotope set. For the two cases with the AFP isotope set, 68 HTC cases are identified as applicable at $25 \mathrm{GWd} / \mathrm{MTU}$, and $126 \mathrm{HTC}$ cases were determined to be applicable at $50 \mathrm{GWd} / \mathrm{MTU}$. Only HTC experiments have high enough assessed similarity for 
validation of models with the AFP isotope set. For both isotope sets, a larger number of HTC cases is applicable to the higher burnup case because the fuel composition used in the HTC experiments is a closer match to the higher burnup fuel.

Bias and bias uncertainties were assessed for each of the application models using both nontrending and trending techniques, as discussed in Section 6 . The nontrending biases and bias uncertainties were consistent across the four applications, with the biases ranging from -0.00132 to -0.00236 and the bias uncertainties ranging from 0.00530 to 0.00672 . The trending techniques considered trends on the energy of the average lethargy of neutrons causing fission (EALF) and, separately, on $c_{k}$. The applicable experiments bounded the EALF values of all four of the applications. The results for the trending analysis using EALF showed consistent results with biases ranging between 0.00044 and -0.00206 , and bias uncertainties ranging between 0.00646 and 0.00724 . The trending analysis using $c_{k}$ produced bias estimates ranging from -0.00047 to -0.00647 . The larger variability in the $c_{k}$ trend results from the variation of the slope of the trend line and the amount of extrapolation necessary to a $c_{k}$ of 1.0. The bias uncertainties for the $c_{k}$ trending analysis ranged from 0.00657 to 0.01556 . The bias uncertainty results were influenced strongly by the extrapolation distance noted above, and also by the number of applicable experiments.

The potentially applicable critical benchmark experiments do not contain FPs or MAs. As discussed in Section 7, a reactivity margin is needed to address the validation gap. The major actinide isotopes can be validated, so no validation gaps exist for the $A O$ isotope set. A reactivity margin of $1 \%$ of the FP and MA worth is likely appropriate for extended BWR BUC analyses that do not credit residual Gd burnable absorber. A margin of $1.5 \%$ of the total FP and MA worth is likely appropriate for analyses that include residual ${ }^{155} \mathrm{Gd}$ in burnable absorber rods. 


\section{ABBREVIATIONS AND ACRONYMS}

2D

3D

AFP

$A O$

BA

BLO

BOL

BUC

BWR

CE

C/E

CFR

CRC

DOM

EALF

ENDF

FP

GE

HTC

ICSBEP

ISG

JENDL

LCE

LCT

LEU

MA

MCT

MG

MST

MTU

NEA

NRC

PWR

SFP

SDF

SNF

S/U

USL

VAN

WPEC two dimensional

three dimensional

actinide and major fission product isotope set

actinide only isotope set

burnable absorber

Brookhaven, Los Alamos, and Oak Ridge

beginning of life

burnup credit

boiling-water reactor

continuous-energy

calculation over experiment

US Code of Federal Regulations

commercial reactor critical statepoint model

dominant

energy of the average lethargy of neutrons causing fission

evaluated nuclear data file

fission product(s)

General Electric Company

Haut Taux de Combustion

International Criticality Safety Benchmark Evaluation Project

Interim Staff Guidance

Japanese evaluated nuclear data library

laboratory critical experiments

LEU-COMP-THERM critical experiment

low-enriched uranium

minor actinide

MIX-COMP-THERM critical experiment

multigroup

MIX-SOL-THERM critical experiment

metric ton of uranium

Nuclear Energy Agency (Organisation for Economic Co-operation

and Development)

US Nuclear Regulatory Commission

pressurized water reactor

spent fuel pool

sensitivity data file

spent nuclear fuel

sensitivity and uncertainty

upper subcritical limit (in other documents, USL is used as upper safety limit)

vanished lattice

Working Party on International Nuclear Data Evaluation Co-operation 



\section{INTRODUCTION}

Applicants for certificates of compliance for spent nuclear fuel (SNF) transportation and dry storage systems perform analyses to demonstrate that these systems are adequately subcritical per the requirements of Title 10 of the Code of Federal Regulations (10 CFR) Parts 71 and 72 [1]. For pressurized-water reactor (PWR) SNF, these analyses may credit the reduction in assembly reactivity caused by depletion of fissile nuclides and buildup of neutron-absorbing nuclides during power operation. This credit for reactivity reduction during depletion is commonly referred to as burnup credit (BUC). US Nuclear Regulatory Commission (NRC) staff review BUC analyses according to the guidance in the Division of Spent Fuel Storage and Transportation Interim Staff Guidance (ISG) 8, Revision 3 [2], Burnup Credit in the Criticality Safety Analyses of PWR Spent Fuel in Transportation and Storage Casks.

BUC for boiling-water reactor (BWR) SNF is not addressed in ISG-8, but NUREG/CR-7194 [3] provides a technical basis for peak reactivity BWR BUC methods. Peak reactivity occurs when the lattice - a two-dimensional (2D) slice of the assembly-neutron multiplication factor $\left(k_{\text {inf }}\right)$ reaches its highest value at some burnup beyond beginning of life (BOL). This is a common feature of BWR assemblies caused by depletion of the burnable absorber (BA) at a more rapid rate than depletion of the fuel. BWR BUC beyond the burnup of peak reactivity has not previously been evaluated. In this document, extended BWR BUC is defined as credit for the reduction in reactivity at burnups greater than the peak reactivity burnup. Studies assessing the impacts of axial coolant density distributions, control blade usage, and axial burnup profiles on extended BWR BUC are documented in NUREG/CR-7224 [4]. Similar studies of reactor operating conditions and assembly-specific operating histories are contained in NUREG/CR-7240 [5]. The impact of each of these phenomena was evaluated to identify limiting conditions and assumptions for use in extended BWR BUC analyses.

Approaches for validation of isotopic compositions and effective neutron multiplication factor $\left(k_{\text {eff }}\right)$ calculations for PWR BUC analyses are provided in NUREG/CR-7108 [6] and NUREG/CR-7109 [7], respectively. Peak reactivity BUC analysis, including isotopic depletion and criticality validation aspects, is discussed in NUREG/CR-7194 [3]. Approaches to validate the isotopic compositions used in extended BWR BUC are addressed in a separate document, NUREG/CR-7251 [8].

Validation of $k_{\text {eff }}$ calculations for extended BWR BUC are considered in this document. Validation is presented for the GBC-68 cask [9], at burnups of 25 and $50 \mathrm{GWd} / \mathrm{MTU}$ using the actinide-only (AO) and actinide-and-major-fission-product (AFP) isotope sets. The results presented in this document include (1) the selection of potentially applicable benchmark experiments, (2) sample bias and bias uncertainty results, and (3) estimation of potential reactivity margins for unvalidated minor actinides (MAs) and fission products (FPs).

Section 2 of this document describes the codes, methods, models and data used in the validation techniques addressed in the remainder of the report. As discussed in Section 2.3, new nuclear covariance data have been included in SCALE 6.2.2 [10], and the impact of the data on the validation of $k_{\text {eff }}$ calculations at peak reactivity is assessed in Section 3. Section 4 discusses generation of the sensitivity data used here to identify the potentially applicable critical benchmark experiments documented in Section 5. Example determinations of bias and bias uncertainty are provided in Section 6, and reactivity margins for unvalidated nuclides are examined in Section 7. Finally, Section 8 summarizes the studies included in this document and the conclusions that can be drawn from them. 



\section{CODES, METHODS, MODELS, AND DATA}

This section provides details on the codes, methods, models and data used as part of the validation efforts discussed in the remainder of the report. Codes and their methods are described in Section 2.1, while the computational models used in the validation studies are described in Section 2.2. The nuclear data, sources of critical experiments with sensitivity data, and the covariance data included in SCALE 6.2.2 [10] are discussed in Section 2.3.

\subsection{Codes and Methods}

Critical experiment selection was performed using sensitivity/uncertainty $(\mathrm{S} / \mathrm{U})$ techniques, which require sensitivity data for each model and nuclear covariance data. The sensitivity data for the application models are generated using the TSUNAMI-3D sequence in SCALE 6.2.2 [10]; the TSUNAMI-3D code and its methods are described in Section 2.1.1. The sources of sensitivity data for the benchmark experiments are described in Section 2.3.2. The selection of potentially applicable critical experiments is based on the $c_{k}$ index generated with TSUNAMI-IP, which is discussed in Section 2.1.2. Nuclear covariance data used both in the selection of critical experiments (Section 5) and in the estimation of reactivity margins for unvalidated nuclides (Section 7) are discussed in Section 2.3.3. The margins proposed in Section 7 are based on nuclear covariance data propagated to $k_{\text {eff }}$ uncertainty performed in TSUNAMI-IP. The validation techniques used to determine sample bias and bias uncertainty values presented in Section 3 and Section 6 are summarized in Section 2.1.3.

\subsubsection{TSUNAMI-3D}

The TSUNAMI-3D sequence is used for three-dimensional (3D) cross section sensitivity generation for $S / U$ analysis. The sequence provides automated processing of material input and cross section data, neutron transport, calculation of sensitivity coefficients (i.e., sensitivity of $k_{\text {eff }}$ to nuclear data variation), and determination of uncertainty in $k_{\text {eff }}$ due to cross section covariances. Sensitivities based on the fluxes calculated by KENO are written to a sensitivity data file (SDF) containing the nuclide-, energy-, and reaction-dependent $k_{\text {eff }}$ sensitivity coefficients. These energydependent sensitivities are determined for each nuclide in the model using first-order perturbation theory. SCALE 6.2.2 can generate sensitivity data using either continuous-energy (CE) or multigroup (MG) methods. Both the MG and CE methods are used here to provide a comparison of the calculated sensitivities. The CE and MG sensitivity results for the GBC-68 cask model are compared in Section 4. Further details of the CE and MG sensitivity calculation methodologies are available in Section 6 of the SCALE 6.2.2 manual [10].

\subsubsection{TSUNAMI-IP}

The TSUNAMI-IP sequence provides a range of S/U analysis capabilities in SCALE 6.2.2 [10]. It is used for two primary purposes in these studies: (1) to calculate the integral parameter $c_{k}$ for critical experiment selection and (2) to propagate nuclear data uncertainties to determine an uncertainty in $k_{\text {eff }}$ for estimation of potential reactivity margins for unvalidated isotopes. Each of these calculations relies on nuclear covariance data; the SCALE 6.2.2 covariance data libraries are discussed in Section 2.3.3. A brief discussion of each TSUNAMI-IP calculation is provided in this section. Additional details are available in Section 6.5.1 of the SCALE 6.2.2 manual.

TSUNAMI-IP is used to evaluate the similarity of critical experiments and application models and to determine uncertainties in cask reactivity due to cross section covariance data. The similarity metric calculated here is $c_{k}$. $c_{k}$ is the correlation coefficient of the effect of nuclear data uncertainty on $k_{\text {eff }}$ of the application and experiment and can be determined by dividing the covariance 
between the experiment and application by the product of the uncertainties in the experiment and the application [11], as shown in Eq. (1).

$$
c_{k}=\frac{\sigma_{\text {AppExp }}^{2}}{\sigma_{\mathrm{App}} \sigma_{\mathrm{Exp}}},
$$

where: $c_{k}$ is the similarity between an application and an experiment, $\sigma^{2}{ }_{\text {AppExp }}$ is the covariance between the application and the experiment, $\sigma_{\text {App }}$ is the uncertainty in the application $k_{\text {eff }}$ due to cross section covariances (uncertainties), and

$\sigma_{\text {Exp }}$ is the uncertainty in the experiment $k_{\text {eff }}$ due to cross section covariances (uncertainties).

In essence, $c_{k}$ is the fraction of the cross section-induced uncertainty in $k_{\text {eff }}$ that is shared by two systems. A $c_{k}$ value of 1 indicates that the $k_{\text {eff }}$ values for two compared systems would be affected identically by nuclear data errors, which are the primary contributors to the computational method's bias. A $c_{k}$ value $\geq 0.8$ is considered to have a high enough degree of similarity to be acceptable for use in validation studies [11], and it is used as the cutoff for the acceptably similar experiments identified in Section 5.

Other parameters are available within TSUNAMI-IP to quantify the similarity between an application and benchmark experiments. While only the integral parameter $c_{k}$ is used for experiment selection in the main body and recommendations of this report, the integral index $E$ is discussed in Appendix $A$. Integral index $E$ differs from $c_{k}$ in that it does not consider the uncertainties of the nuclear data; it only considers the similarity of the sensitivity data. The $\mathrm{E}$ parameter is used in Section 4.3 to compare application SDFs generated from MG and CE TSUNAMI-3D. It is used in that specific context because all sensitivities are given equal weight. Differences in important isotopes with low uncertainties may not have a large impact on $c_{k}$, but they should be evident based on the values of the integral index $E$.

The propagation of nuclear covariances to uncertainties in $k_{\text {eff }}$ is also performed by TSUNAMI-IP. The uncertainty contribution from each isotope and reaction is calculated by multiplying the sensitivity of $k_{\text {eff }}$ by the uncertainty in the isotope/reaction cross section. The complete list of these results by isotope and reaction is generated by specifying the uncert_long keyword in TSUNAMIIP input. The total isotope contribution to $k_{\text {eff }}$ uncertainty is calculated by taking the square root of the sum of the squares of the uncertainties associated with relevant nuclear reactions.

\subsubsection{Validation Methods}

The primary purpose of this report is to demonstrate that sufficient applicable critical experiments exist to allow validation of $k_{\text {eff }}$ calculations in support of extended BWR BUC. A secondary purpose is to generate representative bias and bias uncertainty values for the GBC-68 cask model. Two statistical techniques for generating the bias and uncertainty values have been selected from NUREG/CR-6698 [12] for this purpose. The nontrending and unweighted lower prediction bands are used, with three different trending parameters used in the trending method. The trending parameters are the average enrichment of the lattice (for peak reactivity only), the energy of the average lethargy of neutrons causing fission (EALF), and $c_{k}$. No trending analysis on enrichment is performed for the extended BUC cases because the isotopic composition of the burned fuel assembly deviates too much from the fresh case for the results to be meaningful. The trending method used is equivalent to upper subcritical limit (USL)-1 with no administrative 
margin. The desired final results of this analysis are representative values of the bias and bias uncertainty values for extended BWR BUC applications.

\subsubsection{Critical Experiment Correlations}

A series of critical experiments is often performed with a limited number of parameters that are varied systematically to cover a range in some parameter space. Primarily, performing experiment series allows for the determination of system sensitivity to specific parameters such as lattice pitch. An additional benefit to performing experiments in series is that several related experiments can be done at lower cost per experiment and in less time than if each experiment had been performed in isolation.

The use of experiment series in validation creates additional complexities because of the correlations among the individual experiments within the series. The correlation between a pair of experiments is a result of shared experimental components that include fissile, reflector, or absorbing materials, detector systems, and procedures. Many of these shared characteristics should have very little effect on the results of the experiments or the independence of the data measured or derived from the experiments. The use of common materials, however, can create correlations among the experiments that demonstrably reduce the independence of each experiment in a series. This can impact the determination of the computational bias, but it is far more likely to affect the uncertainty in the bias. The uncertainty is increased because several measurements of the same system do not provide as much unique information as the same number of measurements of different systems. Thus, the correlation among experiments in a series acts to reduce the effective number of experiments in a validation set. The smaller number of effective experiments would lead to a larger uncertainty, so neglecting the correlations is nonconservative because it results in a lower bias uncertainty.

The impact of critical experiment correlations may be larger for BUC analyses than for other applications because a smaller number of experiments are applicable for performing the validation. For peak reactivity BWR BUC validation, for instance, most of the applicable experiments are drawn from the LEU-COMP-THERM-008, LEU-COMP-THERM-011, and LEUCOMP-THERM-051 evaluations [3] in the International Criticality Safety Benchmark Evaluation Project (ICSBEP) Handbook [13]. These experiments are documented in three different series, but all three were performed at the Babcock and Wilcox Lynchburg Research Center using the same fuel rods and the same fuel rod pitch. The HTC experiments [14] are another set of experiments which may be highly correlated and are used in BUC validation. The fissile material is the same in all 156 cases, and is a specific mix of actinides intended to represent PWR fuel near discharge from the reactor. The experiments were carried out over a range of fuel rod pitches and with different absorbers and reflectors. These variations will reduce the correlations among the experiments, but it is not clear by how much. Experiments using the same pitch are likely to be moderately to highly correlated. The small number of applicable experiments from different series and facilities makes BUC validation particularly vulnerable to the effects of critical experiment correlations.

The challenge facing criticality safety practitioners and regulators is to establish a reliable method of determining the correlations among the critical experiments and ultimately to determine methods to incorporate them into usable validation techniques. Further information on the determination of correlation coefficients is available in Hoefer et al. [15] and in Marshall, Rearden, and Pevey [16]. One proposed validation technique incorporating correlations into trending 
analysis is also available [17]. Further work is needed to develop correlation coefficients and validation techniques that are defensible in a regulatory proceeding, and to assess the impact of these new methods on BUC validation.

\subsection{Models}

The GBC-68 computational benchmark model was developed in NUREG/CR-7157 [9] as a generic BUC cask for modeling BWR SNF. The KENO model of the fuel loaded in the cask explicitly represents each fuel rod in the General Electric Company (GE) 14 fuel assemblies, including the gap and cladding. Part-length rods are truncated at the appropriate elevation so that both the full lattice (referred to as full or dominant and abbreviated as "DOM") and the vanished lattice (VAN) are included explicitly in the KENO model. The fuel assembly channel model is simplified in KENO and is represented with constant thickness and squared corners. All fuel assemblies in the GBC-68 cask model are assumed to contain fuel with identical compositions and irradiation histories. A single average fuel composition is used for fuel pins without gadolinium, and seven unique compositions are used for the rings modeling the gadolinium fuel pins in each axial node.

All KENO models contain 25 axial nodes, each 6 inches in length $(15.24 \mathrm{~cm})$. Figure $2-1$ shows a radial view of the GBC-68 half-cask model depicting the cask body, basket, and fuel assemblies. Figure 2-2 provides an axial view of the model with each unique axial fuel composition shown in a different color.

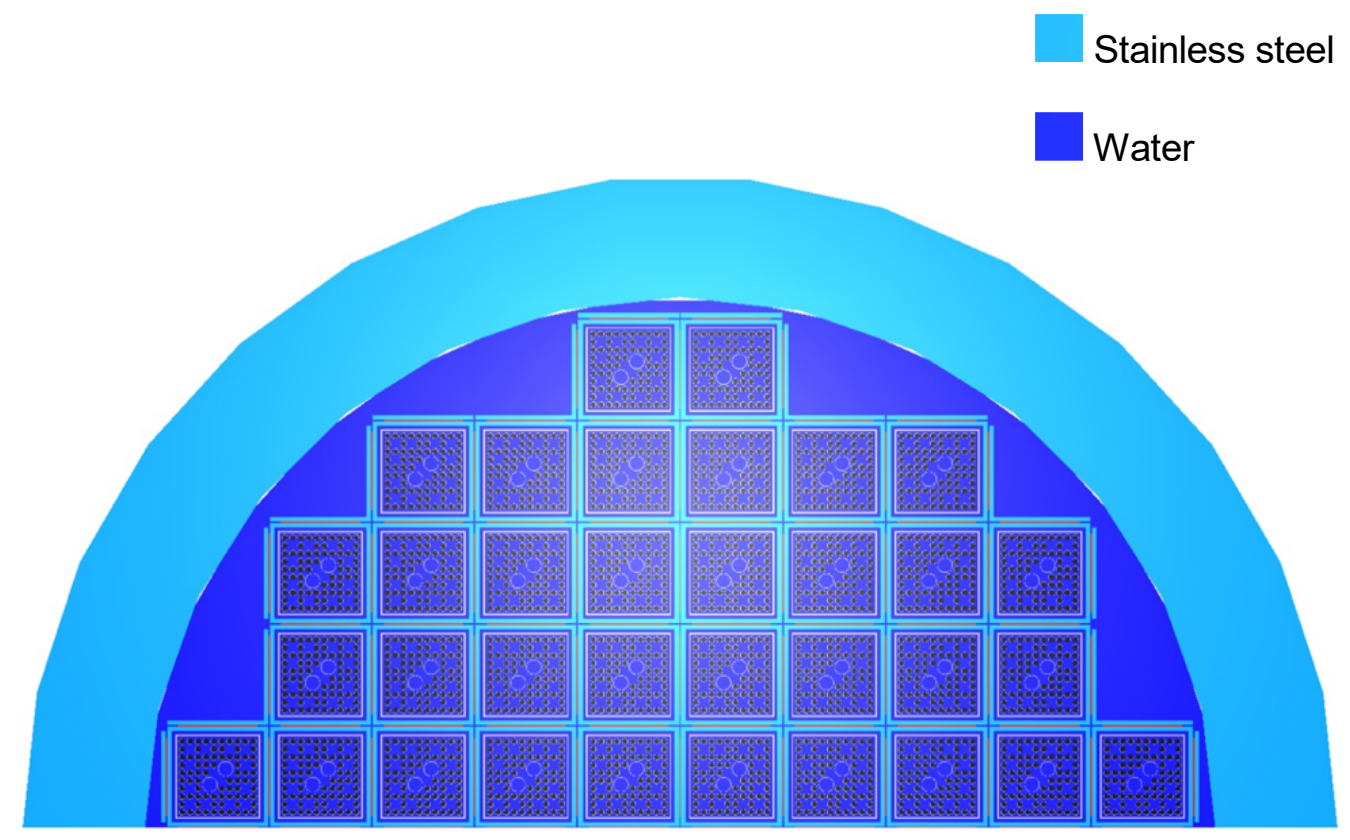

Figure 2-1 Radial View of the GBC-68 Cask Model in KENO in the VAN Lattice 


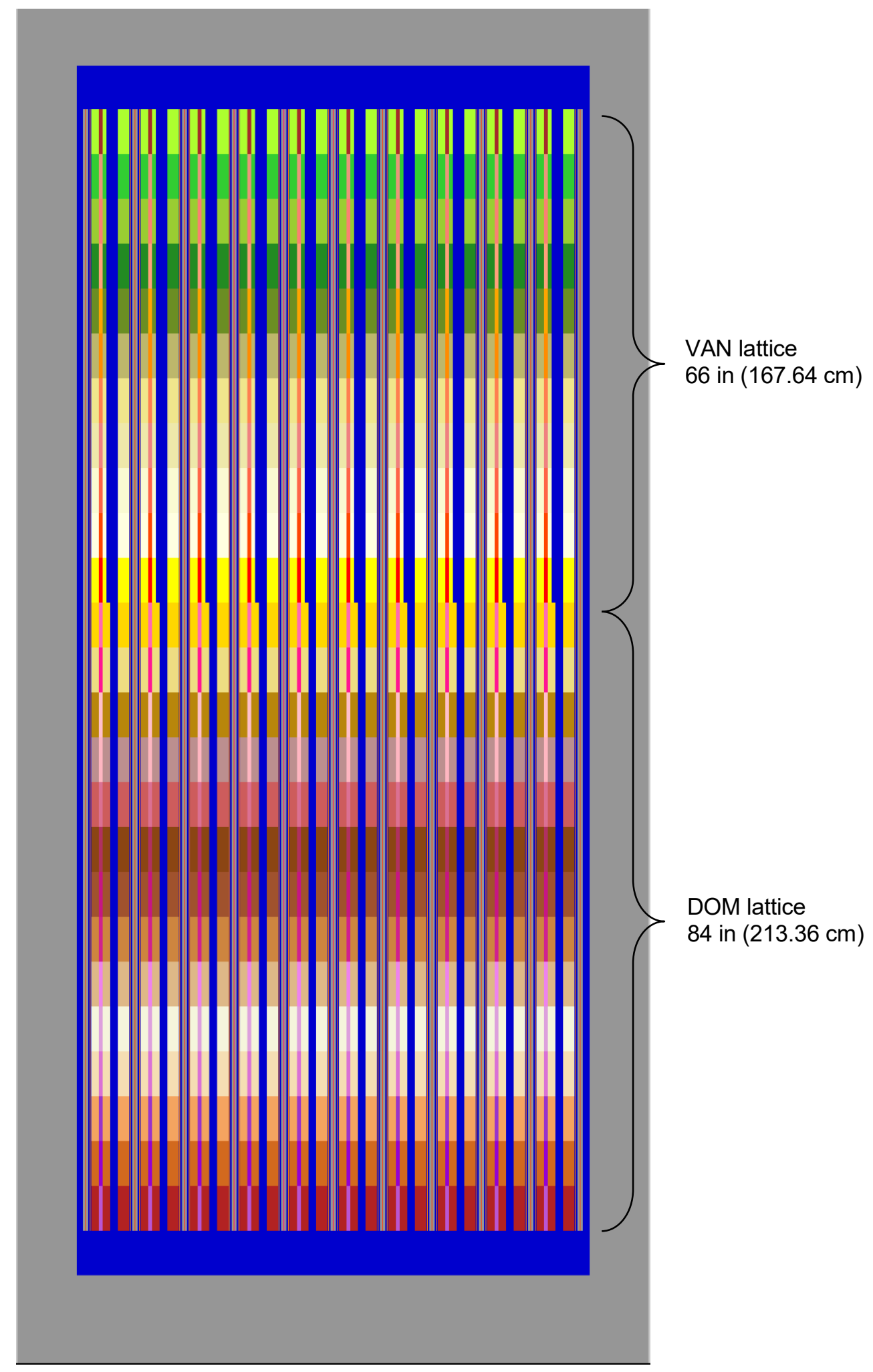

Figure 2-2 Axial View of the GBC-68 Cask KENO Model 


\subsection{Data}

A range of different data types is used in this work. Nuclear data are used for the neutron transport calculations, sensitivity data generated with TSUNAMI-3D for both experiments and the application models are used in conjunction with covariance (uncertainty) data for critical experiment selection and the determination of reactivity margins for unvalidated isotopes. These data sets are described in the following subsections.

\subsubsection{Nuclear Data}

The nuclear data used in the transport calculations consist of reaction cross sections, fission multiplicities $(\bar{v})$, and fission neutron energy distributions $(\mathrm{X})$. All these data are contained in the nuclear data libraries distributed with SCALE [10]. The libraries based on ENDF/B-VII.1 [18] are used here, and most results presented are based on the CE data. Some results are generated using the MG libraries; any MG data will be explicitly identified.

\subsubsection{Sensitivity Data}

S/U methods are used to identify potentially applicable experiments for validating $k_{\text {eff }}$ calculations in extended BWR BUC analyses. Sensitivity data are therefore needed for the applications and the experiments being considered. The sensitivity data for the applications are generated as a part of this work, as discussed in Section 4.

A set of 1,643 critical experiments with available SDFs was generated for use in NUREG/CR7194 [3]. The same suite of experiments is considered here. This set includes all experiments considered in NUREG/CR-7109 [7] except for the French fission product experiments, all the experiments in the VALID suite [19], and a number of experiments with sensitivity data generated by the Nuclear Energy Agency (NEA) [20]. The NEA experiments are drawn from the LEU-COMPTHERM (LCT), MIX-COMP-THERM (MCT) and MIX-SOL-THERM (MST) categories. Almost 1,400 LCT experiments and more than $500 \mathrm{MIX}$ experiments are included in the ICSBEP Handbook [13]; a subset of these experiments have SDFs available on the Handbook. The complete suite of experiments consists of over 1,100 low-enriched uranium (LEU) experiments and more than $475 \mathrm{MIX}$ experiments; the entire list of experiments is provided in Appendix $\mathrm{B}$. The SDFs for the experiments are generally based on ENDF/B-VII.0 libraries with 238 energy groups. The SDFs were generated in SCALE 6 or SCALE 6.1 and are acceptable when screening experiment similarity. The sensitivities do not change dramatically with different cross section libraries, so the similarity assessment between the application and experiments is unaffected. This was demonstrated in sensitivity studies using ENDF/B-V and ENDF/B-VI in NUREG/CR-7109 [7]. The $k_{\text {eff }}$ values associated with the SDFs generated with different cross section libraries should not be used in validation.

\subsubsection{Covariance Data}

Two different sets of nuclear covariance data are used in aspects of this work. These libraries express the uncertainties in the nuclear data which result primarily from measurement and evaluation. The primary covariance library used is the 56-group library developed for SCALE 6.2 [10]. The 44-group covariance library originally developed for SCALE 6 is used here only for comparison with results for the peak reactivity validation results presented in NUREG/CR-7194 [3]. Brief descriptions of each of these libraries are presented in this section. 


\subsubsection{56-group covariance library}

The default covariance library in SCALE 6.2 [10] is the 56-group library based primarily on ENDF/B-VII.1. The complete list of sources of covariance data for the library are provided in Table 10.2.1 of the SCALE 6.2 manual. They originate from one of six sources:

1. ENDF/B-VII.1 evaluations [18],

2. updates to erroneous ENDF/B-VII.1 evaluations [10],

3. ENDF/B-VI evaluations,

4. low-fidelity evaluations from the Brookhaven, Los Alamos, and Oak Ridge (BLO) collaboration [21],

5. the NEA Working Party on International Nuclear Data Evaluation Co-operation (WPEC) subgroup 26 [22], and

6. Japanese evaluated nuclear data library (JENDL)-4.0 [23].

The source of the covariance data for each nuclide is identified in Table 10.2.1 of the SCALE 6.2 manual [10]. Many nuclides have the same covariance data from the previous SCALE 6/SCALE 6.144-group covariance library, but the major isotopes have been updated, along with all the fission energy spectrum uncertainties. Testing of the new covariance library is discussed in Marshall et al. [24], where some of the major differences are highlighted. The most relevant changes for validation of SNF include a large reduction in the uncertainty of ${ }^{239} \mathrm{Pu} \bar{v}$, as well as increases in the uncertainty associated with ${ }^{235} \mathrm{U} \bar{v}$ and $\mathrm{X}$. Taken together, these changes will reduce the importance of ${ }^{239} \mathrm{Pu}$ sensitivity and will increase the importance of ${ }^{235} \mathrm{U}$ sensitivity in determining $c_{k}$ [24]. This is discussed further in Section 3, which addresses the impact of the updated covariance data on validation of $k_{\text {eff }}$ calculations using the peak reactivity method.

\subsubsection{44-group covariance library}

The 44-group covariance library distributed with SCALE 6.0 and SCALE 6.1 [25] is also distributed with SCALE 6.2 to allow for comparisons with the new covariance data. The sources for data in the older library include the following:

1. ENDF/B-VII evaluations,

2. ENDF/B-VI evaluations,

3. JENDL-3.3 evaluations [26],

4. low-fidelity BLO evaluations [21], and

5. WPEC subgroup 26 evaluations [22].

Energy-dependent uncertainties for $x$ are based on the method developed in Broadhead and Wagschal [27]. The source of the covariance data for each isotope is provided in Table 10.2.6 of the SCALE 6.2 manual [10]. As mentioned previously, the 44-group covariance library is used in this work only to provide an assessment of the impact of implementing the new covariance library on the $k_{\text {eff }}$ validation results presented in NUREG/CR-7194 [3] for peak reactivity analyses. 



\section{IMPACT OF NEW COVARIANCE DATA ON PEAK REACTIVITY VALIDATION}

An assessment of the validation of $k_{\text {eff }}$ calculations using the peak reactivity methodology is provided in Section 4 of NUREG/CR-7194 [3]. Critical experiment benchmarks were selected for that assessment based on similarity indicated by the integral parameter $c_{k}$. As mentioned in the previous section, changes to the covariance data included in SCALE 6.2 impact the similarity determinations and therefore the entire validation assessment. The impact of the change in covariance data on the calculated $c_{k}$ values was first reported by Marshall et al. [24], but without further analysis of the impact on the validation itself. This section provides $c_{k}$ results for the AFP isotope set and VAN lattice in the GBC-68 cask, validation based on the experiments selected from these results, and estimated reactivity allowances for unvalidated isotopes. These results are generated with the new 56-group covariance library and compared with the prior results from NUREG/CR-7194 that were generated using the 44-group covariance library to demonstrate the impact of the new covariance library on the validation of peak reactivity BWR BUC.

\subsection{Potentially Applicable Experiments}

The same SDFs used in NUREG/CR-7194 [3] are used here to isolate the changes coming from the differences in covariance data. The application model is a 2D slice of the GBC-68 cask, including the VAN lattice at a burnup of approximately $7.5 \mathrm{GWd} / \mathrm{MTU}$. Assuming each assembly has an initial loading of 6 rods containing $2 \mathrm{wt} \% \mathrm{Gd}_{2} \mathrm{O}_{3}$, this burnup is very near the reactivity peak for this lattice. The depleted fuel is modeled using the AFP isotope set. All 1,643 experiments are represented with SDFs from a range of sources, as discussed in Section 2.3.2.

The $c_{k}$ values calculated for all 1,643 experiments compared to the GBC-68 peak reactivity model are shown in Figure 3-1. The results with the 44-group covariance library use the same closed, color-coded markers that are used in Figure 4.3 of NUREG/CR-7194. The results with the new 56-group covariance library are black open markers of the same shape. The figure clearly shows that the new covariance library increases $c_{k}$ values for LCT experiments and generally lowers the $\mathrm{C}_{k}$ values for mixed uranium/plutonium systems. The MCT and MST experiments are significantly lower, while most of the HTC cases remain largely unchanged. These $c_{k}$ changes are the result of increased uncertainty in ${ }^{235} \mathrm{U} \bar{v}$ and $\mathrm{X}$ and decreased uncertainty in ${ }^{239} \mathrm{Pu} \bar{v}$ [24]. Larger uncertainties essentially result in higher weights for reactions in determining the $c_{k}$ value. The similarities between the uranium sensitivities in the LCT experiments are therefore emphasized more with the new covariance data, and the similarity in plutonium sensitivities is emphasized less. These changes result in a net increase in the number of experiments which have a $c_{k}$ of 0.8 or more in comparison to the GBC-68 computational benchmark with fuel at peak reactivity.

Of the 1,643 experiments, 111 have a $c_{k}$ value in excess of 0.8 for the GBC-68 cask with the VAN lattice at a burnup of approximately $7.5 \mathrm{GWd} / \mathrm{MTU}$. This is an increase from 67 cases meeting the same criterion with the 44-group covariance data, as reported in NUREG/CR-7194. Forty-two cases have a $c_{k}$ value greater than 0.9 ; no cases met this higher criterion with the 44-group covariance data. The most similar experiments are still identified as LCT-008, LCT-051, and LCT011. The most similar experiments all come from LCT-008, followed by LCT-051 and LCT-011. The top 42 experiments are drawn from these three evaluations and represent all cases with $c_{k}$ values above 0.9 . 


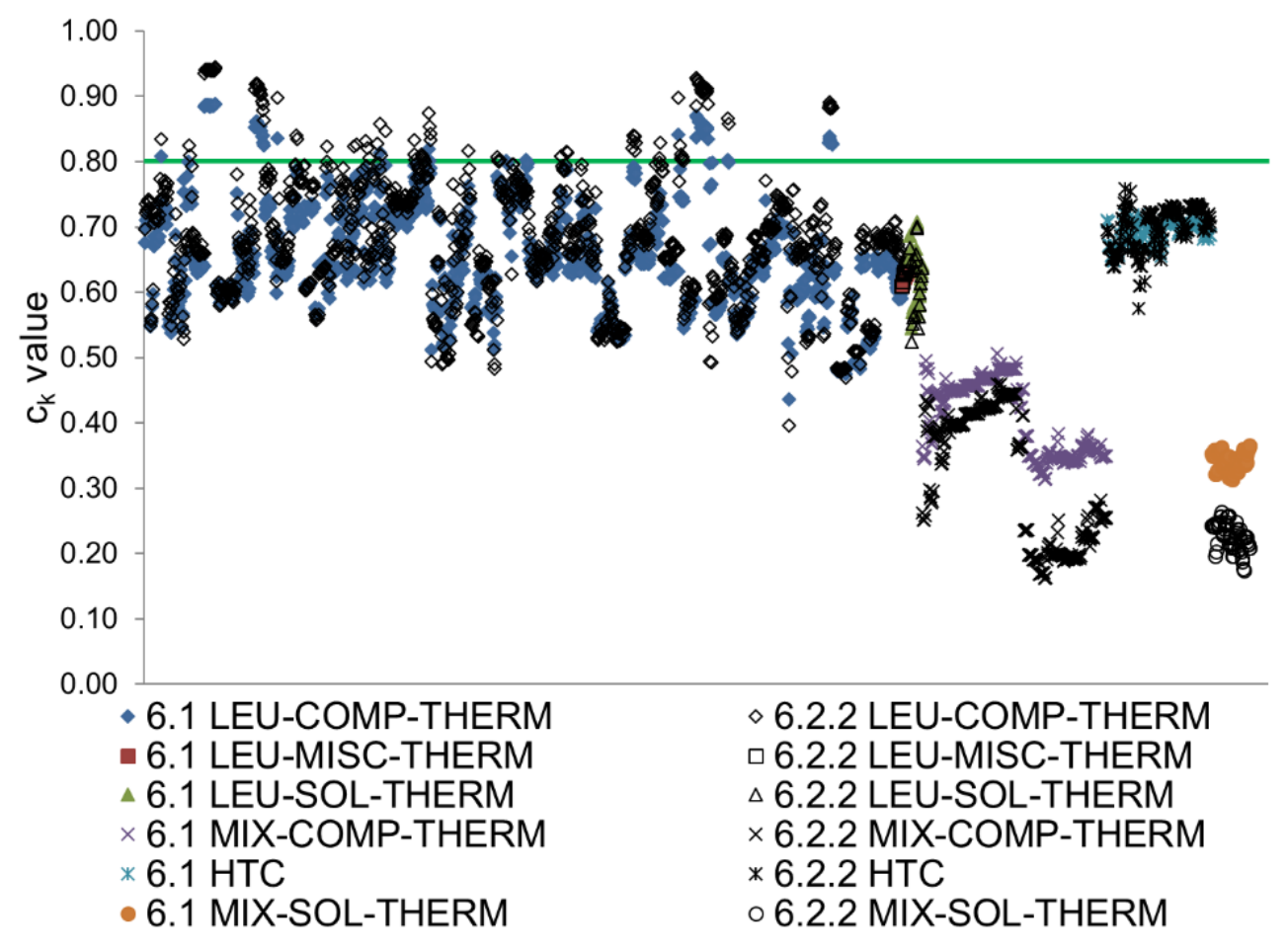

Figure 3-1 $c_{k}$ Values for Critical Experiments Compared to GBC-68 with Vanished Lattice and AFP Isotope Set

Of the 111 experiments, 8 are not used in the sample validation for the reasons discussed below. The single case from LCT-003 is excluded because of large uncertainties in the gadolinium concentration in the water used in the experiment. The three cases from LCT-033 are omitted because the fissile material is $\mathrm{UF}_{4}$ instead of $\mathrm{UO}_{2}$. The two LCT-045 cases are excluded because the fissile material is $\mathrm{U}_{3} \mathrm{O}_{8}$ instead of $\mathrm{UO}_{2}$. Lastly, two cases from LCT-051 are omitted because there are large uncertainties about the boron content of the absorber plates used in those cases. The $c_{k}$ values for the remaining 103 cases used in the sample validation are shown in Figure 3-2. 


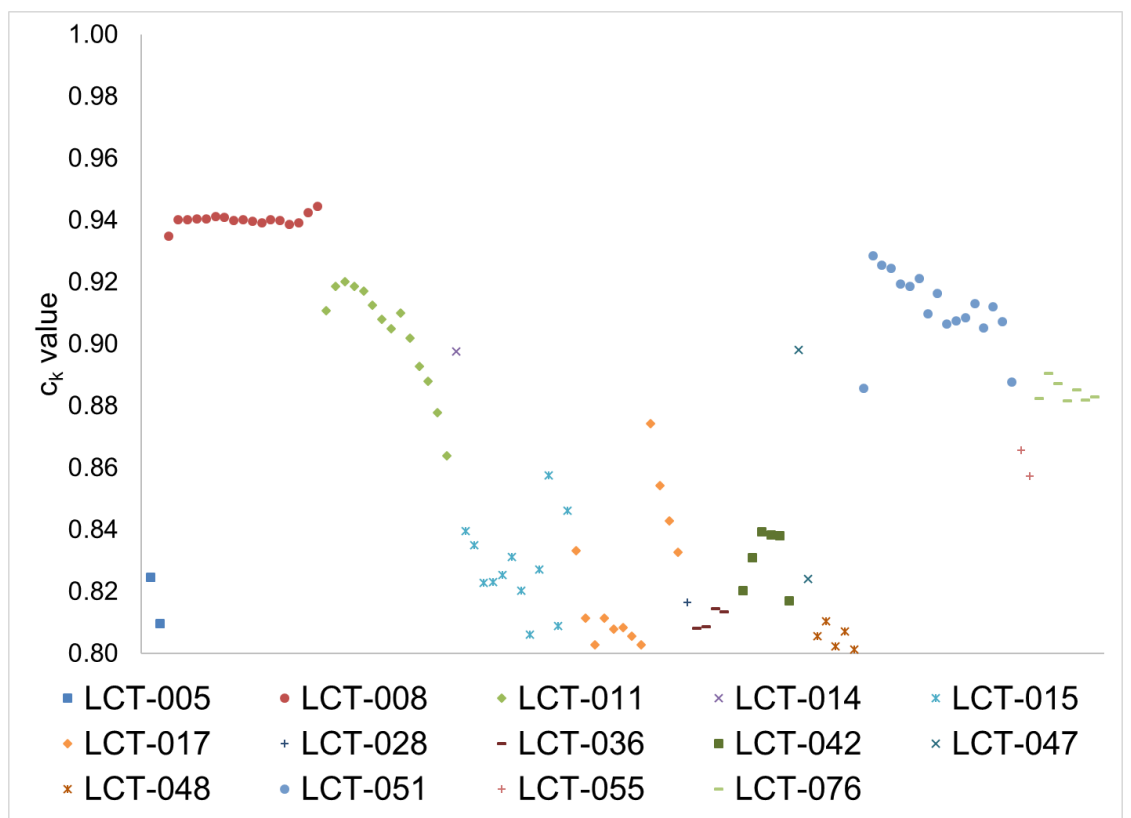

Figure 3-2 $c_{k}$ Values Greater than 0.8 with Vanished Lattice and AFP Isotope Set

\subsection{Bias and Bias Uncertainty Determination}

The purpose of validation is to quantify the suitability of a computational method for a particular criticality safety application [28]. Guidance for performing validation is provided in Dean and Tayloe [12]. This section presents sample bias and bias uncertainty determinations for peak reactivity $k_{\text {eff }}$ calculations using a nontrending method and a linear regression trending method with a variety of trending parameters. Fuel enrichment and EALF are the traditional trending parameters used here, and the $\mathrm{c}_{\mathrm{k}}$ parameter is also used. The methods and trending parameters are the same as those used in NUREG/CR-7194 [3]. They are regenerated here to assess the impact of the new covariance data in SCALE 6.2 [10] on the validation results.

\subsubsection{Nontrending Analysis}

The bias and bias uncertainty are determined using the inverse variance weighted nontrending method discussed in [12], which results in a lower tolerance limit. Considering the 103 experiments identified previously in Section 3.1, the bias is -0.00319 , and the bias uncertainty is 0.00553. The bias and bias uncertainty reported in Section 4.5.1 of NUREG/CR-7194 for the set of 62 experiments are -0.00354 and 0.00526 , respectively. The resulting bias from the larger set of experiments is slightly smaller, but the magnitude of the difference between the identified experiment sets is negligible. The uncertainty in the bias is slightly larger with the larger data set, which is contrary to initial expectations. A larger data set reduces the one-sided multiplier used to create a 95/95 tolerance limit. The multiplier is reduced from 2.022 with 62 experiments to 1.927 with 103 experiments, so the increased number of experiments has only a small impact on the one-sided multiplier. In this case, the larger set of experiments has a higher variability than the smaller set, and the resulting confidence interval is therefore wider. As with the bias, however, the magnitude of the change is small and indicates no significant differences between the validation 
analyses. The sum of bias and bias uncertainty, or the calculational margin [28], for the 103 experiment suite is -0.00872 . This is essentially equal to the calculational margin of -0.00879 reported in NUREG/CR-7194.

The USL resulting from this sample validation would subtract the calculational margin, administrative margin, and margins for unvalidated isotopes from 1 . The administrative margin is typically 0.05 for dry storage and transportation systems [29]. An additional reactivity margin for unvalidated isotopes is needed because none of the identified applicable experiments contain any of the actinides present in SNF other than uranium or any FPs. These reactivity margins are discussed further in Section 3.3. There do not appear to be any significant impacts to the calculational margin resulting from the use of the new covariance library in selecting applicable benchmark experiments for peak reactivity $k_{\text {eff }}$ validation using the nontrending approach.

\subsubsection{Traditional Trending Analysis}

The trending analysis of the 103 experiments identified in Section 3.1 is presented here for comparison with the validation results presented in Section 4.5.2 of NUREG/CR-7194. As before, enrichment and EALF are used as the trending parameters. The bias, bias uncertainty, and calculational margin values for both trends and both experiment sets are shown below in Table 3-1. The enrichment trend is shown in Figure 3-3, and the EALF trend is shown in Figure 3-4. The critical experiment results are presented as a ratio of calculated $k_{\text {eff }}$ result divided by expected benchmark $k_{\text {eff, }}$ referred to as a $\mathrm{C} / \mathrm{E}$ ratio or $\mathrm{C} / \mathrm{E}$ value.

Table 3-1 Bias, Bias Uncertainty, and Calculational Margin from Trending Analyses

\begin{tabular}{|c|c|c|c|c|c|}
\hline Parameter & $\begin{array}{l}\text { Application } \\
\text { value }\end{array}$ & $\begin{array}{c}\text { Experiment } \\
\text { set }\end{array}$ & Bias & $\begin{array}{c}\text { Bias } \\
\text { uncertainty }\end{array}$ & $\begin{array}{c}\text { Calculational } \\
\text { margin }\end{array}$ \\
\hline Enrichmont & 351 & 62 & -0.00136 & 0.00604 & -0.00740 \\
\hline Enricnment & $3.51 \mathrm{~W} \%=0$ & 103 & -0.00069 & 0.00660 & -0.00729 \\
\hline FAIF & م2217 0V & 62 & -0.00396 & 0.00577 & -0.00973 \\
\hline EALF & $0.2 \angle 1 / \mathrm{eV}$ & 103 & -0.00314 & 0.00765 & -0.01080 \\
\hline
\end{tabular}

The enrichment trend results are similar between the two experiment sets. The 103 experiment set has a smaller bias but a larger uncertainty, yielding an equivalent calculational margin. The higher uncertainty is also observed in the nontrending analysis discussed in the previous section. The bias is somewhat lower for the 103 experiment set, but it is not reduced enough to indicate a significant difference between the experiment sets.

The bias resulting from the EALF trend is also slightly smaller for the 103 experiment set than it is for the 62 experiment set. The magnitude of the difference is larger for the EALF trend, but it is still not a significant difference. The bias uncertainty is larger for the EALF trend, as it is for the enrichment trend and the nontrending method. The increase in the bias uncertainty is larger than the reduction in the bias, so the resulting calculational margin is larger. The calculational margin is significantly larger for the EALF trend than for the enrichment trend in both experiment sets. There do not appear to be any significant impacts to the calculational margin resulting from the use of the new covariance library in selecting applicable benchmark experiments for peak reactivity $k_{\text {eff }}$ validation via traditional trending techniques. 


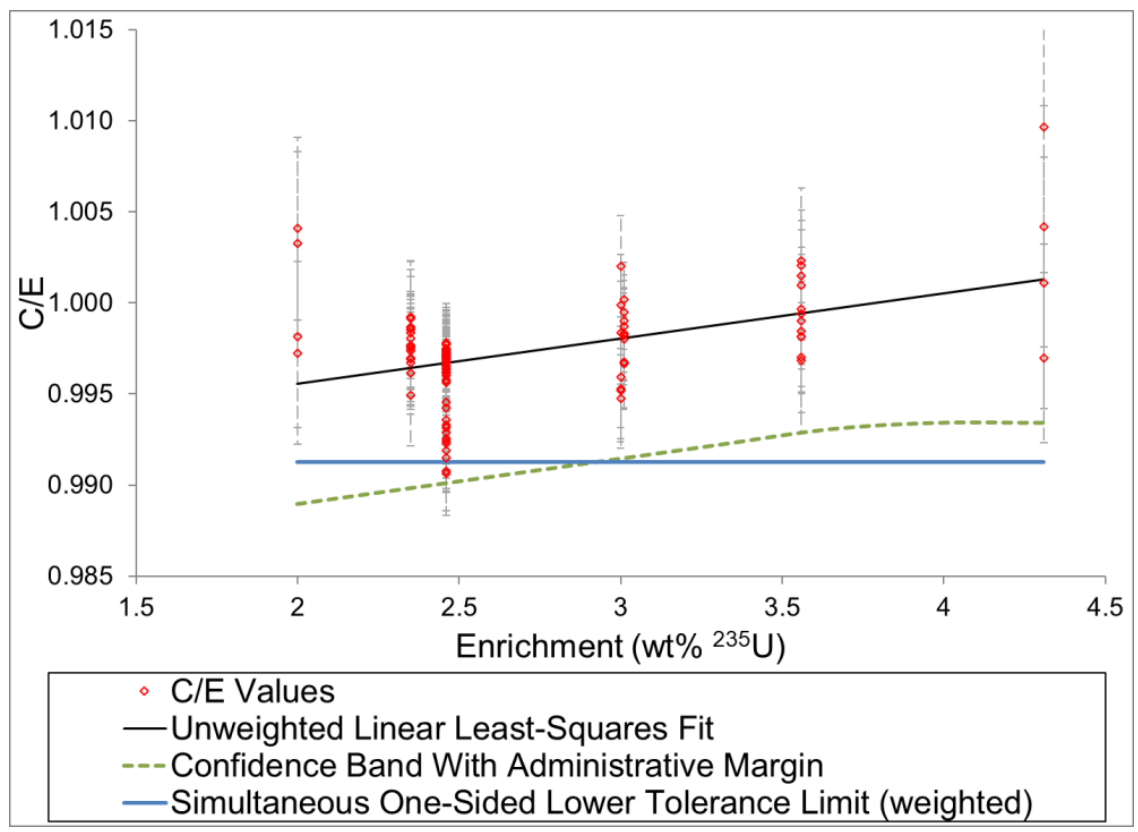

Figure 3-3 C/E Trend as a Function of Enrichment

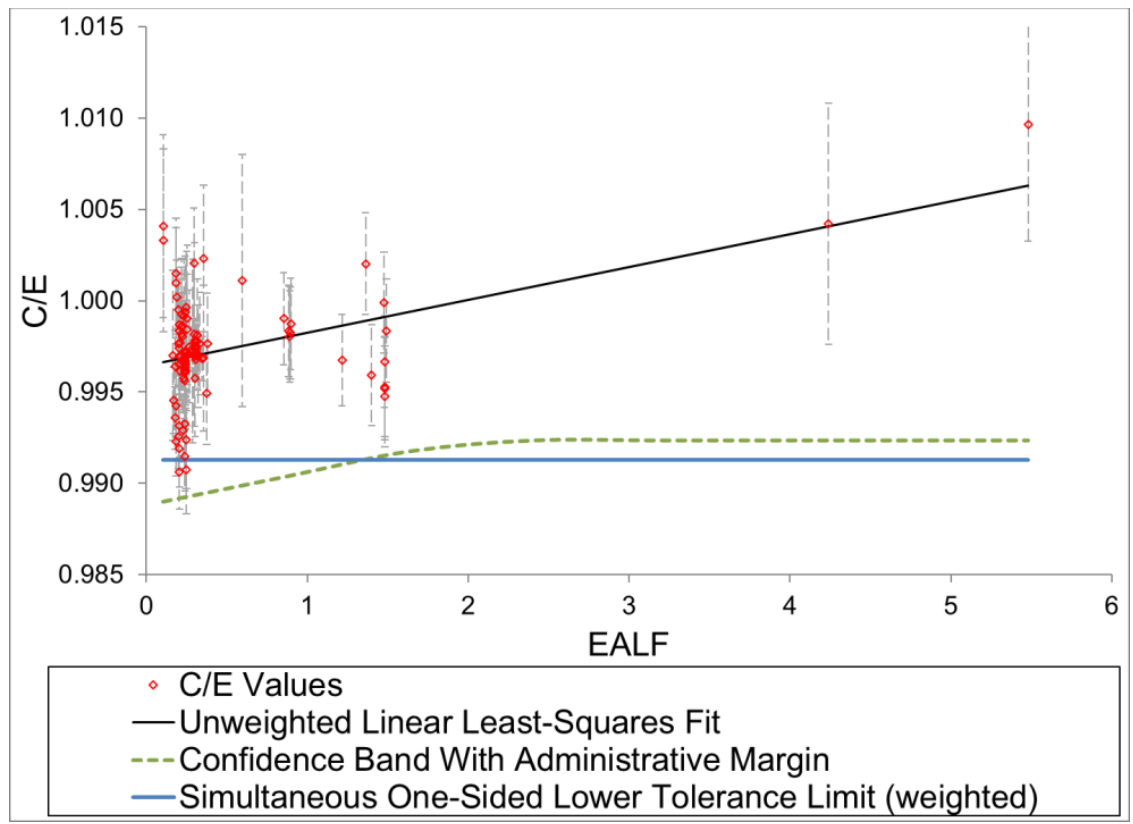

Figure 3-4 C/E Trend as a Function of EALF

\subsection{3 $\mathrm{c}_{\mathrm{k}}$ Trending}

The use of $c_{k}$ as a trending parameter is recommended as part of TSUNAMI validation [11], and $c_{k}$ was used as a trending parameter in NUREG/CR-7194 [3]. The $c_{k}$ trend using the 103 experiment set and the $c_{k}$ values from the 56-group covariance library are shown in Figure 3-5. The changes in the $c_{k}$ values induce a significant shift in the trend compared to that shown in Figure 4.11 of NUREG/CR-7194. The bias and bias uncertainty are determined by extrapolation to a $c_{k}$ value of 1 because this value represents an exact match to the application system. For the 103 experiment 
set with the new $c_{k}$ values, the bias is -0.00587 , and the bias uncertainty is 0.00654 . Therefore, the calculational margin is -0.01241 , which is significantly larger than the margin determined in the previous section for enrichment and EALF trends. The calculational margin is also significantly larger than that from the $c_{k}$ trend of the 62 experiment set.

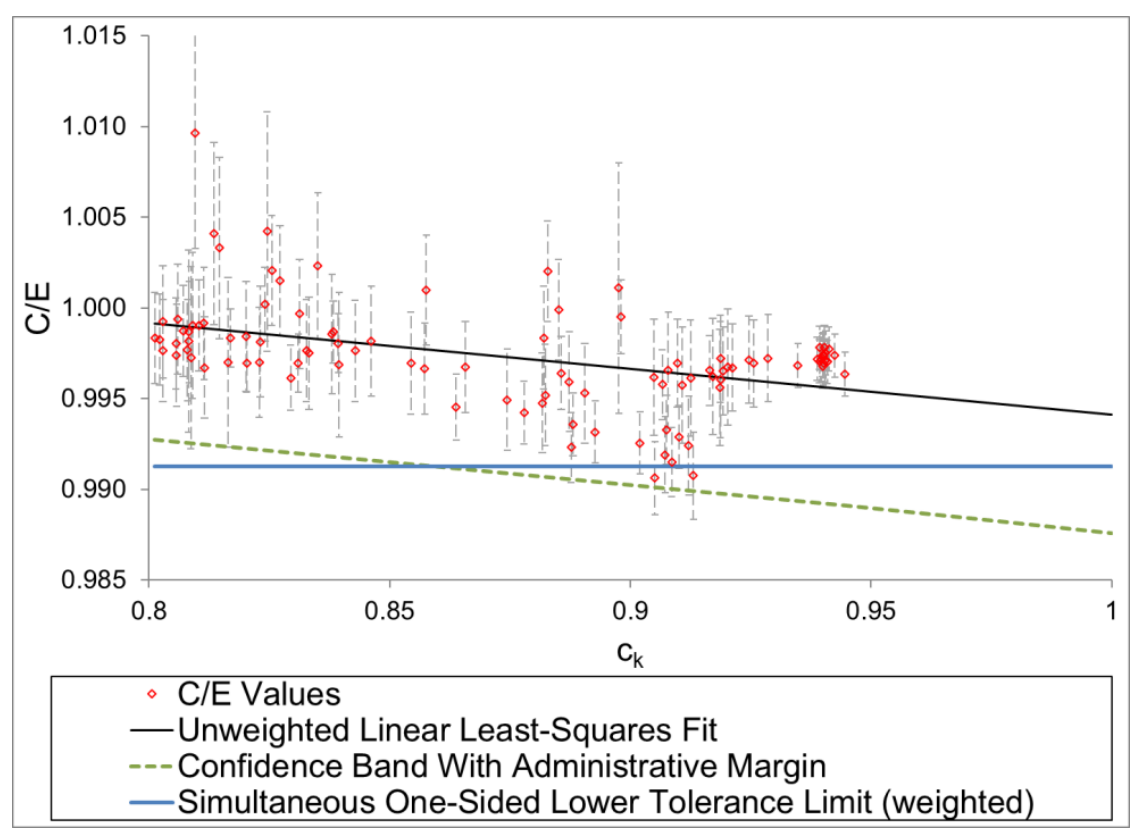

Figure 3-5 C/E Trend for the 103 experiment Set as a Function of $c_{k}$ Value

The bias and bias uncertainty are examined for the 62 experiment set using the $c_{k}$ values from the 56-group library. This isolates the difference in the $c_{k}$ values from the difference in the experiments included in the validation set. The trend is shown in Figure 3-6. The resulting bias is -0.00355 , the bias uncertainty is 0.00580 , and the calculational margin is -0.00935 . These values are similar to the values presented in NUREG/CR-7194. Therefore, it can be concluded that changing the experiments included in the validation is responsible for a larger share of the difference in bias and bias uncertainty than the change in the $c_{k}$ values. Note that the difference is driven by higher $\mathrm{C} / \mathrm{E}$ values in experiments with lower $c_{k}$ values. These less similar experiments have higher $C / E$ values and cause the trend with a negative slope shown in Figure 3-5 as compared to the flat extrapolation shown in Figure 3-6. 


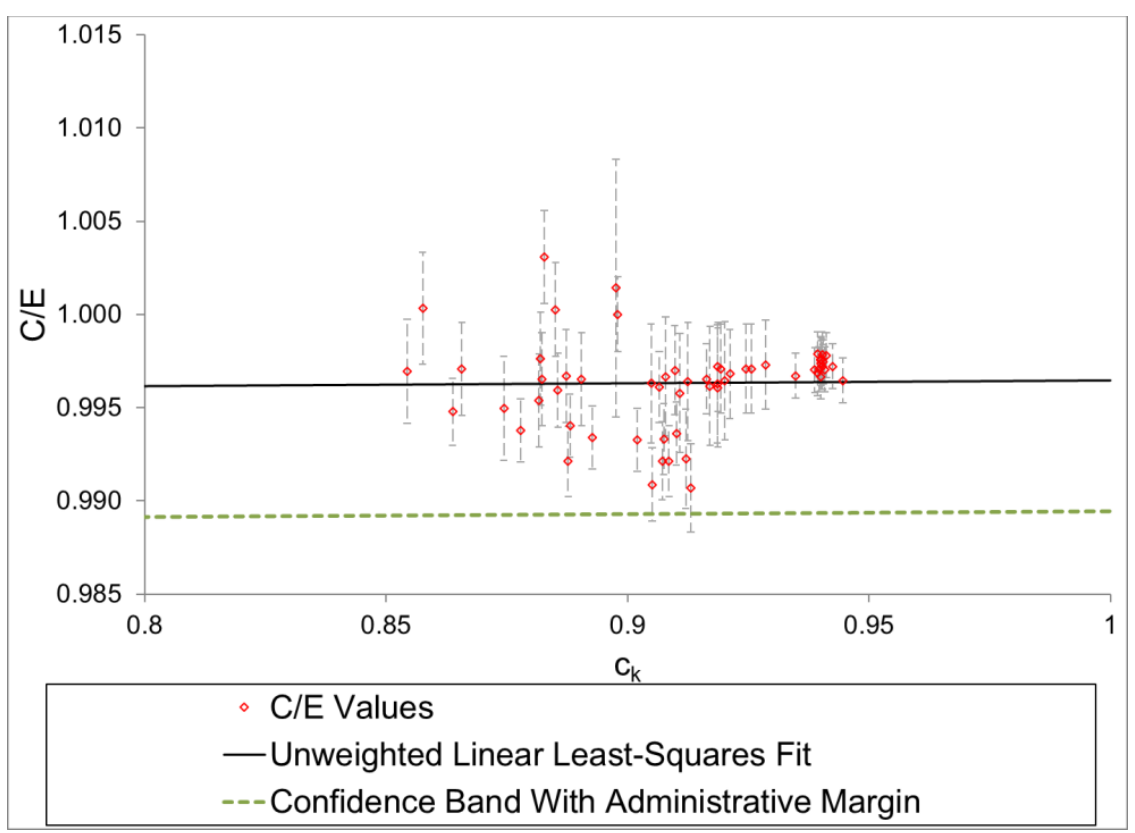

Figure 3-6 C/E Trend for the 62 experiment Set as a Function of 56-group Covariance $c_{k}$ Value

\subsection{Reactivity Margins for Unvalidated Isotopes}

Validation gaps and weaknesses must be addressed [28], and the same gaps exist in the sample validations presented here as those present in NUREG/CR-7194 [3]. Namely, none of the applicable experiments identified in Section 3.1 contain actinides other than uranium. Also, none of the experiments contain gadolinium or any other FPs or MAs. The S/U-based approach to estimating reactivity margins for the unvalidated isotopes is used here exactly as it was in NUREG/CR-7194, but the updated 56-group covariance data released with SCALE 6.2 is used instead of the older 44-group data. All four application models used in NUREG/CR-7194 are analyzed again here to investigate the impact of the covariance data change on the potentially bounding factors that were previously recommended. These models include three GBC-68 loadings and a BWR spent fuel pool (SFP) rack model.

The uncertainty in $k_{\text {eff }}$ due to uncertainty in plutonium isotopes and ${ }^{241} \mathrm{Am}$ is shown for all four models in Table 3-2. The uncertainty drops significantly for ${ }^{238} \mathrm{Pu},{ }^{239} \mathrm{Pu}$, and ${ }^{240} \mathrm{Pu}$ relative to the 44-group covariance library. The uncertainty contribution increases for ${ }^{241} \mathrm{Pu},{ }^{242} \mathrm{Pu}$, and ${ }^{241} \mathrm{Am}$. The uncertainty contribution from ${ }^{239} \mathrm{Pu}$ dominates the other contributions so that essentially all of the uncertainty comes from the single isotope. The total uncertainty is therefore reduced by a factor of $\sim 2$ with the new covariance data. Therefore, the $2 \sigma$ penalty factor can likely be reduced from approximately $0.3 \% \Delta k$ to $0.175 \% \Delta k$.

The change in the Pu covariance data was particularly large in SCALE 6.2 and future variations are expected to be smaller [24]. It is conservative, however, to maintain the higher penalty factor. The impact of other covariance data releases, like ENDF/B-VIII [30], should be evaluated to ensure that a conservative estimate of the penalty factor is applied. 
Table 3-2 $k_{\text {eff }}$ Uncertainty Contributions from Major Transuranic Nuclides

\begin{tabular}{|c|c|c|c|c|c|c|c|c|}
\hline \multirow{4}{*}{ Nuclide } & \multicolumn{8}{|c|}{1 sigma uncertainty ( $\left.\% \Delta \mathrm{k}_{\text {eff }}\right)$} \\
\hline & \multirow{2}{*}{\multicolumn{2}{|c|}{ VAN AO }} & \multirow{2}{*}{\multicolumn{2}{|c|}{$\begin{array}{l}\text { GBC-68 } \\
\text { VAN AFP }\end{array}$}} & \multirow{2}{*}{\multicolumn{2}{|c|}{ FULL AFP }} & \multirow{2}{*}{\multicolumn{2}{|c|}{$\begin{array}{c}\text { NUREG/CR-7109 } \\
\text { SFP AFP }\end{array}$}} \\
\hline & & & & & & & & \\
\hline & 44 grp & 56 grp & 44 grp & 56 grp & 44 grp & 56 grp & 44 grp & 56 grp \\
\hline${ }^{238} \mathrm{Pu}$ & $6.55 E-5$ & 2.60E-4 & 6.27E-5 & $2.39 E-4$ & 8.76E-5 & $2.96 \mathrm{E}-4$ & 1.24E-4 & $3.65 E-4$ \\
\hline${ }^{239} \mathrm{Pu}$ & 1.38E-1 & 7.20E-2 & 1.33E-1 & 7.03E-2 & $1.53 \mathrm{E}-1$ & 7.94E-2 & $1.54 \mathrm{E}-1$ & 8.03E-2 \\
\hline${ }^{240} \mathrm{Pu}$ & 7.83E-3 & 3.03E-3 & 7.34E-3 & 2.84E-3 & $9.10 \mathrm{E}-3$ & $3.49 \mathrm{E}-3$ & 1.13E-2 & $4.44 E-3$ \\
\hline${ }^{241} \mathrm{Pu}$ & 1.67E-3 & $2.49 \mathrm{E}-3$ & $1.64 \mathrm{E}-3$ & $2.48 \mathrm{E}-3$ & 1.99E-3 & $3.18 \mathrm{E}-3$ & $3.28 \mathrm{E}-3$ & $6.06 \mathrm{E}-3$ \\
\hline${ }^{242} \mathrm{Pu}$ & 1.77E-4 & 1.97E-4 & $1.65 \mathrm{E}-4$ & 1.88E-4 & $2.58 \mathrm{E}-4$ & $2.98 \mathrm{E}-4$ & 4.96E-4 & $5.73 E-4$ \\
\hline${ }^{241} \mathrm{Am}$ & 8.88E-4 & $1.92 E-3$ & 8.27E-4 & $1.78 \mathrm{E}-3$ & 1.17E-3 & $2.38 E-3$ & 1.07E-4 & $2.05 E-4$ \\
\hline Total & 0.138 & 0.072 & 0.134 & 0.070 & 0.153 & 0.080 & 0.155 & 0.081 \\
\hline
\end{tabular}

The uncertainty contribution of residual $\mathrm{Gd}$ is shown for the three application models containing $\mathrm{Gd}$ in Table 3-3. As noted in NUREG/CR-7194, only ${ }^{155} \mathrm{Gd}$ is considered because only traces of the naturally occurring ${ }^{157} \mathrm{Gd}$ remain at peak reactivity. The larger neutron absorption cross section of ${ }^{157} \mathrm{Gd}$ causes it to burn out much more quickly than ${ }^{155} \mathrm{Gd}$, and there is no appreciable FP generation of ${ }^{157} \mathrm{Gd}$. The uncertainty contribution from ${ }^{155} \mathrm{Gd}$ nearly doubles with the new covariance library. A conservative $2 \sigma$ penalty factor of $0.09 \% \Delta k$ is recommended based on the new data. As with the Pu factor, evaluation of future covariance data libraries is recommended to ensure conservative factors are used.

Table 3-3 $k_{\text {eff }}$ Uncertainty Contribution from ${ }^{155} \mathrm{Gd}$

\begin{tabular}{|lcc|}
\hline \multirow{2}{*}{ Model } & \multicolumn{2}{c|}{ Uncertainty $(\% \Delta \mathrm{k})$} \\
\cline { 2 - 3 } GBC-68 VAN & 44 group & 56 group \\
\hline GBC-68 FULL & 0.015 & 0.034 \\
NUREG/CR-7109 SFP & 0.019 & 0.038 \\
\hline
\end{tabular}

The uncertainty contribution from the MAs and FPs is shown in Table 3-4 for both the 56- and 44-group covariance libraries for the three application systems with MAs and FPs modeled in the fuel composition. The MAs considered are ${ }^{236} \mathrm{U},{ }^{237} \mathrm{~Np}$, and ${ }^{243} \mathrm{Am}$. The top $15 \mathrm{FPs}$ typically used in BUC [7] are included, and they are ${ }^{95} \mathrm{Mo},{ }^{99} \mathrm{Tc},{ }^{101} \mathrm{Ru},{ }^{103} \mathrm{Rh},{ }^{109} \mathrm{Ag},{ }^{133} \mathrm{Cs},{ }^{147} \mathrm{Sm},{ }^{149} \mathrm{Sm},{ }^{150} \mathrm{Sm}$, ${ }^{151} \mathrm{Sm},{ }^{152} \mathrm{Sm},{ }^{143} \mathrm{Nd},{ }^{145} \mathrm{Nd},{ }^{151} \mathrm{Eu}$, and ${ }^{153} \mathrm{Eu}$. ${ }^{155} \mathrm{Gd}$ is also typically included as a FP, but here it is treated separately because it is inseparable in the fuel composition from residual burnable absorber $\mathrm{Gd}$. The uncertainty contributions from the MAs and major FPs are small because of the relatively low concentrations at the low burnup associated with peak reactivity. Many of the nuclides in this set have the same low-fidelity covariance evaluations in both libraries and therefore have the same uncertainty contribution from both libraries. The major contributors to uncertainty are ${ }^{149} \mathrm{Sm}$, which is unchanged, and ${ }^{143} \mathrm{Nd}$, which has a slightly higher uncertainty contribution with the new library. Overall, the same reactivity margin of $0.06 \% \Delta k$ recommended in NUREG/CR-7194 appears appropriate for the new covariance data library. It is unlikely that new covariance evaluations will impact the overall uncertainty from these isotopes significantly, especially considering their low sensitivities at low burnups. 
Table 3-4 $k_{\text {eff }}$ Uncertainty Contribution from Major FPs and MAs

\begin{tabular}{|c|c|c|c|c|c|c|}
\hline \multirow{4}{*}{ Nuclide } & \multicolumn{6}{|c|}{1 sigma uncertainty $(\% \Delta \mathrm{k})$} \\
\hline & \multicolumn{4}{|c|}{ GBC-68 } & \multirow{2}{*}{\multicolumn{2}{|c|}{$\begin{array}{c}\text { NUREG/CR-7109 SFP } \\
\text { AFP }\end{array}$}} \\
\hline & \multicolumn{2}{|c|}{ VAN AFP } & \multicolumn{2}{|c|}{ FULL AFP } & & \\
\hline & 44-group & 56-group & 44-group & 56-group & 44-group & 56-group \\
\hline${ }^{95} \mathrm{Mo}$ & 1.31E-03 & $1.26 \mathrm{E}-03$ & 1.62E-03 & $1.56 \mathrm{E}-03$ & $1.70 \mathrm{E}-03$ & 1.63E-03 \\
\hline${ }^{99} \mathrm{Tc}$ & 1.96E-03 & 2.75E-03 & 2.14E-03 & 3.07E-03 & 2.99E-03 & $4.22 \mathrm{E}-03$ \\
\hline${ }^{101} \mathrm{Ru}$ & 1.65E-03 & 1.66E-03 & 2.05E-03 & 2.07E-03 & $3.23 E-03$ & $3.22 \mathrm{E}-03$ \\
\hline${ }^{103} \mathrm{Rh}$ & 5.38E-03 & 5.50E-03 & $6.75 \mathrm{E}-03$ & 6.91E-03 & 8.32E-03 & 8.48E-03 \\
\hline${ }^{109} \mathrm{Ag}$ & 1.95E-04 & 1.99E-04 & 2.65E-04 & 2.71E-04 & 3.98E-04 & 3.86E-04 \\
\hline${ }^{133} \mathrm{Cs}$ & 4.33E-03 & 4.38E-03 & $5.25 \mathrm{E}-03$ & 5.31E-03 & 7.74E-03 & 7.70E-03 \\
\hline${ }^{147} \mathrm{Sm}$ & $1.60 \mathrm{E}-03$ & $1.60 \mathrm{E}-03$ & 1.90E-03 & 1.90E-03 & 4.77E-04 & $4.75 \mathrm{E}-04$ \\
\hline${ }^{149} \mathrm{Sm}$ & 1.09E-02 & 1.09E-02 & 1.13E-02 & 1.13E-02 & 1.01E-02 & 9.98E-03 \\
\hline${ }^{150} \mathrm{Sm}$ & $1.02 E-03$ & $1.02 \mathrm{E}-03$ & 1.14E-03 & 1.15E-03 & 1.65E-03 & 1.64E-03 \\
\hline${ }^{151} \mathrm{Sm}$ & 6.02E-03 & 6.05E-03 & 5.97E-03 & 6.01E-03 & 6.06E-03 & 6.08E-03 \\
\hline${ }^{152} \mathrm{Sm}$ & $1.62 \mathrm{E}-03$ & 1.63E-03 & $1.95 \mathrm{E}-03$ & 1.96E-03 & 2.96E-03 & 2.96E-03 \\
\hline${ }^{143} \mathrm{Nd}$ & 9.94E-03 & 1.03E-02 & 1.04E-02 & 1.08E-02 & 1.37E-02 & $1.44 \mathrm{E}-02$ \\
\hline${ }^{145} \mathrm{Nd}$ & 4.09E-03 & 4.48E-03 & 5.10E-03 & 5.48E-03 & 7.89E-03 & 8.34E-03 \\
\hline${ }^{151} \mathrm{Eu}$ & 1.13E-04 & 1.13E-04 & 1.23E-04 & 1.23E-04 & 6.71E-06 & 6.66E-06 \\
\hline${ }^{153} \mathrm{Eu}$ & 7.86E-04 & $9.40 \mathrm{E}-04$ & 1.00E-03 & 1.13E-03 & 1.65E-03 & $1.80 \mathrm{E}-03$ \\
\hline 236U & 8.05E-03 & 6.72E-03 & 9.79E-03 & 8.30E-03 & 1.33E-02 & 1.03E-02 \\
\hline${ }^{237} \mathrm{~Np}$ & $1.00 \mathrm{E}-03$ & 1.47E-03 & 1.26E-03 & 1.88E-03 & 1.46E-03 & 2.14E-03 \\
\hline${ }^{243} \mathrm{Am}$ & 1.92E-06 & 2.46E-06 & 3.58E-06 & 4.62E-06 & 7.63E-06 & 9.77E-06 \\
\hline Total & 0.020 & 0.020 & 0.022 & 0.022 & 0.027 & 0.026 \\
\hline
\end{tabular}

The reactivity margin for major actinides are significantly lower with the new covariance library than the same margin resulting from the old library. The $2 \sigma$ factor drops from $0.3 \% \Delta k$ [3] to $0.175 \% \Delta k$. The factor for ${ }^{155} \mathrm{Gd}$, however, nearly doubles from $0.05 \% \Delta k$ to $0.09 \% \Delta k$. The factor for MAs and major FPs is unaffected and remains at $0.06 \% \Delta k$. The sum of the three factors for the new covariance library is $0.325 \% \Delta k$, which is lower than the recommended value from NUREG/CR-7194 of $0.41 \% \Delta k$. Both factors are fairly small, especially in comparison to the bias uncertainty and administrative margins associated with criticality safety validation.

\subsection{Summary}

This section has presented a brief overview of the impact of the new 56-group covariance library released with SCALE 6.2 [10]. The validation assessment presented in NUREG/CR-7194 [3] for peak reactivity analyses was performed again with the new covariance library, and the results are presented here. The assessment focuses on identification of and selection of potentially applicable experiments, sample determinations of bias and bias uncertainty, and estimation of reactivity margins for unvalidated isotopes.

The new covariance library tends to increase the importance of uranium while decreasing the importance of plutonium in assessing similarity of critical experiments with SNF applications [24]. For low burnup, peak reactivity BWR fuel, this generally results in LCT experiments having higher $\mathrm{C}_{\mathrm{k}}$ values for GBC-68 applications. Therefore, more experiments may be applicable for validation with the new covariance library: 103 experiments compared to 62 for the VAN lattice model with the AFP isotope set. These results are discussed in Section 3.1. 
Sample bias and bias uncertainty values for the 103 experiment set were generated and are discussed in Section 3.2. Various nontrending and trending approaches were used, and the results are comparable with the values generated in NUREG/CR-7194. The resulting bias and bias uncertainty are significantly different for the $c_{k}$ trend, although this appears to be a result of the change in experiment set and not the variation in $c_{k}$ values.

Reactivity margins for unvalidated isotopes are discussed in Section 3.3. These factors are needed because the experiments identified as being potentially applicable do not contain plutonium, americium, or FPs. The S/U methods use the uncertainty induced in $k_{\text {eff }}$ by nuclear data uncertainty to provide estimates of the magnitude of the error that could be present and undetected because of the lack of benchmark experiments. The sum of the independent factors for major actinides, ${ }^{155} \mathrm{Gd}$, MAs, and FPs is lower with the new covariance library than with the old library. This is primarily a result of large reductions in the uncertainty associated with ${ }^{239} \mathrm{Pu}$. The uncertainty in ${ }^{155} \mathrm{Gd}$ is larger, but the smaller sensitivity to ${ }^{155} \mathrm{Gd}$ reduces the overall impact of this change. Similar assessments of the impact of new covariance data should be performed as new data are released. 


\section{SENSITIVITY DATA GENERATION}

The validation of extended BWR BUC $k_{\text {eff }}$ calculations relies on S/U methods, which allow rigorous assessment of critical experiment applicability and quantification of any necessary allowances for isotopes absent from the validation suite. The use of these methods requires sensitivity data for the application and for the critical experiment models which might be used in the validation. Covariance data are also needed for similarity assessments and uncertainty analysis of unvalidated isotopes. The 56-group covariance data from SCALE 6.2 [10] are used in all analyses of extended BWR BUC presented in this report. A brief description of this data library is presented in Section 2.3.3, and a more complete description is provided in the SCALE 6.2 manual [10].

This section focuses on the generation of the sensitivity data used in the validation analyses. As discussed in Section 2.1.1, sensitivity data are generated using the TSUNAMI-3D sequence within SCALE. Prior to SCALE 6.2, TSUNAMI-3D employed only MG methods to generate sensitivity data. New CE methods are available beginning with SCALE 6.2, and these methods are used in this report. Few published reports provide comparisons of the CE and MG methods in TSUNAMI-3D [31, 32], so SDFs are generated using both techniques. A comparison of the two methods is summarized here, providing confidence that the SDFs generated by CE TSUNAMI can be used in this work.

The validation of $k_{\text {eff }}$ calculations for extended BWR BUC analysis is evaluated in this report at two different burnups, 25 and $50 \mathrm{GWd} / \mathrm{MTU}$, and with the AO and AFP isotope sets. Unique SDFs are required for each of the four combinations to allow comparisons to benchmark model SDFs. The comparisons are performed using TSUNAMI-IP to identify potentially applicable benchmark experiments. The selection of potentially applicable experiments is documented in Section 5.

\subsection{MG TSUNAMI-3D Models}

The MG TSUNAMI-3D models are half-cask models with a reflective boundary condition applied on the $-Y$ face. Explicit modeling of only half the cask allows a finer mesh to be used for collection of flux moments within memory constraints. The mesh used has 62 mesh intervals in the $X$ direction, 31 in the $Y$ direction, and 33 in the $Z$ direction. The radial mesh is essentially a uniform square mesh that is $3 \mathrm{~cm}$ on each side. The axial mesh is varied with finer mesh near the ends of the fuel assemblies and larger mesh along the central axial portion of the assemblies. The water in the vanished rod locations within the VAN lattice is divided into 6-inch axial segments for better resolution of the flux moments within this lattice.

SDFs were generated at both 25 and $50 \mathrm{GWd} / \mathrm{MTU}$ with both the AO and AFP isotope sets. The forward Monte Carlo calculations used 11,000 particles per generation and ran until an uncertainty of $0.025 \% \Delta k$ was achieved. The first 25 generations were discarded, and a total of $700-1,600$ generations were required to achieve the desired statistical uncertainty. The adjoint Monte Carlo calculations used 33,000 particles per generation and were run until a statistical uncertainty of $0.125 \% \Delta k$ was achieved. This required $2,600-3,900$ adjoint generations per calculation.

Direct perturbation calculations were performed using MG KENO to confirm that the sensitivity data generated by TSUNAMI-3D was accurate. Separate calculations were performed for each burnup and isotope set. Direct perturbations were performed for the water mixture in the axial zone with the highest sensitivity, the water mixture in the vanished lattice positions, fuel isotopes in the axial zone with the highest sensitivity, and ${ }^{10} \mathrm{~B}$ in the absorber panels. These mixtures and isotopes were chosen because of their high sensitivities and corresponding importance to the overall reactivity of the model. Summaries of the comparisons of TSUNAMI-3D sensitivities and 
direct perturbation sensitivities are provided in Table 4-1 for $25 \mathrm{GWd} / \mathrm{MTU}$ and the AO isotope set, Table 4-2 for $25 \mathrm{GWd} / \mathrm{MTU}$ and the AFP isotope set, Table 4-3 for $50 \mathrm{GWd} / \mathrm{MTU}$ and the AO isotope set, and Table 4-4 for $50 \mathrm{GWd} / \mathrm{MTU}$ and the AFP isotope set. Agreement between TSUNAMI and direct perturbations is generally good. The relative difference between the two estimates of the moderator sensitivity in the fuel rod unit cell is higher than the desired targets of $5 \%$ and 2 standard deviations [33].The absolute differences are small enough, less than 0.01 [33], that the discrepancies are acceptable and the SDF can be used for analysis.

\section{Table 4-1 Summary of Comparisons of MG TSUNAMI-3D and Direct Perturbation} Sensitivities for 25 GWd/MTU Burnup and AO Isotope Set

\begin{tabular}{|c|c|c|c|c|c|c|c|}
\hline \multirow[b]{2}{*}{ Material } & \multicolumn{2}{|c|}{ TSUNAMI-3D } & \multicolumn{2}{|c|}{ Direct perturbation } & \multicolumn{3}{|c|}{ Comparison } \\
\hline & Sensitivity & Unc. & Sensitivity & Unc. & $\begin{array}{l}\text { Rel. Diff. } \\
(\%)\end{array}$ & Rel. Diff. $(\sigma)$ & Abs. Diff. \\
\hline $\begin{array}{l}\mathrm{H}_{2} \mathrm{O} \text {, fuel } \\
\text { rod cell }\end{array}$ & 2.95E-02 & 8.26E-04 & 2.74E-02 & 4.45E-04 & 7.48 & 2.19 & 0.0021 \\
\hline $\begin{array}{l}\mathrm{H}_{2} \mathrm{O}, \\
\text { VAN cell }\end{array}$ & 5.77E-02 & 1.93E-03 & 5.83E-02 & 8.77E-04 & -1.03 & 0.28 & -0.0006 \\
\hline${ }^{10} \mathrm{~B}$ & $-5.11 \mathrm{E}-02$ & 6.06E-05 & $-5.03 E-02$ & 8.06E-04 & 1.78 & 1.10 & -0.0009 \\
\hline${ }^{235} \mathrm{U}$ & 3.88E-02 & 1.31E-04 & 3.80E-02 & 5.78E-04 & 2.23 & 1.43 & 0.0008 \\
\hline${ }^{238} U$ & $-1.65 E-02$ & 1.00E-04 & $-1.62 \mathrm{E}-02$ & 2.49E-04 & 1.61 & 0.97 & -0.0003 \\
\hline${ }^{239} \mathrm{Pu}$ & 1.27E-02 & 4.94E-05 & 1.26E-02 & 1.95E-04 & 0.97 & 0.61 & 0.0001 \\
\hline
\end{tabular}

Table 4-2 Summary of Comparisons of MG TSUNAMI-3D and Direct Perturbation Sensitivities for 25 GWd/MTU Burnup and AFP Isotope Set

\begin{tabular}{|lccccccc|}
\hline & \multicolumn{2}{c}{ TSUNAMI-3D } & \multicolumn{2}{c}{ Direct perturbation } & \multicolumn{3}{c|}{ Comparison } \\
\cline { 2 - 8 } Material & Sensitivity & Unc. & Sensitivity & Unc. & $\begin{array}{c}\text { Rel. Diff. } \\
(\%)\end{array}$ & Rel. Diff. ( $\sigma)$ & Abs. Diff. \\
\hline $\begin{array}{l}\mathrm{H}_{2} \mathrm{O} \text {, fuel } \\
\text { rod cell }\end{array}$ & $2.12 \mathrm{E}-02$ & $1.14 \mathrm{E}-03$ & $2.01 \mathrm{E}-02$ & $3.61 \mathrm{E}-04$ & 5.76 & 0.96 & 0.0012 \\
$\begin{array}{l}\mathrm{H}_{2} \mathrm{O}, \\
\mathrm{VAN} \text { cell }\end{array}$ & $5.52 \mathrm{E}-02$ & $2.52 \mathrm{E}-03$ & $5.34 \mathrm{E}-02$ & $9.42 \mathrm{E}-04$ & 3.43 & 0.68 & 0.0018 \\
${ }^{10} \mathrm{~B}$ & $-5.11 \mathrm{E}-02$ & $8.55 \mathrm{E}-05$ & $-5.03 \mathrm{E}-02$ & $8.35 \mathrm{E}-04$ & 1.59 & 0.95 & -0.0008 \\
${ }^{235} \mathrm{U}$ & $2.96 \mathrm{E}-02$ & $1.16 \mathrm{E}-04$ & $3.02 \mathrm{E}-02$ & $4.94 \mathrm{E}-04$ & -2.00 & 1.19 & -0.0006 \\
${ }^{238} \mathrm{U}$ & $-1.14 \mathrm{E}-02$ & $1.35 \mathrm{E}-04$ & $-1.15 \mathrm{E}-02$ & $1.95 \mathrm{E}-04$ & -0.86 & 0.42 & 0.0001 \\
${ }^{239} \mathrm{Pu}$ & $1.53 \mathrm{E}-02$ & $7.18 \mathrm{E}-05$ & $1.48 \mathrm{E}-02$ & $5.26 \mathrm{E}-04$ & 3.57 & 0.99 & 0.0005 \\
\hline
\end{tabular}


Table 4-3 Summary of Comparisons of MG TSUNAMI-3D and Direct Perturbation Sensitivities for $50 \mathrm{GWd} / \mathrm{MTU}$ Burnup and AO Isotope Set

\begin{tabular}{|c|c|c|c|c|c|c|c|}
\hline \multirow[t]{2}{*}{ Material } & \multicolumn{2}{|c|}{ TSUNAMI-3D } & \multicolumn{2}{|c|}{ Direct perturbation } & \multicolumn{3}{|c|}{ Comparison } \\
\hline & Sensitivity & Unc. & Sensitivity & Unc. & $\begin{array}{l}\text { Rel. Diff. } \\
(\%)\end{array}$ & Rel. Diff. (o) & Abs. Diff. \\
\hline $\begin{array}{l}\mathrm{H}_{2} \mathrm{O} \text {, fuel } \\
\text { rod cell }\end{array}$ & $4.51 \mathrm{E}-02$ & 1.32E-03 & $4.28 E-02$ & 6.08E-04 & 5.30 & 1.56 & 0.0023 \\
\hline $\begin{array}{l}\mathrm{H}_{2} \mathrm{O}, \\
\text { VAN cell }\end{array}$ & 6.23E-02 & 2.09E-03 & 6.13E-02 & 7.96E-04 & 1.60 & 0.44 & 0.0010 \\
\hline${ }^{10} \mathrm{~B}$ & $-5.07 E-02$ & 7.16E-05 & $-5.08 \mathrm{E}-02$ & 6.86E-04 & -0.16 & 0.12 & 0.0001 \\
\hline $235 \mathrm{U}$ & $5.23 E-02$ & 1.48E-04 & 5.02E-02 & 6.68E-04 & 4.19 & 3.07 & 0.0021 \\
\hline${ }^{238} \mathrm{U}$ & $-2.28 E-02$ & $1.42 \mathrm{E}-04$ & $-2.27 E-02$ & 3.03E-04 & 0.36 & 0.25 & -0.0001 \\
\hline${ }^{239} \mathrm{Pu}$ & $2.50 \mathrm{E}-02$ & 8.34E-05 & $2.48 \mathrm{E}-02$ & 3.16E-04 & 0.69 & 0.52 & 0.0002 \\
\hline
\end{tabular}

Table 4-4 Summary of Comparisons of MG TSUNAMI-3D and Direct Perturbation Sensitivities for $50 \mathrm{GWd} / \mathrm{MTU}$ Burnup and AFP Isotope Set

\begin{tabular}{|c|c|c|c|c|c|c|c|}
\hline \multirow[b]{2}{*}{ Material } & \multicolumn{2}{|c|}{ TSUNAMI-3D } & \multicolumn{2}{|c|}{ Direct perturbation } & \multicolumn{3}{|c|}{ Comparison } \\
\hline & Sensitivity & Unc. & Sensitivity & Unc. & $\begin{array}{l}\text { Rel. Diff. } \\
(\%)\end{array}$ & Rel. Diff. ( $\sigma)$ & Abs. Diff. \\
\hline $\begin{array}{l}\mathrm{H}_{2} \mathrm{O} \text {, fuel } \\
\text { rod cell }\end{array}$ & $4.65 \mathrm{E}-02$ & 1.38E-03 & $4.42 E-02$ & 8.61E-04 & 5.14 & 1.40 & 0.0023 \\
\hline $\begin{array}{l}\mathrm{H}_{2} \mathrm{O}, \\
\text { VAN cell }\end{array}$ & 6.11E-02 & 2.36E-03 & 5.92E-02 & 1.12E-03 & 3.12 & 0.71 & 0.0018 \\
\hline${ }^{10} \mathrm{~B}$ & -5.07E-02 & 7.82E-05 & $-4.93 E-02$ & $9.30 \mathrm{E}-04$ & 2.87 & 1.51 & -0.0014 \\
\hline $235 \mathrm{U}$ & 5.61E-02 & $1.52 E-04$ & 5.46E-02 & 1.01E-03 & 2.77 & 1.48 & 0.0015 \\
\hline${ }^{238} \mathrm{U}$ & -1.95E-02 & $1.44 \mathrm{E}-04$ & $-1.92 E-02$ & 3.55E-04 & 1.55 & 0.78 & -0.0003 \\
\hline${ }^{239} \mathrm{Pu}$ & 3.34E-02 & 9.08E-05 & $3.40 \mathrm{E}-02$ & 6.14E-04 & -1.68 & 0.92 & -0.0006 \\
\hline
\end{tabular}

\subsection{CE TSUNAMI-3D Models}

The CE TSUNAMI-3D models are half-cask models, with a reflective boundary condition applied on the -Y face. Both the MG and CE TSUNAMI-3D models are based on the same KENO models. The CLUTCH method [31] is used to generate sensitivity data in CE TSUNAMI. This method uses an $F^{*}(r)$ function as the importance function in calculating sensitivities, with a recommended cubic mesh of 1-2 cm on a side [31]. The mesh implemented in the CE TSUNAMI models used 140 mesh intervals in the $X$ direction, 80 in the $Y$ direction, and 25 in the $Z$ direction. The radial mesh is rectangular with $1.35 \mathrm{~cm}$ in the $X$ direction and $1.19 \mathrm{~cm}$ in the $Y$ direction. The axial mesh is $31.5 \mathrm{~cm}$ over the bottom portion of the cask model and $6 \mathrm{~cm}$ over the top $90 \mathrm{~cm}$ of the model. The finer axial mesh is used in the upper portion of the cask model because the majority of the fissions occur in this region.

SDFs were generated at both 25 and $50 \mathrm{GWd} / \mathrm{MTU}$ with both the AO and AFP isotope sets. The CE TSUNAMI methods only require a single forward calculation with no separate adjoint calculation. The calculations used 30,000 particles per generation. The first 1,000 generations, which were skipped for the $k_{\text {eff }}$ calculation, are used to tally the $F^{*}(r)$ function. 
The Monte Carlo uncertainty in the calculated $k_{\text {eff }}$ was approximately $0.00005 \Delta k$ for all 4 simulations. Three of the calculations completed 11,000 total generations; 10,000 of these generations were active. The calculation at a burnup of $50 \mathrm{GWd} / \mathrm{MTU}$ with the AO isotope set reached a $k_{\text {eff }}$ uncertainty of less than $0.00005 \Delta k$ and terminated after 10,341 total, or 9,341 active, generations.

Direct perturbation calculations were performed using CE KENO to confirm that the sensitivity data generated by TSUNAMI-3D was accurate. Direct perturbations are needed for confirmation because there is no guidance on the required uncertainty distribution of the $F^{*}(r)$ function. The available evidence [32] indicates that there is no generic distribution of uncertainties that guarantees accurate sensitivity calculations. As for the MG TSUNAMI-3D calculations, separate calculations were performed for each burnup and isotope set. Direct perturbations were performed for all water in the fuel rod unit cell and all the ${ }^{235} \mathrm{U},{ }^{238} \mathrm{U},{ }^{239} \mathrm{Pu}$, and ${ }^{240} \mathrm{Pu}$ in the SNF. Again, these mixtures and isotopes were chosen because of their high sensitivities and corresponding importance to the overall reactivity of the model. Summaries of the comparisons of TSUNAMI-3D sensitivities and direct perturbation sensitivities are provided in Table 4-5 for 25 GWd/MTU and the AO isotope set, Table 4-6 for $25 \mathrm{GWd} / \mathrm{MTU}$ and the AFP isotope set, Table 4-7 for $50 \mathrm{GWd} /$ MTU and the AO isotope set, and Table 4-8 for $50 \mathrm{GWd} / \mathrm{MTU}$ and the AFP isotope set.

Agreement between TSUNAMI and direct perturbations is generally good. The relative difference between the two estimates of the ${ }^{238} \mathrm{U}$ and ${ }^{240} \mathrm{Pu}$ sensitivities is larger than desired in the $\mathrm{AO}$ cases, with relative differences over $5 \%$ and 2 standard deviations [33]. As with the MG discrepancies, the absolute differences are acceptable because they are less than 0.01 [33].

\section{Table 4-5 Summary of Comparisons of CE TSUNAMI-3D and Direct Perturbation Sensitivities for 25 GWd/MTU Burnup and AO Isotope Set}

\begin{tabular}{lccccccc|}
\hline & \multicolumn{2}{c}{ TSUNAMI-3D } & \multicolumn{2}{c}{ Direct perturbation } & \multicolumn{3}{c|}{ Comparison } \\
\cline { 2 - 8 } Material & Sensitivity & Unc. & Sensitivity & Unc. & Rel. Diff. (\%) & $\begin{array}{c}\text { Rel. Diff. } \\
(\sigma)\end{array}$ & Abs. Diff. \\
\hline $\begin{array}{l}\mathrm{H}_{2} \mathrm{O} \text {, fuel } \\
\text { rod cell }\end{array}$ & $1.94 \mathrm{E}-01$ & $2.54 \mathrm{E}-03$ & $1.99 \mathrm{E}-01$ & $2.57 \mathrm{E}-03$ & -2.76 & 1.52 & -0.0055 \\
${ }^{235} \mathrm{U}$ & $1.88 \mathrm{E}-01$ & $5.98 \mathrm{E}-05$ & $1.87 \mathrm{E}-01$ & $2.62 \mathrm{E}-03$ & 0.67 & 0.48 & 0.0012 \\
${ }^{238} \mathrm{U}$ & $-8.18 \mathrm{E}-02$ & $1.80 \mathrm{E}-04$ & $-7.77 \mathrm{E}-02$ & $1.16 \mathrm{E}-03$ & 5.38 & 3.56 & -0.0042 \\
${ }^{239} \mathrm{Pu}$ & $6.43 \mathrm{E}-02$ & $5.07 \mathrm{E}-05$ & $6.25 \mathrm{E}-02$ & $9.07 \mathrm{E}-04$ & 2.80 & 1.93 & 0.0018 \\
${ }^{240} \mathrm{Pu}$ & $-1.98 \mathrm{E}-02$ & $8.73 \mathrm{E}-06$ & $-1.88 \mathrm{E}-02$ & $2.78 \mathrm{E}-04$ & 5.51 & 3.71 & -0.0010 \\
\hline
\end{tabular}

Table 4-6 Summary of Comparisons of CE TSUNAMI-3D and Direct Perturbation Sensitivities for 25 GWd/MTU Burnup and AFP Isotope Set

\begin{tabular}{|c|c|c|c|c|c|c|c|}
\hline \multirow[b]{2}{*}{ Material } & \multicolumn{2}{|c|}{ TSUNAMI-3D } & \multicolumn{2}{|c|}{ Direct perturbation } & \multicolumn{3}{|c|}{ Comparison } \\
\hline & Sensitivity & Unc. & Sensitivity & Unc. & Rel. Diff. (\%) & $\begin{array}{l}\text { Rel. Diff. } \\
(\sigma)\end{array}$ & Abs. Diff. \\
\hline $\begin{array}{l}\mathrm{H}_{2} \mathrm{O} \text {, fuel } \\
\text { rod cell }\end{array}$ & 1.93E-01 & 2.57E-03 & 1.96E-01 & 2.81E-03 & -1.54 & 0.79 & -0.0030 \\
\hline${ }^{235} \mathrm{U}$ & 2.08E-01 & $6.15 E-05$ & 2.10E-01 & 3.23E-03 & -1.30 & 0.85 & -0.0027 \\
\hline${ }^{238} \mathrm{U}$ & $-7.58 \mathrm{E}-02$ & 1.86E-04 & $-7.43 E-02$ & 1.18E-03 & 2.01 & 1.25 & -0.0015 \\
\hline${ }^{239} \mathrm{Pu}$ & 9.94E-02 & 1.17E-04 & 9.73E-02 & 1.53E-03 & 2.18 & 1.38 & 0.0021 \\
\hline${ }^{240} \mathrm{Pu}$ & $-2.54 \mathrm{E}-02$ & $1.04 \mathrm{E}-05$ & $-2.55 E-02$ & 3.91E-04 & -0.50 & 0.32 & 0.0001 \\
\hline
\end{tabular}


Table 4-7 Summary of Comparisons of CE TSUNAMI-3D and Direct Perturbation Sensitivities for $50 \mathrm{GWd} / \mathrm{MTU}$ Burnup and AO Isotope Set

\begin{tabular}{|c|c|c|c|c|c|c|c|}
\hline \multirow[b]{2}{*}{ Material } & \multicolumn{2}{|c|}{ TSUNAMI-3D } & \multicolumn{2}{|c|}{ Direct perturbation } & \multicolumn{3}{|c|}{ Comparison } \\
\hline & Sensitivity & Unc. & Sensitivity & Unc. & Rel. Diff. (\%) & $\begin{array}{l}\text { Rel. Diff. } \\
(\sigma)\end{array}$ & Abs. Diff. \\
\hline $\begin{array}{l}\mathrm{H}_{2} \mathrm{O} \text {, fuel } \\
\text { rod cell }\end{array}$ & 2.15E-01 & 2.82E-03 & 2.23E-01 & 3.19E-03 & -3.42 & 1.79 & -0.0076 \\
\hline${ }^{235} \mathrm{U}$ & 1.79E-01 & 6.50E-05 & $1.81 \mathrm{E}-01$ & 2.68E-03 & -0.68 & 0.46 & -0.0012 \\
\hline${ }^{238} \mathrm{U}$ & $-7.95 \mathrm{E}-02$ & 1.92E-04 & 8.69E-02 & 1.39E-03 & 2.86 & 1.80 & -0.0022 \\
\hline${ }^{239} \mathrm{Pu}$ & 9.01E-02 & 5.85E-05 & $-7.72 \mathrm{E}-02$ & 1.21E-03 & 3.71 & 2.32 & 0.0032 \\
\hline${ }^{240} \mathrm{Pu}$ & $-2.76 \mathrm{E}-02$ & 1.09E-05 & $-2.63 E-02$ & 4.16E-04 & 4.74 & 3.00 & -0.0012 \\
\hline
\end{tabular}

Table 4-8 Summary of Comparisons of CE TSUNAMI-3D and Direct Perturbation Sensitivities for $50 \mathrm{GWd} / \mathrm{MTU}$ Burnup and AFP Isotope Set

\begin{tabular}{|c|c|c|c|c|c|c|c|}
\hline \multirow[t]{2}{*}{ Material } & \multicolumn{2}{|c|}{ TSUNAMI-3D } & \multicolumn{2}{|c|}{ Direct perturbation } & \multicolumn{3}{|c|}{ Comparison } \\
\hline & Sensitivity & Unc. & Sensitivity & Unc. & Rel. Diff. (\%) & $\begin{array}{l}\text { Rel. Diff. } \\
(\sigma)\end{array}$ & Abs. Diff. \\
\hline $\begin{array}{l}\mathrm{H}_{2} \mathrm{O} \text {, fuel } \\
\text { rod cell }\end{array}$ & 2.23E-01 & 2.76E-03 & 2.24E-01 & 3.64E-03 & -0.65 & 0.32 & -0.0015 \\
\hline${ }^{235} \mathrm{U}$ & 2.05E-01 & 6.64E-05 & 2.10E-01 & $3.41 \mathrm{E}-03$ & -2.07 & 1.27 & -0.0043 \\
\hline${ }^{238} \mathrm{U}$ & $-6.84 \mathrm{E}-02$ & 1.92E-04 & $1.16 \mathrm{E}-01$ & 1.98E-03 & 1.84 & 1.05 & -0.0012 \\
\hline${ }^{239} \mathrm{Pu}$ & 1.17E-01 & 6.09E-05 & $-6.71 \mathrm{E}-02$ & 1.16E-03 & 1.40 & 0.81 & 0.0016 \\
\hline${ }^{240} \mathrm{Pu}$ & $-2.89 E-02$ & 2.01E-05 & $-2.81 \mathrm{E}-02$ & 4.70E-04 & 2.71 & 1.62 & -0.0008 \\
\hline
\end{tabular}

\subsection{Comparison of MG and CE Sensitivities}

Two integral parameters were used to compare the sensitivity data generated by the MG and CE TSUNAMI-3D calculations: $c_{k}$ and $E$. The integral parameter $c_{k}$ is used as it is the most common parameter for comparing systems. As discussed in Section 2.1.2, E is used as an additional parameter because all sensitivities are given equal weight in determining this parameter. Direct comparisons of high sensitivity isotopes and reactions are also made. The resulting total sensitivity profile for ${ }^{1} \mathrm{H}$ in the fuel rod unit cell with the highest sensitivity at $25 \mathrm{GWd} / \mathrm{MTU}$ burnup and the AO isotope set is provided in Figure 4-1 from both MG and CE TSUNAMI-3D. The ${ }^{10} \mathrm{~B}$ $(n, \alpha)$ sensitivity profiles are provided in Figure 4-2 from both TSUNAMI-3D calculations for the 25 GWd/MTU burnup and the AFP isotope set. The comparisons for the total sensitivity of ${ }^{235} \mathrm{U}$ from the highest sensitivity axial zone are provided in Figure 4-3 for the AO isotope set at 50 GWd/MTU burnup and in Figure 4-4 for ${ }^{239} \mathrm{Pu}$ for the AFP isotope set at the same burnup. All of these comparisons show excellent agreement. 


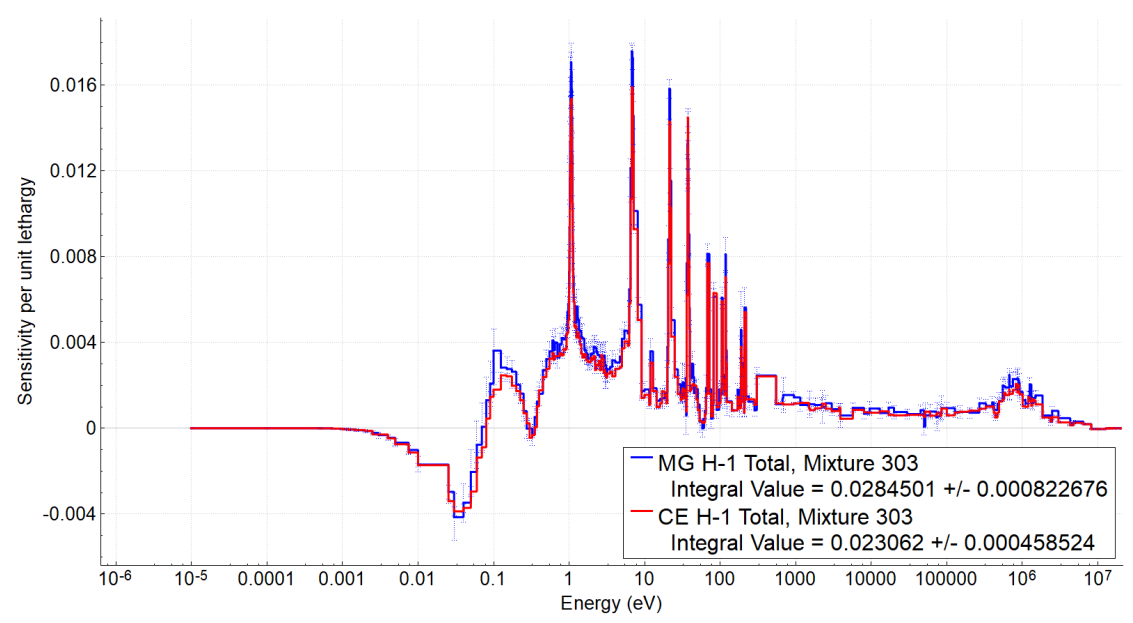

Figure 4-1 ${ }^{1} \mathrm{H}$ Total Sensitivity Profiles from MG and CE TSUNAMI-3D

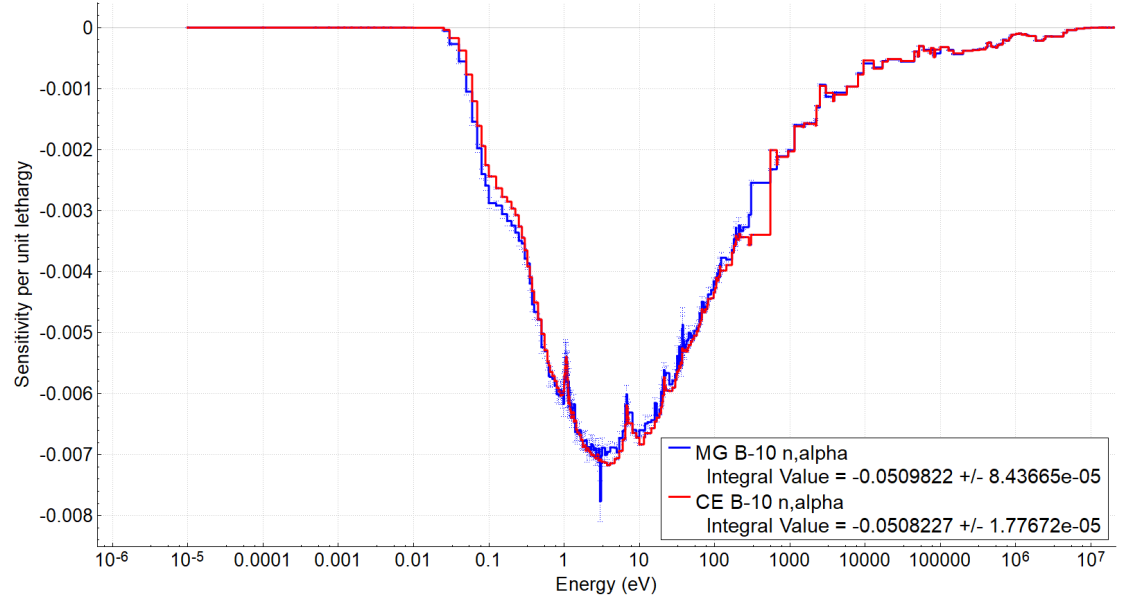

Figure 4-2 ${ }^{10} B(n, \alpha)$ Sensitivity Profiles from MG and CE TSUNAMI-3D

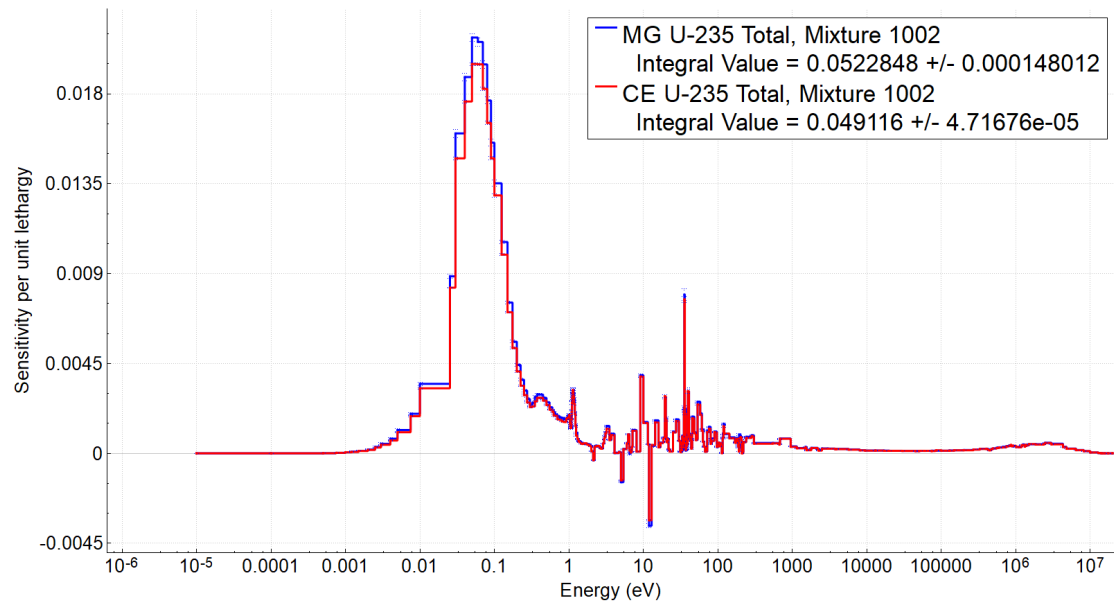

Figure 4-3 ${ }^{235} \mathrm{U}$ Total Sensitivity Profiles from MG and CE TSUNAMI-3D 


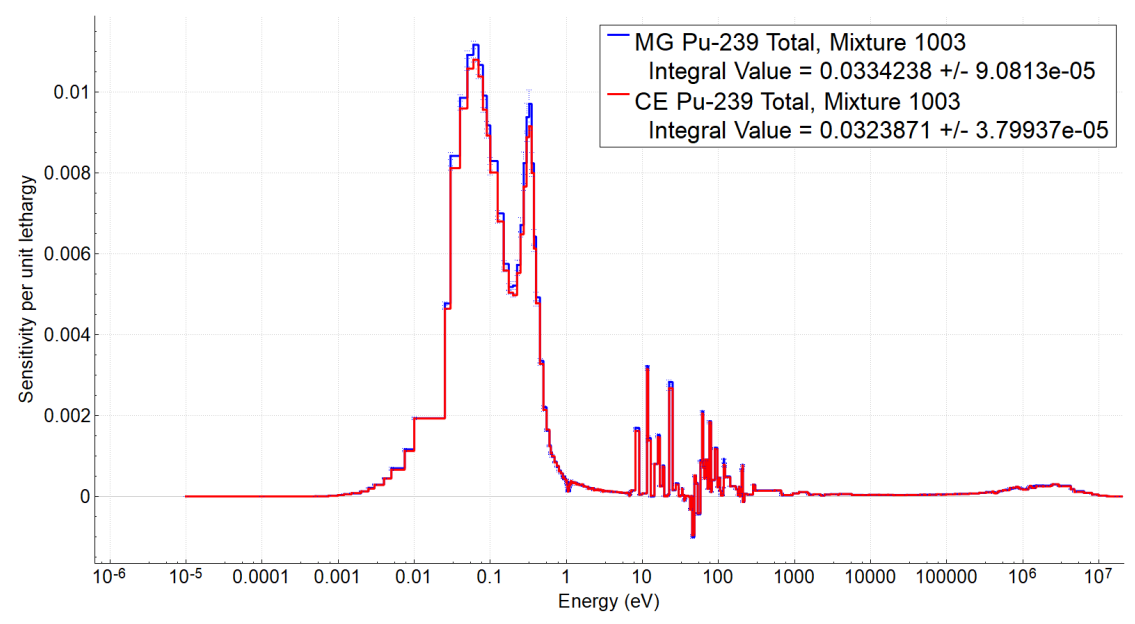

Figure 4-4 ${ }^{239} \mathrm{Pu}$ Total Sensitivity Profiles from MG and CE TSUNAMI-3D

The results of the $c_{k}$ and $E$ calculations are provided in Table 4-9. All $4 c_{k}$ values are in excess of 0.98 , and all $4 \mathrm{E}$ values are in excess of 0.999 . These results also indicate excellent agreement between the two methods for the same application systems. The higher values for $E$ likely indicate that the differences between the SDFs occur in isotopes and reactions with relatively large uncertainties. The larger uncertainty reactions receive a higher weight in the calculation of $c_{k}$, but these reactions are also generally of low sensitivity.

Table 4-9 Integral Parameters Comparing MG and CE TSUNAMI-3D

\begin{tabular}{|lcccc|} 
Isotope set & \multicolumn{2}{c}{$25 \mathrm{GWd} / \mathrm{MTU}$} & \multicolumn{2}{c|}{$50 \mathrm{GWd} / \mathrm{MTU}$} \\
\cline { 2 - 5 } & $\mathrm{C}_{\mathrm{k}}$ & $\mathrm{E}$ & $\mathrm{C}_{\mathrm{k}}$ & $\mathrm{E}$ \\
\hline $\mathrm{AO}$ & 0.9831 & 0.9994 & 0.9831 & 0.9994 \\
$\mathrm{AFP}$ & 0.9828 & 0.9996 & 0.9833 & 0.9995 \\
\hline
\end{tabular}

TSUNAMI-IP calculates an individual $c_{k}$ for each isotope and reaction. This quantity is calculated in the same way as the integral $c_{k}$, shown in Eq. (1) in Section 2.1.2, except it is not integrated over all isotopes and all reactions. An examination of individual $c_{k}$ values for the comparison of MG and CE sensitivity data at $50 \mathrm{GWd} / \mathrm{MTU}$ burnup and the AFP isotope set revealed only one reaction from the top 50 contributors to overall $c_{k}$ with an individual $c_{k}$ less than 0.95 . This reaction is elastic scatter in ${ }^{56} \mathrm{Fe}$ in the stainless steel basket. The two sensitivity profiles in Figure 4-5 show a much larger sensitivity for the CE calculation than the MG calculation. Direct perturbation calculations were performed for the total sensitivity of ${ }^{56} \mathrm{Fe}$ in the basket; these calculations confirmed that the CE TSUNAMI-3D calculation was more accurate than the MG calculation. The cause of the poor sensitivity prediction from the MG TSUNAMI calculation was not investigated extensively. It is most likely related to the difficulty in collecting accurate flux moments for the thin basket regions with the mesh size used in the model. A finer mesh spacing with planes deliberately located in the stainless steel basket regions would likely improve the MG sensitivity prediction. 


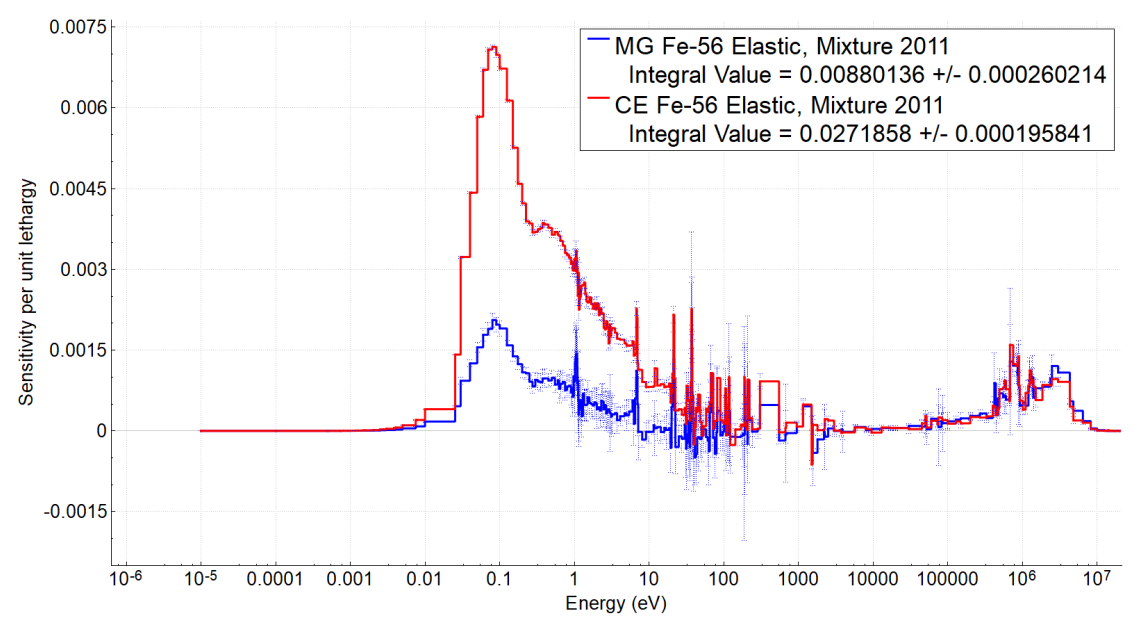

Figure 4-5 ${ }^{56} \mathrm{Fe}$ Elastic Scattering Sensitivity Profiles from MG and CE TSUNAMI-3D

The comparisons of sensitivity data generated from MG and CE TSUNAMI-3D show excellent agreement for the GBC-68 application cases used in this work at both burnups considered with both isotope sets. One reaction/isotope combination with a discrepancy was identified, and the CE method was shown to be more accurate. The SDFs calculated using CE TSUNAMI-3D will be used for experiment selection (see Section 5) and reactivity margin assessments (see Section 7) because they have been shown to be more accurate than the SDFs generated by MG TSUNAMI3D. However, the MG sensitivities are highly similar and are also acceptable for use in these applications.

\subsection{Comparison to GBC-32}

The SDFs for the GBC-68 cask containing fuel depleted to a burnup of $50 \mathrm{GWd} / \mathrm{MTU}$ were compared to the GBC-32 cask containing Westinghouse $17 \times 17$ optimized fuel assemblies depleted to the same burnup. The GBC-32 SDFs were used in NUREG/CR-7109 [7]. Both the AO and AFP isotope sets were considered. The purpose of this comparison is to determine if there are significant differences between the generic cask systems or the fuel depleted in different reactor types that would impact validation of SNF systems. The two systems have a high degree of similarity. The $c_{k}$ value for the two casks with the AO isotope set is 0.94 , and 0.97 for the AFP isotope set. This result indicates that, at least at typical discharge burnups, the BWR and PWR systems are similar. Thus, the same experiments that are useful for PWR BUC validation [7] should also apply to extended BWR BUC validation. Results also indicate that the challenges regarding the lack of applicable validation experiments with FPs will apply to BWR BUC validation as well. 


\section{POTENTIALLY APPLICABLE EXPERIMENTS}

As mentioned in previous sections, the application models used to examine $k_{\text {eff }}$ validation for extended BWR BUC are the GBC-68 computational benchmark cask [9] at burnups of 25 and 50 GWd/MTU with both the AO and AFP isotopes sets. Each application also had five years of cooling time after irradiation. The models are described in Section 2.2, and the GBC-68 cask model is defined in NUREG/CR-7157 [9]. The two selected burnups are intended to bracket the range of burnups over which extended BWR BUC is likely to be applied. Burnups lower than 25 GWd/MTU are likely to be governed by peak reactivity analysis, and assembly average burnups for BWR fuel are unlikely to be significantly greater than $50 \mathrm{GWd} / \mathrm{MTU}$.

TSUNAMI-IP is used to calculate the $c_{k}$ integral parameter assessing similarity of each of a suite of 1,643 laboratory critical experiments (LCEs) to each of the four application models. This method of assessing similarity is discussed in Section 2.1.2 and is based on guidance provided in Rearden et al. [11] and Scaglione et al. [7]. The experiment suite is discussed in Section 2.3.2. It is the same suite that was used for investigations of $k_{\text {eff }}$ validation of the peak reactivity method in NUREG/CR-7194 [3]. The application SDFs were generated using CE TSUNAMI-3D, as discussed in Section 4. The experiment SDFs were all generated with MG TSUNAMI-3D. The difference in SDF generation methods will not significantly impact the assessed similarity of the experiments, because, as shown in Section 4.3, the two methods yield very similar sensitivity data. No commercial reactor critical statepoint models (CRCs) are used in this work.

\subsection{Application 1: $25 \mathrm{GWd} / \mathrm{MTU}$ and AO Isotope Set}

The full suite of 1,643 critical experiment SDFs was compared to the SDF from the GBC-68 model, which had an assembly average burnup of $25 \mathrm{GWd} / \mathrm{MTU}$ and the AO isotope set. A plot of the resulting $c_{k}$ values is provided in Figure 5-1. Each category of experiments is shown as a different data series to help illustrate which types of experiments are most applicable. No distinctions are made in the figure to indicate the source of each individual experiment SDF. As shown in the figure, a number of LCT experiments and a large number of HTC experiments show sufficient similarity with this application to be used in validation. A total of 174 experiments have a $\mathrm{C}_{\mathrm{k}}$ greater than 0.8; 73 are LCT experiments, and the remaining 101 are HTC experiments. Figure $5-2$ shows the $c_{k}$ values greater than 0.8 , highlighting the different series of experiments. The $c_{k}$ values are provided for these 174 experiments in Appendix C, Table C-1. Two cases from the LCT-051 evaluation (Cases 13 and 14) are excluded due to the large uncertainties in the boron content of the poison plates used in those experiments. The two cases use the same poison plates, and they are the only two cases that used those particular plates. Therefore, the final set of potentially applicable experiments consists of 71 LCT experiments and $101 \mathrm{HTC}$ experiments, for a total of 172 experiments. A number of LCT series are represented, including a large number of cases from the LCT-008, LCT-011, and LCT-051 evaluations. Forty-eight of the 71 LCT experiments identified as potentially applicable are from these three series. 


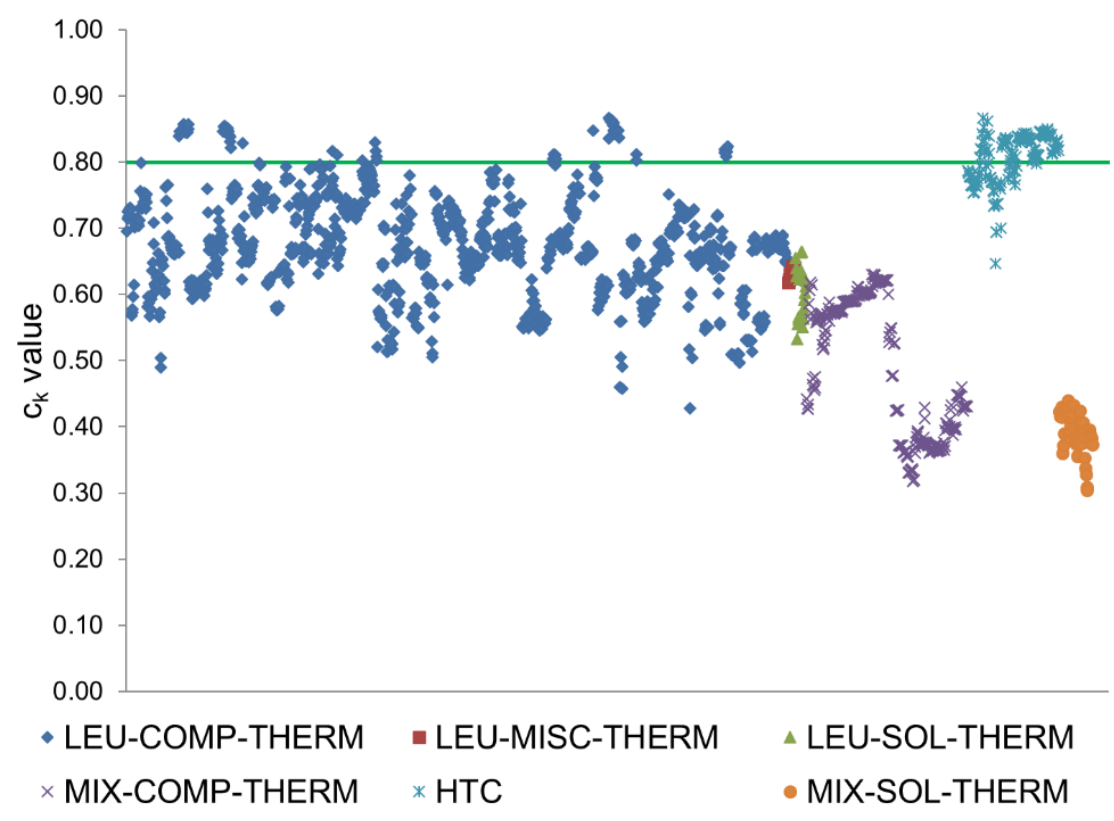

Figure 5-1 $c_{k}$ Values for Critical Experiments Compared to GBC-68 with Fuel at a Burnup of $25 \mathrm{GWd} / \mathrm{MTU}$ and the AO Isotope Set

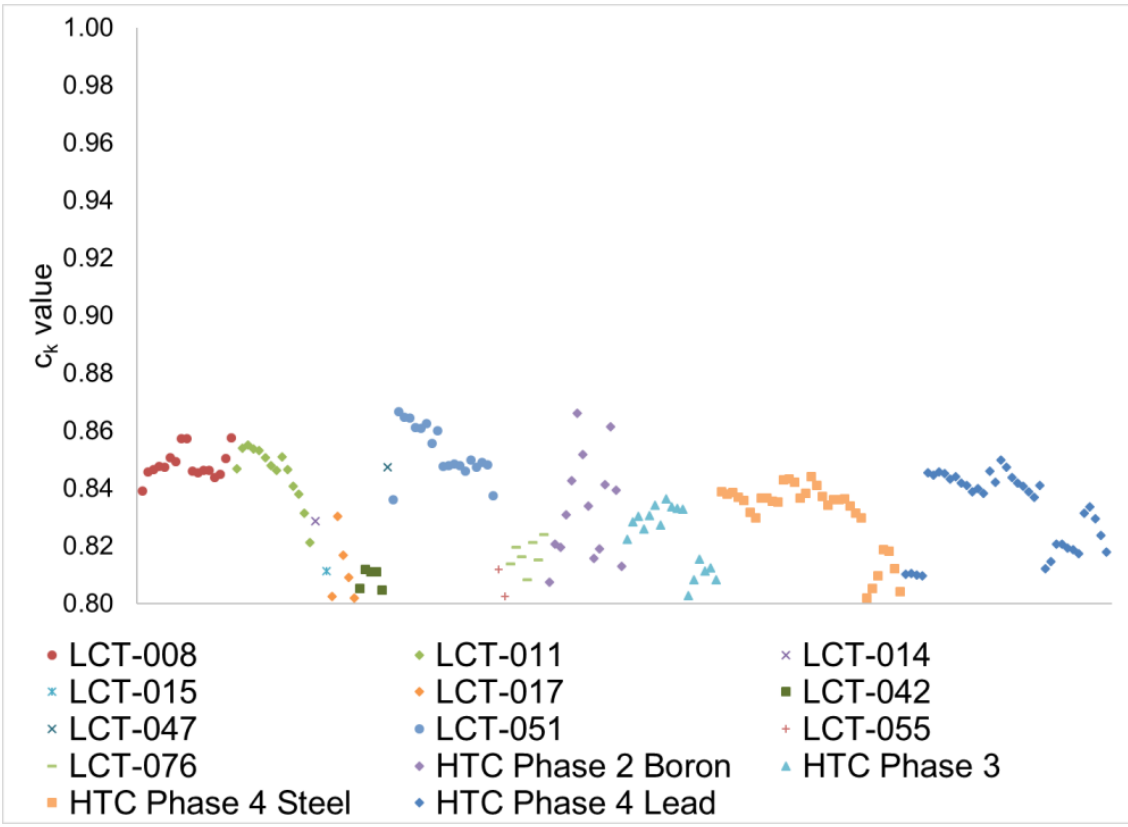

Figure 5-2 $c_{k}$ Values Greater than 0.8 at $25 \mathrm{GWd} / \mathrm{MTU}$ Burnup with the AO Isotope Set

\subsection{Application 2: $25 \mathrm{GWd} / \mathrm{MTU}$ and AFP Isotope Set}

The SDF from the GBC-68 model with an assembly average burnup of $25 \mathrm{GWd} / \mathrm{MTU}$ and the AFP isotope set was compared to the full suite of 1,643 critical experiment SDFs. A plot of the resulting $c_{k}$ values is provided in Figure 5-3. Each category of experiments is shown as a different data series to help identify which types of experiments are most applicable. No distinctions are made in the figure to indicate the source of each individual experiment SDF. As shown in the 
figure, only some HTC, and no LCT experiments, show sufficient similarity with this application to be used in validation. A total of 68 experiments has a $c_{k}$ greater than 0.8 . Figure 5-4 shows the $c_{k}$ values greater than or equal to 0.8 , highlighting the different HTC phases from which applicable experiments are drawn. The $c_{k}$ values are provided for these 68 experiments in Appendix $C$, Table C-2.

A comparison of Figure 5-1 and Figure 5-3 shows that $c_{k}$ values are lower with the AFP isotope set than with the AO isotope set. This is the result of the addition of MAs and major FPs to the application model. None of the experiments contain these isotopes in the quantity and distribution that occurs in SNF. Some MCT experiments show modest increases in $\mathrm{c}_{\mathrm{k}}$ despite the change in compositions. This is a result of the spectral hardening induced by the thermal absorption in FPs; the EALF increases from $0.225 \mathrm{eV}$ with the AO isotopes to $0.275 \mathrm{eV}$ with the AFP set. These are modest increases, and the $\mathrm{C}_{\mathrm{k}}$ values for all MCT experiments (not including the HTC experiments) remain below 0.7 . The $c_{k}$ values for the HTC experiments are relatively low for this application because the fissile material was designed to represent PWR fuel at a burnup of approximately $37.5 \mathrm{GWd} / \mathrm{MTU}$. The HTC experiments have been shown to be poor for validation of low burnup PWR [7] and BWR [3] fuel. A number of the HTC cases are applicable in the lower end of the burnup range, as expected for extended BWR BUC.

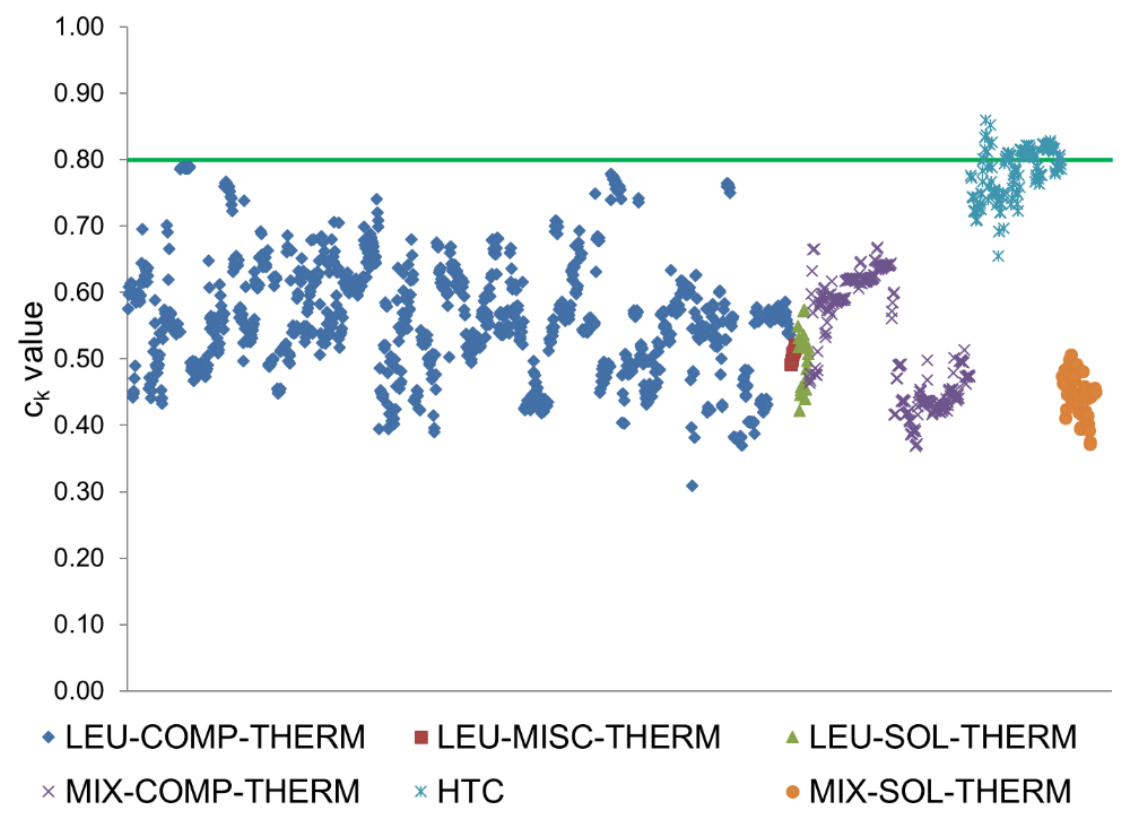

Figure 5-3 $c_{k}$ Values for Critical Experiments Compared to GBC-68 with Fuel at a Burnup of $25 \mathrm{GWd} / \mathrm{MTU}$ and the AFP Isotope Set 


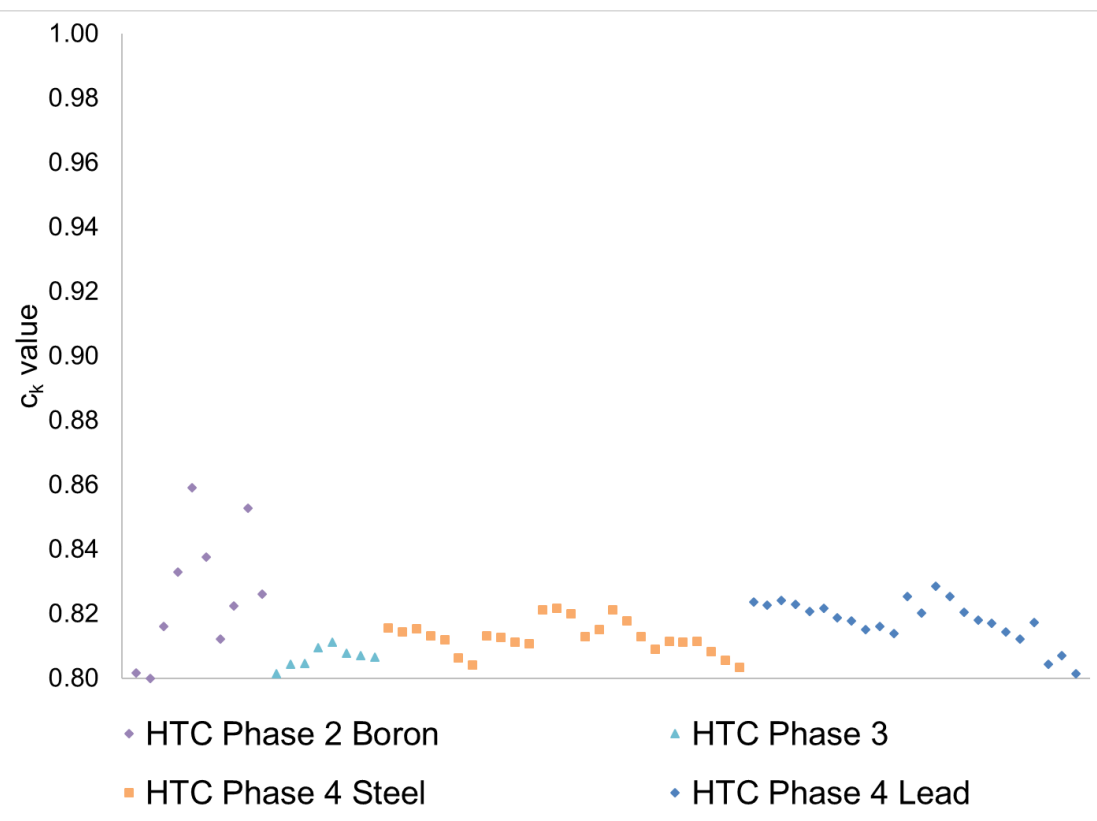

Figure 5-4 $c_{k}$ Values Not Less than 0.8 at 25 GWd/MTU Burnup with the AFP Isotope Set

\subsection{Application 3: $50 \mathrm{GWd} / \mathrm{MTU}$ and AO Isotope Set}

The suite of critical experiment SDFs was compared to the SDF from the GBC-68 model with an assembly average burnup of $50 \mathrm{GWd} / \mathrm{MTU}$ and the AO isotope set. A plot of the resulting $\mathrm{C}_{\mathrm{k}}$ values is provided in Figure 5-5. Each category of experiments is shown as a different data series to help identify which types of experiments are most applicable. No distinctions are made in the figure to indicate the source of each individual experiment SDF. As shown in the figure, a few LCT experiments and the majority of the HTC experiments show sufficient similarity with this application to be used in validation. A total of 175 experiments have a $c_{k}$ greater than $0.8 ; 28$ of the experiments are LCT experiments, and the remaining 147 are HTC experiments. Figure 5-6 shows the $c_{k}$ values greater than 0.8 , highlighting the different series of experiments. The $c_{k}$ values are provided for these 175 experiments in Appendix C, Table C-3. As mentioned in Section 5.1, LCT-051 Cases 13 and 14 are excluded because of large uncertainties associated with the poison plates used in those cases. Therefore, the final set of potentially applicable experiments consists of a total of 173 experiments, including 26 LCT experiments and 147 HTC experiments.

A comparison of Figure 5-1 and Figure 5-5 shows lower $c_{k}$ values for the LCT experiments and higher values for the HTC experiments. The application case at $50 \mathrm{GWd} / \mathrm{MTU}$ has more Pu and a lower $U$ enrichment, both of which make the LCT experiments less applicable. The higher burnup SNF is more similar to the HTC actinide composition than the lower burnup applications. At 25 GWd/MTU, the volume average uranium enrichment is $2.35 \mathrm{wt} \%{ }^{235} \mathrm{U}$, and it drops to $1.10 \mathrm{wt} \%$ ${ }^{235} \mathrm{U}$ at $50 \mathrm{GWd} / \mathrm{MTU}$. The enrichment of the HTC actinide composition is $1.57 \mathrm{wt} \%{ }^{235} \mathrm{U}$ [14], 0.47 wt $\%$ higher than the $50 \mathrm{GWd} / \mathrm{MTU}$ application, and $0.78 \mathrm{wt} \%$ lower than the $25 \mathrm{GWd} / \mathrm{MTU}$ application. Similarly, the fraction of Pu that is ${ }^{239} \mathrm{Pu}$ drops from $70.77 \mathrm{wt} \%$ at $25 \mathrm{GWd} / \mathrm{MTU}$ to $53.76 \mathrm{wt} \%$ at $50 \mathrm{GWd} / \mathrm{MTU}$. The HTC fuel composition has $59.2 \mathrm{wt} \%$ of Pu as ${ }^{239} \mathrm{Pu}$, again in significantly better agreement with the higher burnup actinide composition. 


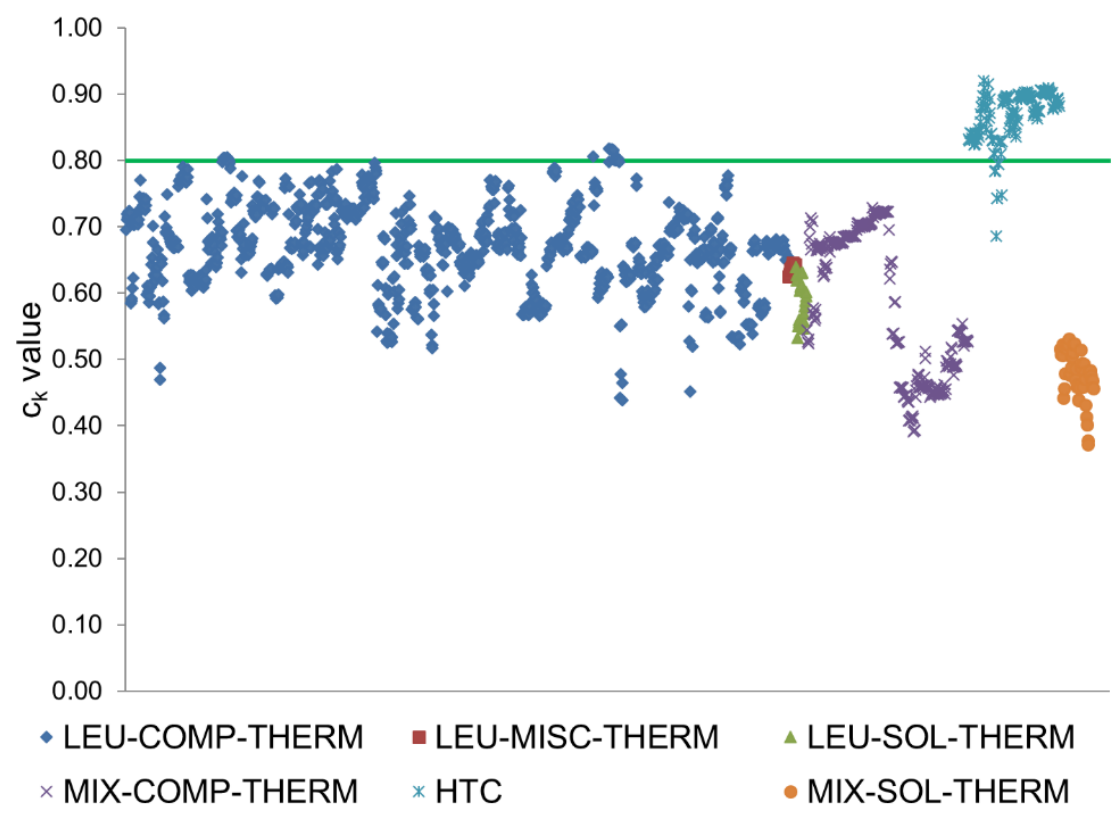

Figure 5-5 $c_{k}$ Values for Critical Experiments Compared to GBC-68 with Fuel at a Burnup of $50 \mathrm{GWd} / \mathrm{MTU}$ and the AO Isotope Set

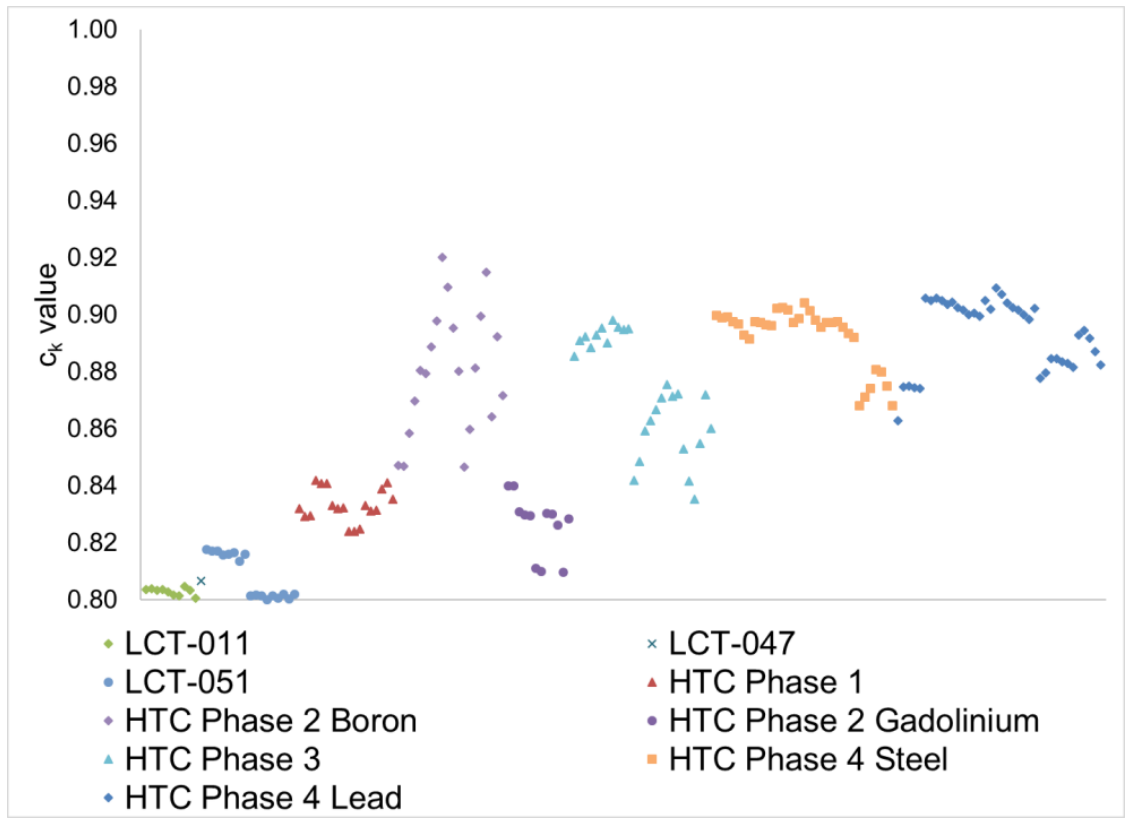

Figure 5-6 $c_{k}$ Values Not Less than 0.8 at $50 \mathrm{GWd} / \mathrm{MTU}$ Burnup with the AO Isotope Set

\subsection{Application 4: $50 \mathrm{GWd} / \mathrm{MTU}$ and AFP Isotope Set}

The SDF from the GBC-68 model with an assembly average burnup of $50 \mathrm{GWd} / \mathrm{MTU}$ and the AFP isotope set was compared to the suite of critical experiment SDFs. A plot of the resulting $c_{k}$ values is provided in Figure 5-7. Each category of experiments is shown as a different data series to help identify which types of experiments are most applicable. No distinctions are made in the figure to indicate the source of each individual experiment SDF. As shown in the figure, only HTC 
experiments show sufficient similarity with this application to be used in validation. A total of 126 HTC cases have a $c_{k}$ greater than 0.8 . Figure 5-8 shows the $c_{k}$ values greater than 0.8 , highlighting the different HTC phases from which applicable experiments are drawn. The $c_{k}$ values are provided for these 126 experiments in Appendix C, Table C-4.

A comparison of Figure 5-5 and Figure 5-7 shows that $c_{k}$ values are lower with the AFP isotope set than with the AO isotopes. This is simply the result of the addition of MAs and major FPs to the application model. As mentioned previously, only HTC experiments retain sufficient similarity for use in validation. A larger number of cases are applicable than identified at a burnup of 25 GWd/MTU because of the better actinide composition agreement, as described in the previous section.

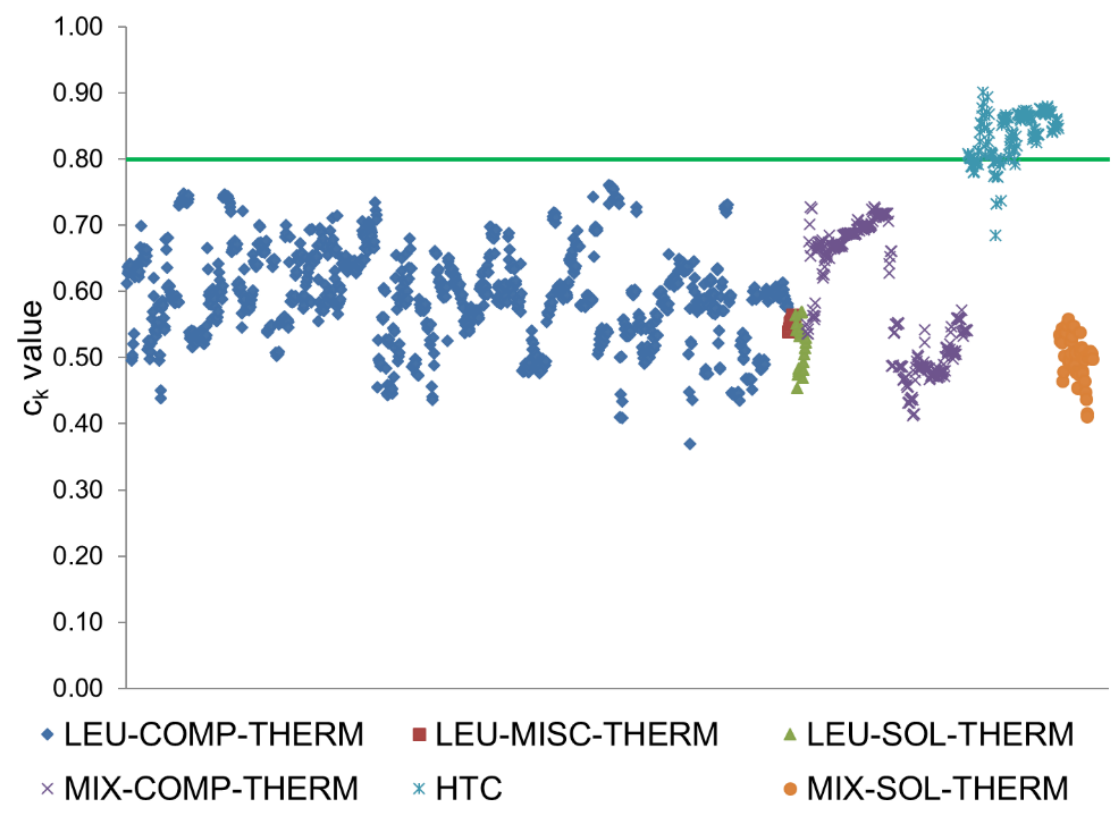

Figure 5-7 $c_{k}$ Values for Critical Experiments Compared to GBC-68 with Fuel at a Burnup of $50 \mathrm{GWd} / \mathrm{MTU}$ and the AFP Isotope Set 


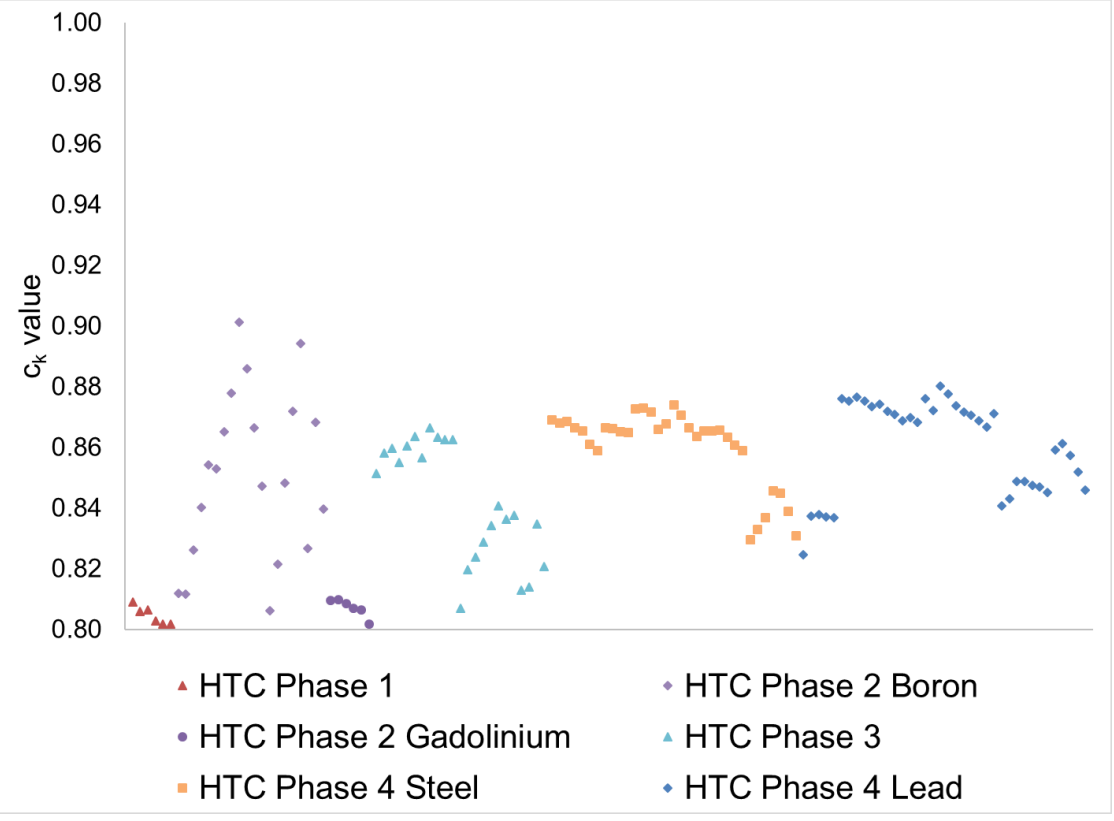

Figure 5-8 $c_{k}$ Values Not Less than 0.8 at $50 \mathrm{GWd} / \mathrm{MTU}$ Burnup with the AFP Isotope Set 



\section{BIAS AND BIAS UNCERTAINTY DETERMINATION}

The primary purpose of validation is to quantify the suitability of a computational method for use in a criticality safety analysis [28]. Typically, this involves the determination of a code bias and a bias uncertainty to estimate a lower bound on the calculated $k_{\text {eff }}$ for a critical system. Some validation approaches determine a single calculational margin which represents a combination of the bias and bias uncertainty. The USL is derived by combining the calculational margin - that is, the bias and bias uncertainty - with an additional administrative margin and any additional margins required to account for gaps or weaknesses in the validation set. The USL is the highest calculated $k_{\text {eff }}$ that can be assumed to represent a subcritical system [28]. A discussion of margins for extended BWR BUC validation is presented in Section 7 to account for the gadolinium, MAs, and FPs not present in critical experiments identified in Section 5 as potentially applicable. This section provides sample bias and bias uncertainty determinations for the four application models considering the applicable experiments identified in the previous section. As discussed in Section 2.1.3, a nontrending method and a trending method with a range of trending parameters is used in these calculations. For the extended burnup credit cases, trends on EALF and $c_{k}$ were considered. The enrichment trend used for the peak reactivity cases was not considered because the burnups of the models that were included depart significantly from fresh fuel compositions. A summary of the sample bias and bias uncertainty values is provided in Table 6-1 in Section 6.4 for all 4 applications.

\subsection{Application 1: $25 \mathrm{GWd} / \mathrm{MTU}$ and AO Isotope Set}

Using the set of 172 critical experiments (101 HTCs and 71 LCTs) that were determined to be applicable in Section 5.1, three sets of biases and bias uncertainties were generated. Bias and bias uncertainty were determined using a nontrending analysis, and they were also determined for trends on EALF and $c_{k}$. The nontrending bias for the $25 \mathrm{GWd} / \mathrm{MTU}$ case with the AO isotope set was developed using the inverse variance weighted nontrending method discussed in Section 2.1.3. The nontrended bias was found to be -0.00172 , and the associated bias uncertainty was found to be 0.00530 . The nontrending calculational margin for the AO isotope set is -0.00702 .

Trending analyses were performed with EALF and $\mathrm{c}_{\mathrm{k}}$ serving as the trending variables. The trend evaluations are shown in Figure 6-1 for the EALF case and Figure 6-2 for the $c_{k}$ case. The 25 GWd/MTU AO model has an EALF of $0.2279 \mathrm{eV}$, which is within the range of EALFs of the applicable benchmarks of $0.08755 \mathrm{eV}$ to $1.4962 \mathrm{eV}$, with the majority of the applicable benchmarks being in the near vicinity of the application case. Evaluation of the trend at the application EALF yields a bias of -0.00182 and a bias uncertainty of 0.00649 , which results in a combined calculational margin of -0.00831 . The trend on $c_{k}$ is extrapolated to a value of 1.0 to evaluate the bias and bias uncertainty. The values of the bias and bias uncertainty for a $\mathrm{c}_{\mathrm{k}}$ trending evaluation are -0.00674 and 0.00762 , which results in a combined calculational margin of -0.01436 . The bias and bias uncertainty are higher than the values found for peak reactivity with $c_{k}$ trending. The bias and bias uncertainty for the $c_{k}$ trend are heavily influenced by the extrapolation of the data from a mean $c_{k}$ of 0.843 to a value of 1.0 . The relatively large extrapolation results because $c_{k}$ values for the $25 \mathrm{GWd} / \mathrm{MTU}$ cases are greater than the threshold value of 0.8 but are still relatively low for the LCT and HTC cases. The slope of the best estimate C/E vs. $C_{k}$ trend line is negative, so the extrapolation of the bias results in a larger magnitude bias than the nontrending evaluation. 


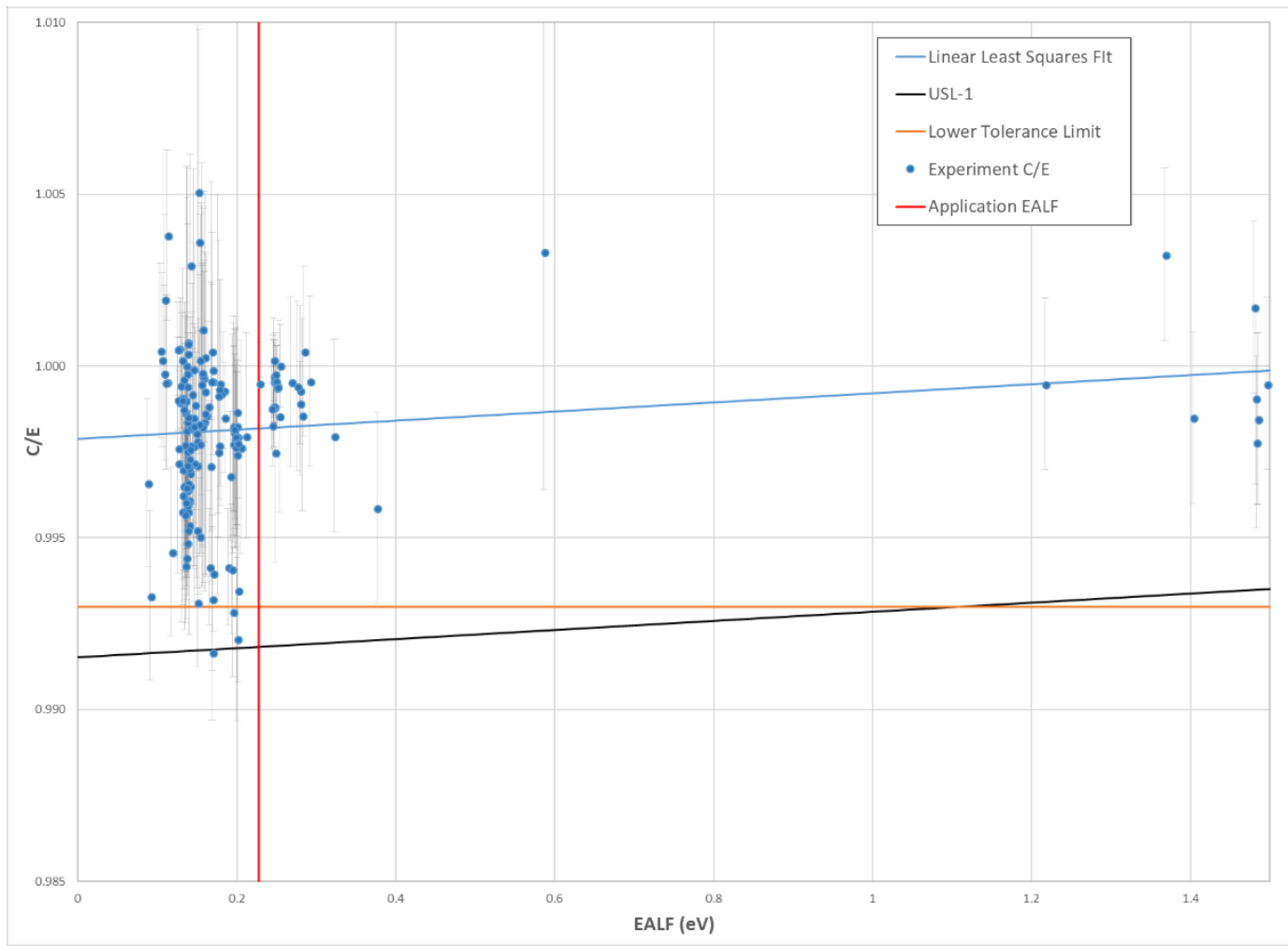

Figure 6-1 C/E vs EALF Trend for Experiments Applicable to the $25 \mathrm{GWd} / \mathrm{MTU}$ AO Case

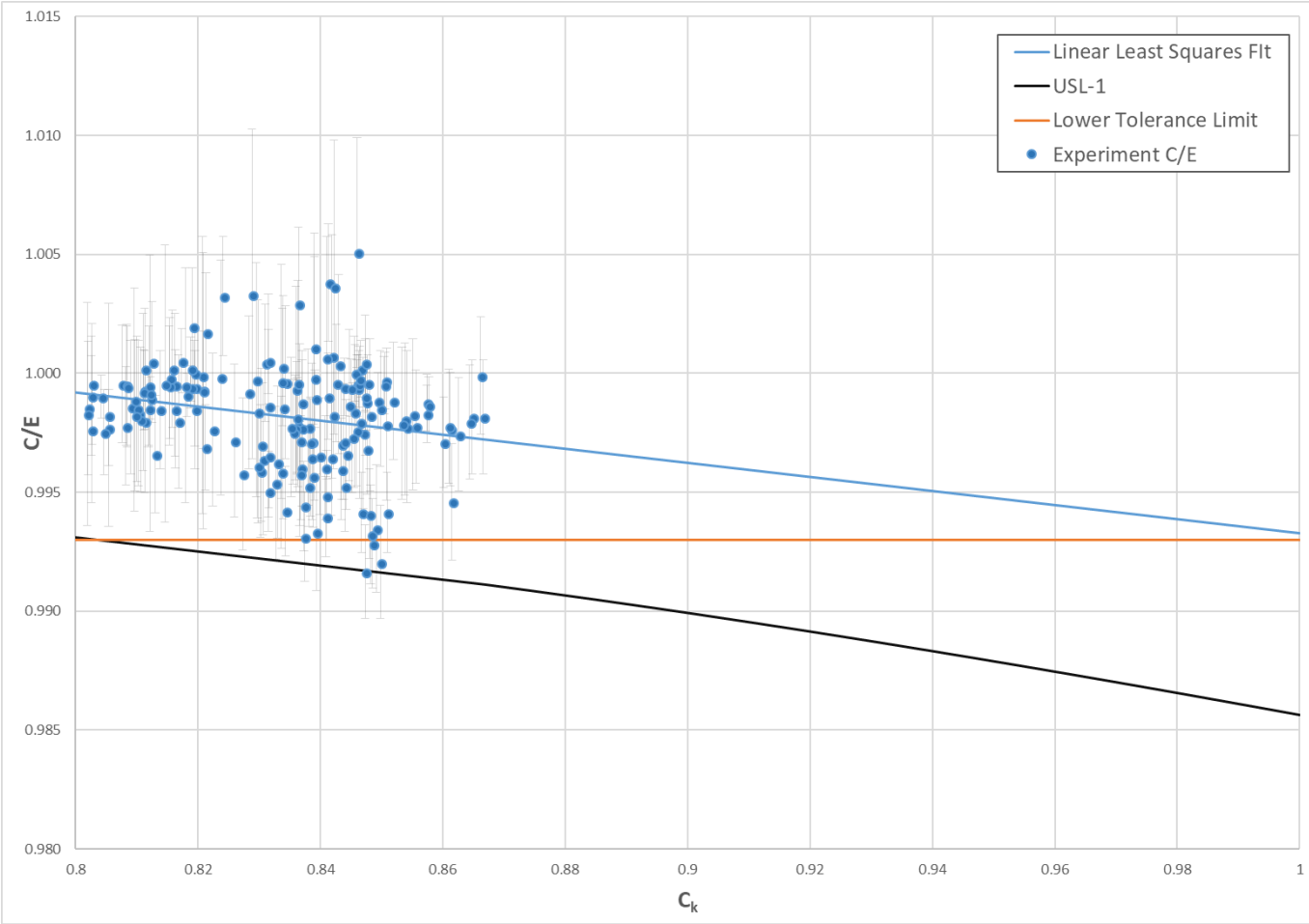

Figure 6-2 C/E vs $C_{k}$ Trend for Experiments Applicable to the $25 \mathrm{GWd} / \mathrm{MTU}$ AO Case 


\subsection{Application 2: $25 \mathrm{GWd} / \mathrm{MTU}$ and AFP Isotope Set}

Using the set of 68 critical experiments (all HTCs) that were determined to be applicable in Section 5.2, three sets of biases and bias uncertainties were generated. The bias and bias uncertainty were determined for a nontrending analysis, and they were also determined for trends on EALF and $c_{k}$. The untrended bias for the $25 \mathrm{GWd} / \mathrm{MTU}$ case with the AFP isotope set was developed using the inverse variance weighted nontrending method discussed in Section 2.1.3. The untrended bias was found to be -0.00236 , and the associated bias uncertainty was found to be 0.00672 . The untrended calculational margin for the AFP isotope set is -0.00908 .

Trending analyses were performed with EALF and $c_{k}$ serving as the trending variables. The trend evaluations are shown in Figure 6-3 for the EALF case and Figure 6-4 for the $c_{k}$ case. The 25 GWd/MTU AFP model has an EALF of $0.2766 \mathrm{eV}$, which is within the range of EALFs of the applicable benchmarks of $0.09114 \mathrm{eV}$ to $0.29172 \mathrm{eV}$, with the majority of the applicable benchmarks being lower in EALF but still in the vicinity of the application case. Evaluation of the trend at the application EALF yields a best estimate bias of 0.00044 , which would be conservatively set to 0 to avoid taking credit for a positive bias and a bias uncertainty of 0.00724 , which results in a combined calculational margin of -0.00724 . The trend on $c_{k}$ is extrapolated to a value of 1.0 to evaluate the bias and bias uncertainty. The values of the bias and bias uncertainty for a $c_{k}$ trending evaluation are -0.00050 and 0.01556 , which results in a combined calculational margin of -0.01606 . The bias and bias uncertainty for the $c_{k}$ trend are heavily influenced by the extrapolation of the data from a mean $c_{k}$ of 0.816 to a value of 1.0 . The relatively large extrapolation is necessary because $c_{k}$ values for the $25 \mathrm{GWd}$ /MTU AFP cases are greater than the threshold value of 0.8 but still relatively low for the HTC cases. The slope of the best estimate trend line is slightly positive, but the small number of points and the large extrapolation to a $c_{k}$ value of 1 leads to a wide statistical prediction band.

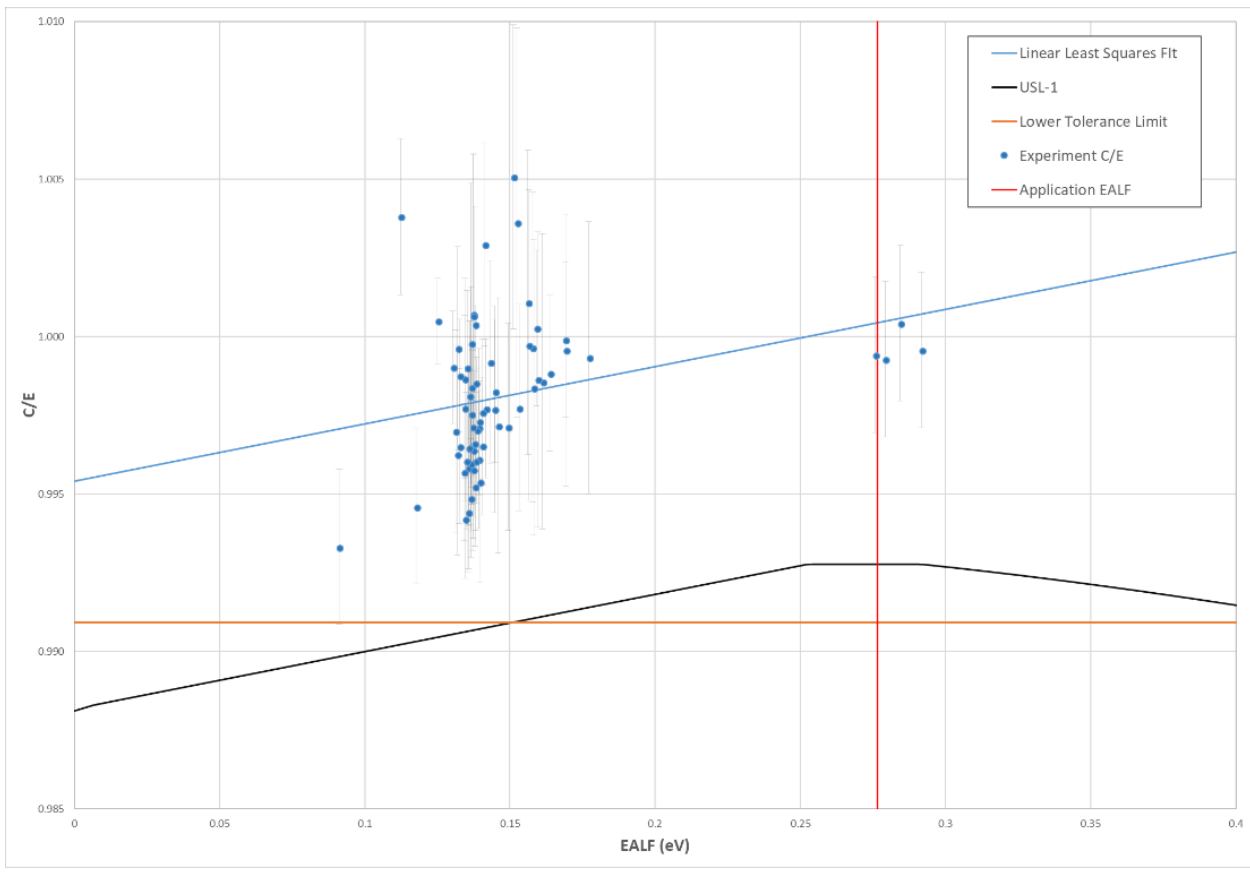

Figure 6-3 C/E vs EALF Trend for Experiments Applicable to the 25 GWd/MTU AFP Case 


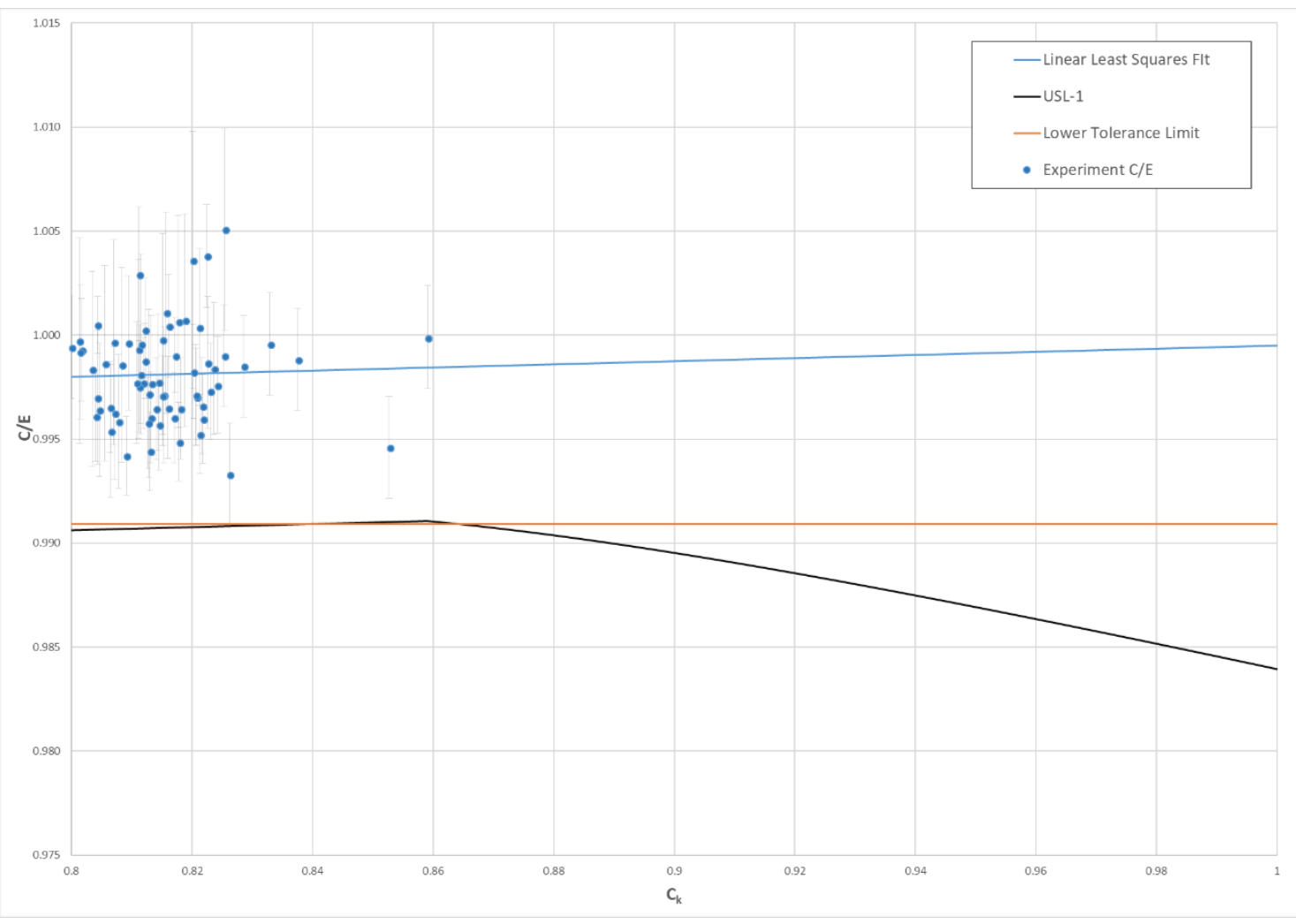

Figure 6-4 C/E vs $C_{k}$ Trend for Experiments Applicable to the $25 \mathrm{GWd} / \mathrm{MTU}$ AFP Case

\subsection{Application 3: $50 \mathrm{GWd} / \mathrm{MTU}$ and AO Isotope Set}

Using the set of 173 critical experiments ( 26 LCTs and 147 HTCs) that were determined to be applicable in Section 5.3, three sets of biases and bias uncertainties were generated. Bias and bias uncertainty were determined for a nontrending analysis, and they were also determined for trends on EALF and $c_{k}$. The nontrending bias for the $50 \mathrm{GWd} / \mathrm{MTU}$ case with the AO isotope set was developed using the inverse variance weighted nontrending method discussed earlier. The untrended bias was found to be -0.00173 , and the associated bias uncertainty was found to be 0.00581 . The untrended calculational margin for the $\mathrm{AO}$ isotope set is -0.00754 .

Trending analyses were performed with EALF and $c_{k}$ serving as the trending variables. The trend evaluations are shown in Figure 6-5 for the EALF case and Figure 6-6 for the $c_{k}$ case. The 50 GWd/MTU AO model has an EALF of $0.2259 \mathrm{eV}$, which is within the range of EALFs of the applicable benchmarks of $0.06748 \mathrm{eV}$ to $0.29172 \mathrm{eV}$, with the majority of the applicable benchmarks being lower in EALF but still in the vicinity of the application case. Evaluation of the trend at the application EALF yields a best estimate bias of -0.00206 and a bias uncertainty of 0.00646 , which results in a combined calculational margin of -0.00852 . The trend on $c_{k}$ is extrapolated to a value of 1.0 to evaluate the bias and bias uncertainty. The values of the bias and bias uncertainty for a $c_{k}$ trending evaluation are -0.00047 and 0.00657 , which result in a combined calculational margin of -0.00704 . The combined bias and bias uncertainty for the $c_{k}$ trend are reduced for the $50 \mathrm{GWd} / \mathrm{MTU}$ AO compared to $25 \mathrm{GWd} / \mathrm{MTU}$ AO and AFP cases because the extrapolation of the data is from a higher mean $c_{k}$ of 0.865 , the trend of the best estimate bias line is upward sloped, and there are a larger number of available experiments, resulting in a smaller statistical uncertainty. 


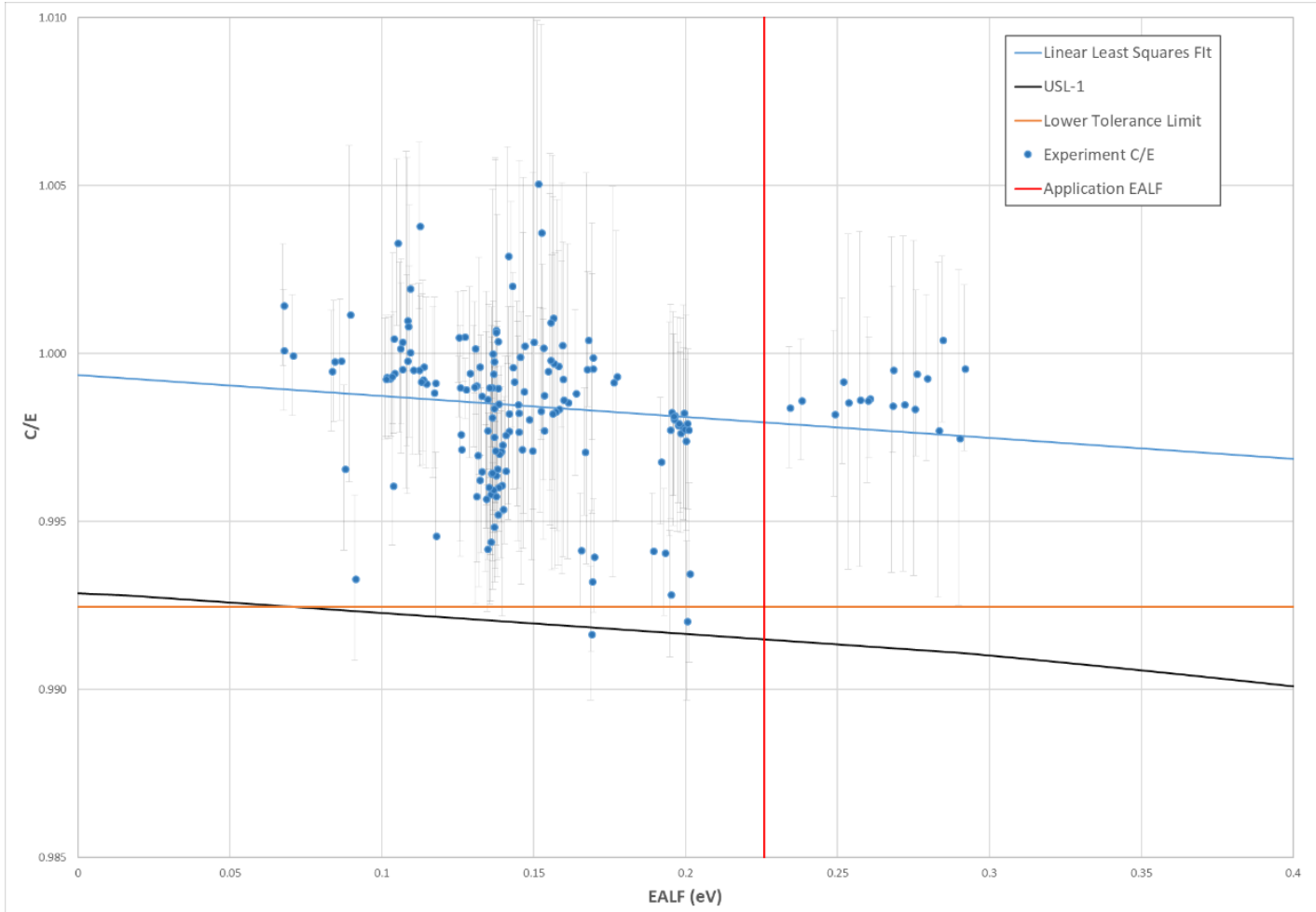

Figure 6-5 C/E vs EALF Trend for Experiments Applicable to the $50 \mathrm{GWd} / \mathrm{MTU}$ AO Case

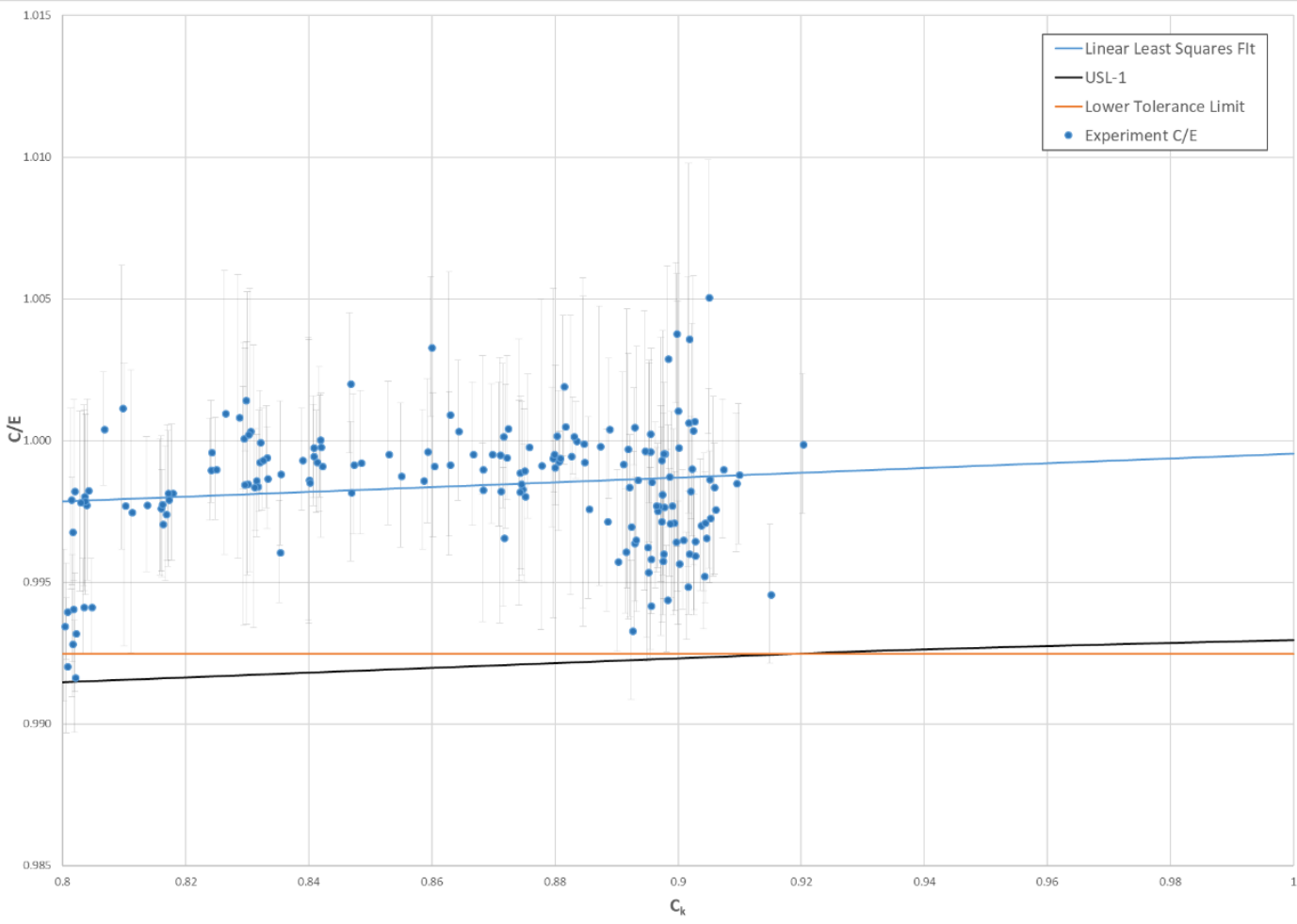

Figure 6-6 C/E vs $C_{k}$ Trend for Experiments Applicable to the $50 \mathrm{GWd} / \mathrm{MTU}$ AO Case 


\subsection{Application 4: $50 \mathrm{GWd} / \mathrm{MTU}$ and AFP Isotope Set}

Using the set of 126 critical experiments (only HTCs), determined to be applicable in Section 5.4, three sets of biases and bias uncertainties were generated. Bias and bias uncertainty were determined for a nontrending analysis, and they were also determined for trends on EALF and $\mathrm{c}_{\mathrm{k}}$. The nontrending bias for the $50 \mathrm{GWd} / \mathrm{MTU}$ case with the AFP isotope set was developed using the inverse variance weighted nontrending method discussed earlier. The untrended bias was found to be -0.00132 , and the associated bias uncertainty was found to be 0.00562 . The untrended calculational margin for the AFP isotope set is -0.00694 .

Trending analyses were performed with EALF and $c_{k}$ serving as the trending variables. The trend evaluations are shown in Figure 6-7 for the EALF case and Figure 6-8 for the $c_{k}$ case. The 50 GWd/MTU AFP model has an EALF of $0.2779 \mathrm{eV}$, which is within the range of EALFs of the applicable benchmarks of $0.06748 \mathrm{eV}$ to $0.29172 \mathrm{eV}$, with the majority of the applicable benchmarks being lower in EALF but still in the vicinity of the application case. Evaluation of the trend at the application EALF yields a best estimate bias of -0.00120 and a bias uncertainty of 0.00680 , which results in a combined calculational margin of 0.00800 . The trend on $c_{k}$ is extrapolated to a value of 1.0 to evaluate the computational margin. The values of the bias and bias uncertainty are -0.00502 and 0.00723 , which result in a calculational margin of -0.01225 . The mean of the critical experiment $c_{k}$ values for this application is 0.850 . The computational margin for the $c_{k}$ trend for this case is reduced compared to the $25 \mathrm{GWd} / \mathrm{MTU}$ AO and AFP cases, but by less than for the AO case. The uncertainty in the bias is about half the $25 \mathrm{GWd} / \mathrm{MTU}$ AO case because the extrapolation distance is significantly less and the number of data points is larger. The best estimate trend line has a negative slope, thus resulting in a large negative bias.

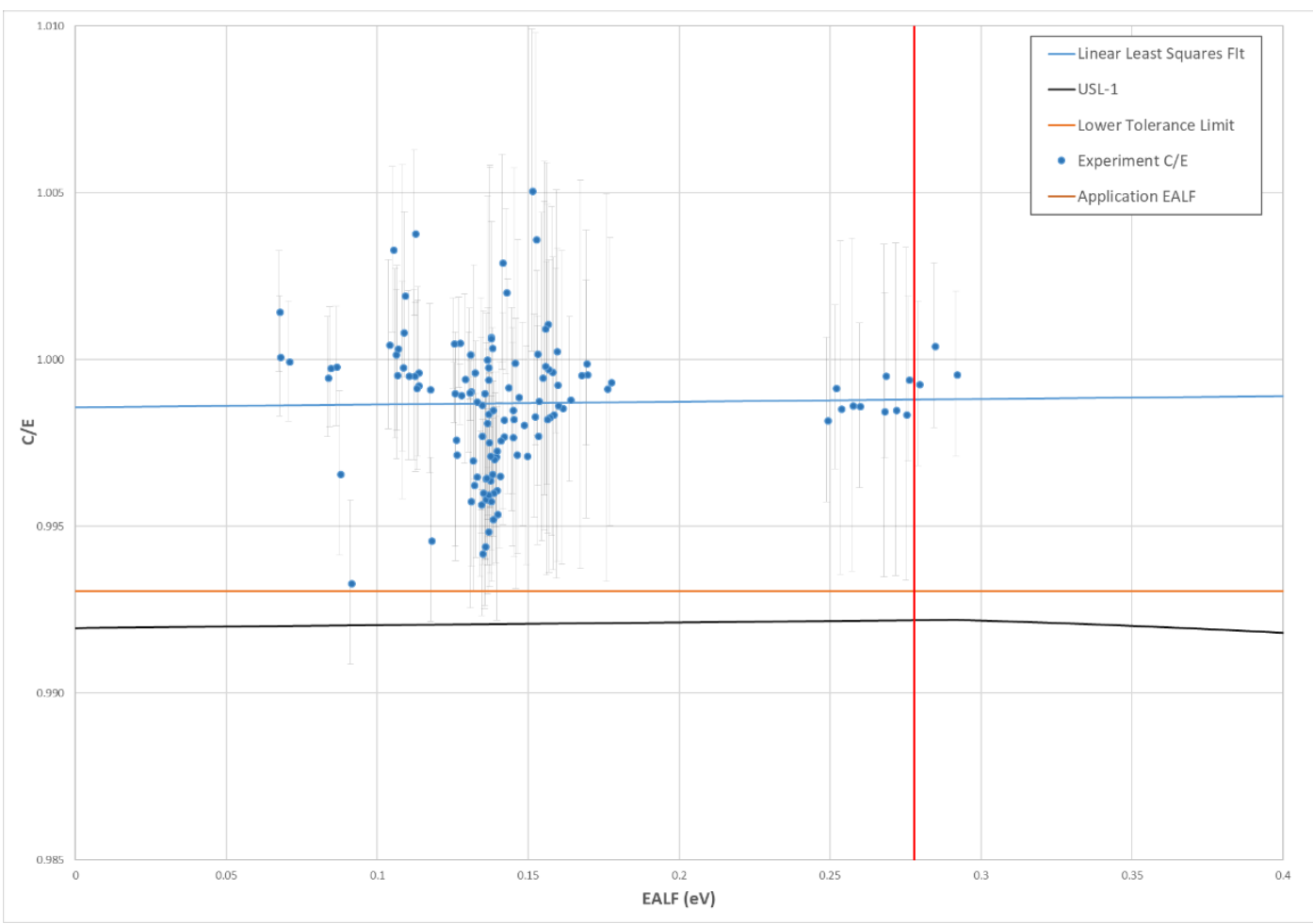

Figure 6-7 C/E vs EALF Trend for Experiments Applicable to the $50 \mathrm{GWd} / \mathrm{MTU}$ AFP Case 


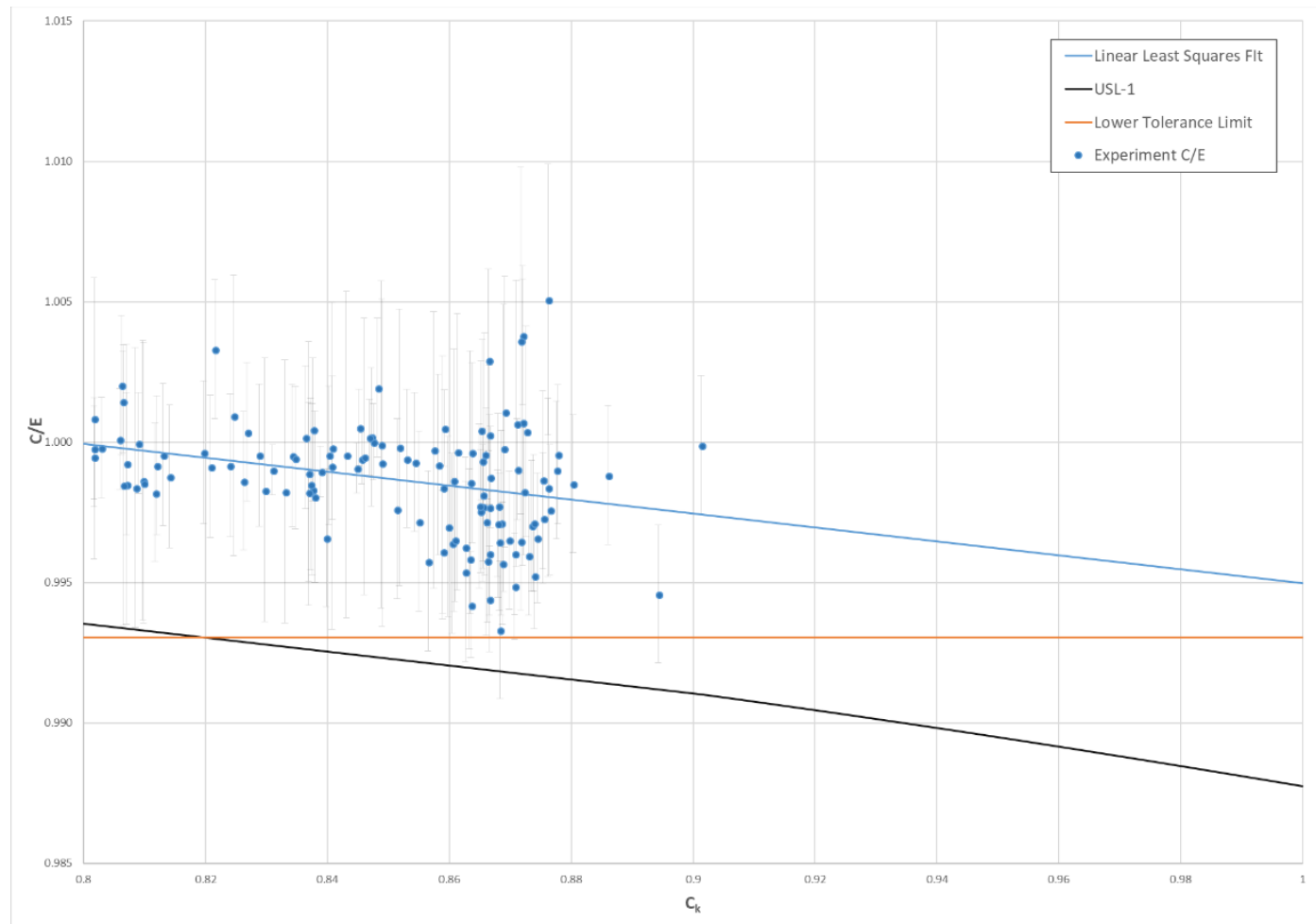

Figure 6-8 C/E vs $C_{k}$ Trend for Experiments Applicable to the $50 \mathrm{GWd} / \mathrm{MTU}$ AFP Case

Table 6-1 Bias and Bias Uncertainty Values for All 4 Applications

\begin{tabular}{|c|c|c|c|c|}
\hline Application & Technique & Bias $(\Delta k)$ & $\begin{array}{c}\text { Bias Uncertainty } \\
(\Delta k)\end{array}$ & $\begin{array}{c}\text { Computational } \\
\text { Margin }(\Delta k)\end{array}$ \\
\hline \multirow{3}{*}{$\begin{array}{c}\text { 1: } 25 \mathrm{GWd} / \mathrm{MTU} \\
\text { and AO Isotope } \\
\text { Set }\end{array}$} & Nontrending & -0.00172 & 0.00530 & -0.00702 \\
\hline & EALF Trend & -0.00182 & 0.00649 & -0.00831 \\
\hline & $c_{k}$ Trend & -0.00674 & 0.00762 & -0.01436 \\
\hline \multirow{3}{*}{$\begin{array}{c}\text { 2: } 25 \text { GWd/MTU } \\
\text { and AFP Isotope } \\
\text { Set }\end{array}$} & Nontrending & -0.00236 & 0.00672 & -0.00908 \\
\hline & EALF Trend & 0.00044 & 0.00724 & -0.00724 \\
\hline & $\mathrm{c}_{\mathrm{k}}$ Trend & -0.00050 & 0.01556 & -0.01606 \\
\hline \multirow{3}{*}{$\begin{array}{c}\text { 3: } 50 \mathrm{GWd} / \mathrm{MTU} \\
\text { and AO Isotope } \\
\text { Set }\end{array}$} & Nontrending & -0.00173 & 0.00581 & -0.00754 \\
\hline & EALF Trend & -0.00206 & 0.00646 & -0.00852 \\
\hline & $c_{k}$ Trend & -0.00047 & 0.00657 & -0.00704 \\
\hline \multirow{3}{*}{$\begin{array}{c}\text { 4: } 50 \mathrm{GWd} / \mathrm{MTU} \\
\text { and AFP Isotope } \\
\text { Set }\end{array}$} & Nontrending & -0.00132 & 0.00562 & -0.00694 \\
\hline & EALF Trend & -0.00120 & 0.00680 & -0.00800 \\
\hline & $c_{k}$ Trend & -0.00502 & 0.00723 & -0.01225 \\
\hline
\end{tabular}





\section{REACTIVITY MARGINS FOR UNVALIDATED ISOTOPES}

As discussed in NUREG/CR-7109 [7] and NUREG/CR-7194 [3], a challenge associated with implementing credit for FPs and MAs $\left({ }^{236} \mathrm{U},{ }^{243} \mathrm{Am}\right.$, and $\left.{ }^{237} \mathrm{~Np}\right)$ in burnup credit analyses is the lack of applicable LCEs that contain these nuclides. Relevant guidance on the validation of criticality safety calculations recommends the inclusion of an appropriate reactivity margin, or penalty, for the presence of any nuclides that cannot be validated explicitly. A method of estimating the bias associated with the FPs is to use the nuclear data-induced uncertainty in $k_{\text {eff }}$ instead of explicit validation of the MAs and FPs. As discussed in Section 2.1.2, TSUNAMI-IP combines the energydependent sensitivity data for each reaction and the covariance data to produce the nuclear datainduced uncertainty in $k_{\text {eff }}$ for each reaction (capture, elastic scatter, etc.) for each isotope. These uncertainties are then combined for all of the nuclides that are not explicitly validated by calculating the root sum square of the uncertainties. Historically, the penalty associated with lack of validation of MAs and FPs has also been expressed as a fraction of the worth of the unvalidated nuclides [7]. Both the absolute and fractional reactivity margins were developed and are provided in this section.

These calculations were performed for two sets of burnup credit models that might be implemented by practitioners. The first set of calculations, consistent with the other sections of the document, used a detailed representation of the fuel, including 25 axial nodes, with 8 fuel compositions for each elevation. A single fuel composition was used for the non-gadolinia rods, and 7 equal volume rings were used for gadolinia-bearing rods. The explicit models contained the total ${ }^{155} \mathrm{Gd}$ concentration resulting from any residual burnable absorber material and from FP gadolinium. This burnable absorber modeling strategy is typical of current peak reactivity methods used in BWR SFP analyses. In anticipation of applications that would use an extended burnup credit approach which would ignore the presence of any gadolinium from residual BA, similar to what is commonly practiced with PWRs, a second model was used. The second model has a single fuel composition for each of the 25 axial elevations, and only includes the concentration of ${ }^{155} \mathrm{Gd}$ produced as a FP while neglecting the presence of any remaining BA gadolinium. The second model is referred to as the non-BA model.

The nuclear data-induced uncertainty for the major actinides, MAs, FPs, and nonfuel materials are presented in Table 7-1 for the detailed model and in Table 7-2 for the non-BA model. The detailed model considered ${ }^{155} \mathrm{Gd}$ separately from the FPs because the majority of the ${ }^{155} \mathrm{Gd}$ absorptions are due to residual BA. The nuclear data uncertainties for the FPs and MAs are slightly larger in the detailed model than in the non-BA model. The presence of residual BA in the upper portion of the fuel assembly forces the flux distribution into lower portions of the assembly that are more heavily burned. The sensitivity of $k_{\text {eff }}$ to the FPs is greater in these regions because of the higher FP concentrations. This higher sensitivity leads to the observed larger $k_{\text {eff }}$ uncertainties. The total uncertainty is also slightly lower in the non-BA application models shown in Table 7-2 because less gadolinium is present and credited in the models.

The combined nuclear data uncertainties for the FPs and MAs are tabulated in Table 7-3 and Table 7-4 for the detailed and non-BA models. Each table contains the absolute reactivity uncertainty and the uncertainty as a fraction of the FP and MA worth. The detailed model exhibits a large reactivity suppression from residual $B A{ }^{155} \mathrm{Gd}$. Critical experiments with gadolinium contain natural gadolinium, and the absorption is dominated by ${ }^{157} \mathrm{Gd}$. Therefore, these experiments do not provide significant validation for ${ }^{155} \mathrm{Gd}$, so a separate reactivity margin is developed for ${ }^{155} \mathrm{Gd}$ in the detailed model and is provided in Table 7-5. 
Table 7-1 Uncertainty in $k_{\text {eff }}(\% \Delta k / k)$ Due to Nuclear Data Uncertainty, Detailed Application Models

\begin{tabular}{|c|c|c|}
\hline Burnup & $25 \mathrm{GWd} / \mathrm{MTU}$ & $50 \mathrm{GWd} / \mathrm{MTU}$ \\
\hline All nuclides & 0.42783 & 0.43205 \\
\hline Major actinides (9) & 0.38650 & 0.38635 \\
\hline${ }^{234} U$ & 0.00321 & 0.00301 \\
\hline${ }^{235} \mathrm{U}$ & 0.26975 & 0.24766 \\
\hline${ }^{238} \mathrm{U}$ & 0.18232 & 0.18365 \\
\hline${ }^{238} \mathrm{Pu}$ & 0.00686 & 0.01200 \\
\hline${ }^{239} \mathrm{Pu}$ & 0.20105 & 0.22160 \\
\hline${ }^{240} \mathrm{Pu}$ & 0.01648 & 0.02006 \\
\hline${ }^{241} \mathrm{Pu}$ & 0.03710 & 0.05044 \\
\hline${ }^{242} \mathrm{Pu}$ & 0.00830 & 0.01261 \\
\hline${ }^{241} \mathrm{Am}$ & 0.03442 & 0.04289 \\
\hline MAs (3) & 0.01936 & 0.02202 \\
\hline${ }^{243} \mathrm{Am}$ & 0.01592 & 0.01709 \\
\hline${ }^{237} \mathrm{~Np}$ & 0.01099 & 0.01382 \\
\hline${ }^{236} \mathrm{U}$ & 0.00068 & 0.00144 \\
\hline FPs (16) & 0.04411 & 0.04978 \\
\hline${ }^{95} \mathrm{Mo}$ & 0.00344 & 0.00383 \\
\hline${ }^{99} \mathrm{Tc}$ & 0.00717 & 0.00835 \\
\hline${ }^{101} \mathrm{Ru}$ & 0.00569 & 0.00658 \\
\hline${ }^{109} \mathrm{Rh}$ & 0.01538 & 0.01673 \\
\hline${ }^{109} \mathrm{Ag}$ & 0.00154 & 0.00197 \\
\hline${ }^{133} \mathrm{Cs}$ & 0.01279 & 0.01427 \\
\hline${ }^{147} \mathrm{Sm}$ & 0.00495 & 0.00531 \\
\hline${ }^{149} \mathrm{Sm}$ & 0.01259 & 0.01326 \\
\hline${ }^{150} \mathrm{Sm}$ & 0.00339 & 0.00418 \\
\hline${ }^{151} \mathrm{Sm}$ & 0.01085 & 0.01169 \\
\hline${ }^{152} \mathrm{Sm}$ & 0.00478 & 0.00520 \\
\hline${ }^{143} \mathrm{Nd}$ & 0.03014 & 0.03471 \\
\hline${ }^{145} \mathrm{Nd}$ & 0.01272 & 0.01433 \\
\hline${ }^{151} \mathrm{Eu}$ & 0.00022 & 0.00023 \\
\hline${ }^{153} \mathrm{Eu}$ & 0.00652 & 0.00822 \\
\hline${ }^{155} \mathrm{Gd}$ & 0.04847 & 0.04708 \\
\hline Nonfuel materials & 0.17024 & 0.17949 \\
\hline
\end{tabular}


Table 7-2 Uncertainty in $k_{\text {eff }}(\% \Delta k / k)$ Due to Nuclear Data Uncertainty, Non-BA Application

\begin{tabular}{|c|c|c|c|c|c|c|c|}
\hline Burnup & $\begin{array}{c}20 \\
\text { GWd/MTU }\end{array}$ & $\begin{array}{c}25 \\
\text { GWd/MTU }\end{array}$ & $\begin{array}{c}30 \\
\text { GWd/MTU }\end{array}$ & $\begin{array}{c}35 \\
\text { GWd/MTU }\end{array}$ & $\begin{array}{c}40 \\
\text { GWd/MTU }\end{array}$ & $\begin{array}{c}45 \\
\text { GWd/MTU }\end{array}$ & $\begin{array}{c}50 \\
\text { GWd/MTU }\end{array}$ \\
\hline $\begin{array}{c}\text { All } \\
\text { nuclides }\end{array}$ & 0.42611 & 0.42480 & 0.42299 & 0.42314 & 0.42394 & 0.42534 & 0.42690 \\
\hline $\begin{array}{c}\text { Major } \\
\text { actinides } \\
(9)\end{array}$ & 0.38872 & 0.38507 & 0.38302 & 0.38198 & 0.38152 & 0.38176 & 0.38212 \\
\hline${ }^{234} U$ & 0.00361 & 0.00349 & 0.00341 & 0.00333 & 0.00327 & 0.00322 & 0.00317 \\
\hline${ }^{235} \mathrm{U}$ & 0.31513 & 0.30345 & 0.29399 & 0.28602 & 0.27913 & 0.27289 & 0.26756 \\
\hline${ }^{238} \mathrm{U}$ & 0.17678 & 0.17744 & 0.17853 & 0.17985 & 0.18100 & 0.18264 & 0.18367 \\
\hline${ }^{238} \mathrm{Pu}$ & 0.00176 & 0.00257 & 0.00350 & 0.00449 & 0.00543 & 0.00647 & 0.00756 \\
\hline${ }^{239} \mathrm{Pu}$ & 0.14107 & 0.15377 & 0.16385 & 0.17226 & 0.17958 & 0.18625 & 0.19205 \\
\hline${ }^{240} \mathrm{Pu}$ & 0.00775 & 0.00918 & 0.01041 & 0.01151 & 0.01248 & 0.01339 & 0.01420 \\
\hline${ }^{241} \mathrm{Pu}$ & 0.01799 & 0.02352 & 0.02862 & 0.03329 & 0.03758 & 0.04175 & 0.04540 \\
\hline${ }^{242} \mathrm{Pu}$ & 0.00262 & 0.00387 & 0.00510 & 0.00629 & 0.00744 & 0.00857 & 0.00961 \\
\hline${ }^{241} \mathrm{Am}$ & 0.01530 & 0.01986 & 0.02397 & 0.02774 & 0.03112 & 0.03434 & 0.03728 \\
\hline MAs (3) & 0.01281 & 0.01412 & 0.01530 & 0.01645 & 0.01738 & 0.01826 & 0.01906 \\
\hline${ }^{243} \mathrm{Am}$ & 0.01140 & 0.01221 & 0.01290 & 0.01361 & 0.01410 & 0.01454 & 0.01493 \\
\hline${ }^{237} \mathrm{~Np}$ & 0.00585 & 0.00709 & 0.00823 & 0.00923 & 0.01013 & 0.01100 & 0.01179 \\
\hline${ }^{236} \mathrm{U}$ & 0.00016 & 0.00028 & 0.00043 & 0.00060 & 0.00078 & 0.00098 & 0.00119 \\
\hline FPs (16) & 0.03412 & 0.03922 & 0.03922 & 0.04137 & 0.04329 & 0.04514 & 0.04684 \\
\hline${ }^{95} \mathrm{Mo}$ & 0.00213 & 0.00263 & 0.00263 & 0.00282 & 0.00298 & 0.00314 & 0.00327 \\
\hline${ }^{99} \mathrm{Tc}$ & 0.00430 & 0.00540 & 0.00540 & 0.00585 & 0.00625 & 0.00662 & 0.00695 \\
\hline${ }^{101} \mathrm{Ru}$ & 0.00329 & 0.00421 & 0.00421 & 0.00458 & 0.00492 & 0.00524 & 0.00551 \\
\hline${ }^{109} \mathrm{Rh}$ & 0.00985 & 0.01193 & 0.01193 & 0.01269 & 0.01333 & 0.01389 & 0.01436 \\
\hline${ }^{109} \mathrm{Ag}$ & 0.00071 & 0.00104 & 0.00104 & 0.00119 & 0.00132 & 0.00145 & 0.00156 \\
\hline${ }^{133} \mathrm{Cs}$ & 0.00787 & 0.00973 & 0.00973 & 0.01046 & 0.01107 & 0.01165 & 0.01212 \\
\hline${ }^{147} \mathrm{Sm}$ & 0.00277 & 0.00341 & 0.00341 & 0.00367 & 0.00389 & 0.00410 & 0.00428 \\
\hline${ }^{149} \mathrm{Sm}$ & 0.02084 & 0.02021 & 0.02021 & 0.01979 & 0.01938 & 0.01894 & 0.01864 \\
\hline${ }^{150} \mathrm{Sm}$ & 0.00196 & 0.00266 & 0.00266 & 0.00292 & 0.00317 & 0.00340 & 0.00362 \\
\hline${ }^{151} \mathrm{Sm}$ & 0.00954 & 0.01061 & 0.01061 & 0.01102 & 0.01136 & 0.01168 & 0.01195 \\
\hline${ }^{152} \mathrm{Sm}$ & 0.00294 & 0.00358 & 0.00358 & 0.00381 & 0.00403 & 0.00418 & 0.00434 \\
\hline${ }^{143} \mathrm{Nd}$ & 0.01824 & 0.02291 & 0.02291 & 0.02479 & 0.02642 & 0.02794 & 0.02926 \\
\hline${ }^{145} \mathrm{Nd}$ & 0.00764 & 0.00952 & 0.00952 & 0.01027 & 0.01091 & 0.01150 & 0.01203 \\
\hline${ }^{151} \mathrm{Eu}$ & 0.00018 & 0.00020 & 0.00020 & 0.00021 & 0.00022 & 0.00022 & 0.00023 \\
\hline${ }^{153} \mathrm{Eu}$ & 0.00302 & 0.00445 & 0.00445 & 0.00509 & 0.00563 & 0.00620 & 0.00669 \\
\hline${ }^{155} \mathrm{Gd}$ & 0.00503 & 0.00769 & 0.00769 & 0.00902 & 0.01025 & 0.01155 & 0.01275 \\
\hline $\begin{array}{l}\text { Nonfuel } \\
\text { materials }\end{array}$ & 0.17069 & 0.17447 & 0.17447 & 0.17651 & 0.17886 & 0.18112 & 0.18350 \\
\hline
\end{tabular}


Table 7-3 Reactivity Margin for Lack of Validation of FPs and MAs for Explicit Criticality Safety Calculations

\begin{tabular}{|lcc|}
\hline Burnup & \multicolumn{2}{c}{ GWd/MTU } \\
\cline { 2 - 3 } & 25 & 50 \\
\hline FP and MA uncertainty $(\Delta \mathrm{k})$ & 0.00048 & 0.00054 \\
FP and MA worth $(\Delta \mathrm{k})$ & 0.03495 & 0.04256 \\
Uncertainty/worth $(\%)$ & $1.37 \%$ & $1.27 \%$ \\
\hline
\end{tabular}

Table 7-4 Reactivity Margin for Lack of Validation of FPs and MAs for Non-BA Criticality Safety Calculations

\begin{tabular}{|l|ccccccc|}
\hline Burnup & \multicolumn{7}{|c|}{ GWd/MTU } \\
\cline { 2 - 8 } & 20 & 25 & 30 & 35 & 40 & 45 & 50 \\
\hline $\begin{array}{l}\text { FP and MA } \\
\text { uncertainty }\end{array}$ & 0.00036 & 0.00042 & 0.00042 & 0.00045 & 0.00047 & 0.00049 & 0.00051 \\
$\begin{array}{l}(\Delta \mathrm{k}) \\
\text { Worth }(\Delta \mathrm{k})\end{array}$ & 0.03903 & 0.04135 & 0.04371 & 0.04567 & 0.04704 & 0.04847 & 0.04953 \\
$\begin{array}{l}\text { Uncertainty/ } \\
\text { worth }(\%)\end{array}$ & $0.92 \%$ & $1.02 \%$ & $0.96 \%$ & $0.99 \%$ & $1.00 \%$ & $1.01 \%$ & $1.03 \%$ \\
\hline
\end{tabular}

Table 7-5 Reactivity Margin for Lack of Validation of Residual BA ${ }^{155} \mathrm{Gd}$ in Explicit Criticality Safety Calculations

\begin{tabular}{|l|cc|}
\hline \multirow{2}{*}{ Burnup } & \multicolumn{2}{|c|}{ GWd/MTU } \\
\cline { 2 - 3 } & 25 & 50 \\
Residual ${ }^{155} \mathrm{Gd}$ uncertainty $(\Delta \mathrm{k})$ & 0.00048 & 0.00047 \\
Residual ${ }^{155} \mathrm{Gd}$ worth $(\Delta \mathrm{k})$ & 0.08282 & 0.07845 \\
Uncertainty/worth $(\%)$ & $0.59 \%$ & $0.60 \%$ \\
\hline
\end{tabular}




\section{SUMMARY AND CONCLUSIONS}

This document provides an assessment of validation of $k_{\text {eff }}$ calculations for BWR BUC analyses. The examination of the validation of peak reactivity cask $k_{\text {eff }}$ calculations, originally assessed in NUREG/CR-7194 [3], is discussed in Section 3. The generation of sensitivity data for the GBC-68 cask at multiple burnups beyond peak reactivity, including multiple isotope sets, is discussed in Section 4. Section 5 identifies potentially applicable experiments for use in validation based on these sensitivity data. Example determinations of bias and bias uncertainty for both burnups and both isotope sets are presented in Section 6. Finally, reactivity allowances to account for unvalidated isotopes are included in Section 7. Summaries of these discussions are presented in Section 8.1, and relevant conclusions are provided in Section 8.2.

\subsection{Assessment Summary}

The validation of $k_{\text {eff }}$ calculations in the peak reactivity method were initially assessed in NUREG/CR-7194 [3] using SCALE 6.1 [25]. As discussed in Section 2.3.3, SCALE 6.2 [10] includes a significant revision to the nuclear covariance data. The impact of this change is reviewed in detail in Section 3. The primary result of the updated covariance data is an increase in the number of LCEs with a $c_{k}$ of 0.8 or higher compared to the peak reactivity GBC-68 model. The bias and bias uncertainty values that result from this larger set of experiments may lead to a slightly larger total computational margin than that observed in NUREG/CR-7194. The reactivity margins for unvalidated isotopes are significantly lower for actinides, are somewhat larger for ${ }^{155} \mathrm{Gd}$, and are unchanged for the remaining FPs. The total margin across all three of these factors is somewhat lower than that recommended in NUREG/CR-7194.

New sensitivity data were generated using TSUNAMI-3D models of the GBC-68 cask containing fuel depleted beyond peak reactivity to allow S/U-based critical experiment selection. The TSUNAMI-3D sequence was used in both MG and CE modes, and both the MG and CE SDFs were confirmed to contain accurate sensitivities by comparison to direct perturbation calculations. The discussion of the generation and comparison of these SDFs is contained in Section 4. The sensitivity data calculated from both techniques were very similar. The SDFs generated using CE TSUNAMI were used for determinations of critical benchmark similarity and reactivity margins for unvalidated isotopes. The SDFs resulting from the MG TSUNAMI calculations for the applications were not used in this report. The existing critical experiment SDFs were all generated with MG TSUNAMI.

A set of four application cases was defined to examine the number of available applicable benchmarks and to perform sample determinations of bias and bias uncertainty. All four cases included SNF in a flooded GBC-68 cask. The fuel was depleted to 25 and $50 \mathrm{GWd} / \mathrm{MTU}$, and the $A O$ and AFP isotope sets were considered for both burnups. The discussion of potentially applicable experiments is contained in Section 5. For the two cases with the AO isotope set, 172 experiments were identified as applicable at a burnup of $25 \mathrm{GWd} / \mathrm{MTU}$, and 173 applicable experiments were identified for the $50 \mathrm{GWd} / \mathrm{MTU}$ case. A combination of LCT and HTC cases are identified as applicable at both burnups; nearly three times as many LCTs appear to be applicable at $25 \mathrm{GWd} / \mathrm{MTU}$ than at $50 \mathrm{GWd} / \mathrm{MTU}$. For the two cases with the AFP isotope set, $68 \mathrm{HTC}$ cases are identified as applicable at $25 \mathrm{GWd} / \mathrm{MTU}$, and $126 \mathrm{HTC}$ cases were determined to be applicable at $50 \mathrm{GWd} / \mathrm{MTU}$. For both isotope sets, more HTC cases are applicable at higher burnup because the fuel used in the HTC experiments is a closer match to higher burnup discharged fuel. 
Bias and bias uncertainties were assessed for each of the four application models using trending and nontrending techniques. The trending techniques considered trends on EALF and on $\mathrm{c}_{\mathrm{k}}$. The nontrending biases and bias uncertainties were consistent, with the biases ranging from -0.00132 to -0.00236 , and the bias uncertainties ranging from 0.00530 to 0.00672 , with the highest values occurring for the $25 \mathrm{GWd} / \mathrm{MTU}$ AFP case. The combined calculational margin ranged from 0.00694 to 0.00908 for the untrended analysis. The applicable experiments also bounded all four of the applications' EALF values, which were tightly clustered between $0.22 \mathrm{eV}$ (AO cases) and $0.28 \mathrm{eV}$ (AFP cases). The results for the trending analysis using EALF as the independent variable also showed consistent results, with biases ranging between 0 (best estimate value of +0.00044 ) and -0.00206 , and the bias uncertainties ranging between 0.00646 and 0.00724 . The total calculational margin for the EALF trending evaluation ranged between 0.00724 and 0.00852 . The trending analysis using $\mathrm{c}_{k}$ as the independent variable produced bias estimates ranging from -0.00047 to -0.00647 , resulting from the variation of the slope of the trend line describing that data and the amount of extrapolation necessary to obtain a $c_{k}$ of 1.0. The bias uncertainty results for the $c_{k}$ trending analysis ranged from 0.00657 to 0.01556 . The bias uncertainty results were influenced by the previously mentioned extrapolation distance and number of applicable experiments. The biases and bias uncertainties found here compare reasonably well with those found for PWR fuel in NUREG/CR-7109 [7], where the bias and bias uncertainty were found to be $\sim-0.00150$ and $\sim 0.01500$ when evaluated with a trend on EALF (Table 7.3 of NUREG/CR-7109 [7]) and the bias varied from $\sim-0.00150$ to $\sim 0.00630$ and the bias uncertainty varied from $\sim 0.00850$ to $\sim 0.01500$ when evaluated with a trend on $c_{k}$ (Table 7.6 of NUREG/CR-7109 [7]).

The identified potentially applicable critical benchmark experiments do not contain FPs or MAs, so a reactivity margin is needed to address the validation gap as discussed in Section 7 . The major actinide isotopes can be validated, so no additional margins are necessary for analyses using the $\mathrm{AO}$ isotope set. A reactivity margin of $1 \%$ of the FP and MA worth is likely appropriate for extended BWR BUC analyses that do not credit any residual Gd burnable absorber. A margin of $1.5 \%$ of the total FP and MA worth is applicable to models which do credit residual ${ }^{155} \mathrm{Gd}$ in $\mathrm{BA}$ rods, along with FP ${ }^{155} \mathrm{Gd}$.

\subsection{Conclusions}

Several conclusions can be drawn regarding the validation of $k_{\text {eff }}$ calculations associated with BWR BUC analyses.

- Sufficient laboratory critical experiments exist to perform adequate validation of $k_{\text {eff }}$ calculations for peak reactivity and extended BWR BUC analyses.

- Changes in covariance data can impact the applicable critical benchmark experiments to be used in validation. New covariance data should be investigated as they become available to establish their impact on benchmark applicability.

- Accurate sensitivity data for BWR storage and transportation systems can be generated in the TSUNAMI-3D sequence using both the MG and CE modes.

- SNF storage and transportation systems containing BWR or PWR fuel in the typical discharge burnup range share a high degree of similarity. Similar experiments are used for validation of BUC analyses for both PWR and BWR fuel, and similar gaps exist for validating FPs and MAs.

- Validation of extended BWR BUC $k_{\text {eff }}$ calculations can be accomplished with LCT and HTC experiments for the AO isotope set and with HTC experiments for the AFP isotope set. 
- The bias and bias uncertainty values generated for extended BWR BUC are similar to those for peak reactivity analysis. Values vary somewhat based on validation technique, but the bias tends to be approximately $\sim 0.2 \% \Delta k_{\text {eff, }}$ and the bias uncertainty is

approximately $\sim 0.6 \% \Delta k_{\text {eff }}$ for traditional methods. Results varied substantially more in $c_{k}$ based trending analysis, with bias and bias uncertainty values being generally higher. The bias values for the $c_{k}$ trends range from -0.00050 to -0.00674 and the uncertainties range from 0.00657 to 0.01556 . The magnitude of the uncertainties is driven primarily by the amount of extrapolation needed to reach a $c_{k}$ value of 1.

- Reactivity margins for unvalidated MAs and FPs can be estimated using S/U techniques. A margin of $1 \%$ of the MA and FP worth is likely appropriate for extended BWR BUC models that do not credit residual ${ }^{155} \mathrm{Gd}$ from the BAs. Note that crediting FP ${ }^{155} \mathrm{Gd}$ is accounted for in the $1 \%$ margin. Crediting residual BA gadolinium increases the necessary margin to $1.5 \%$ of the MA and FP worth. 



\section{REFERENCES}

1. US Code of Federal Regulations Title 10, "Energy," US Nuclear Regulatory Commission, Washington, DC (2018).

2. Division of Spent Fuel Storage and Transportation, Interim Staff Guidance-8, Revision 3, Burnup Credit in the Criticality Safety Analyses of PWR Spent Fuel in Transportation and Storage Casks, US Nuclear Regulatory Commission (2012).

3. W. J. Marshall, B. J. Ade, S. M. Bowman, I. C. Gauld, G. Ilas, U. Mertyurek, and G. Radulescu, Technical Basis for Peak Reactivity Burnup Credit for BWR Spent Nuclear Fuel in Storage and Transportation Systems, NUREG/CR-7194 (ORNL/TM-2014/240), prepared for the US Nuclear Regulatory Commission by Oak Ridge National Laboratory, Oak Ridge, TN (2015).

4. W. J. Marshall, B. J. Ade, S. M. Bowman, and J. S. Martinez-Gonzalez, Axial Moderator Density Distributions, Control Blade Usage, and Axial Burnup Distributions for Extended BWR Burnup Credit, NUREG/CR-7224 (ORNL/TM-2015/544), prepared for the US Nuclear Regulatory Commission by Oak Ridge National Laboratory, Oak Ridge, TN (2016).

5. B. J. Ade, W. J. Marshall, G. llas, B. R. Betzler, and S. M. Bowman, Impact of Operating Parameters on Extended BWR Burnup Credit, NUREG/CR-7240 (ORNL/TM-2017/46), prepared for the US Nuclear Regulatory Commission by Oak Ridge National Laboratory, Oak Ridge, TN (2018).

6. G. Radulescu, I. C. Gauld, G. llas, and J. C. Wagner, An Approach for Validating Actinide and Fission Product Burnup Credit Criticality Safety Analyses-Isotopic Composition Predictions, NUREG/CR-7108 (ORNL/TM-2011/509), prepared for the US Nuclear Regulatory Commission by Oak Ridge National Laboratory, Oak Ridge, TN (2012).

7. J. M. Scaglione, D. E. Mueller, J. C. Wagner, and W. J. Marshall, An Approach for Validating Actinide and Fission Product Burnup Credit Criticality Safety Analyses-Criticality (keff) Predictions, NUREG/CR-7109 (ORNL/TM-2011/514), prepared for the US Nuclear Regulatory Commission by Oak Ridge National Laboratory, Oak Ridge, TN (2012).

8. I. C. Gauld and U. Mertyurek, Margins for Uncertainty in the Predicted Spent Fuel Isotopic Inventories for BWR Burnup Credit, NUREG/CR-7251 (ORNL/TM-2018/782) prepared for the US Nuclear Regulatory Commission by Oak Ridge National Laboratory, Oak Ridge, TN (2018).

9. D. E. Mueller, J. M. Scaglione, J. C. Wagner, and S. M. Bowman, Computational Benchmark for Estimated Reactivity Margin from Fission Products and Minor Actinides in BWR Burnup Credit, NUREG/CR-7157 (ORNL/TM-2012/96), prepared for the US Nuclear Regulatory Commission by Oak Ridge National Laboratory, Oak Ridge, TN (February 2013).

10. B. T. Rearden and M. A. Jessee, Editors, SCALE Code System, ORNL/TM-2005/39, Version 6.2.2, Oak Ridge National Laboratory (2017).

11. B. T. Rearden, M. L. Williams, M. A. Jessee, D. E. Mueller, and D. A. Wiarda, "Sensitivity and Uncertainty Analysis Capabilities and Data in SCALE," Nucl. Technol. 174 (2), pp. 236-288 (2011). 
12. J. C. Dean and R. W. Tayloe, Jr., Guide for Validation of Nuclear Criticality Safety Calculational Methodology, prepared for the US Nuclear Regulatory Commission by Science Applications International Corporation, Oak Ridge, TN (2001).

13. International Handbook of Evaluated Criticality Safety Benchmark Experiments, NEA/NSC/DOC(95)03, NEA Nuclear Science Committee (2016).

14. D. E. Mueller, K. R. Elam, and P. B. Fox, Evaluation of the French Haut Taux de Combustion (HTC) Critical Experiment Data, NUREG/CR-6979 (ORNL/TM-2007/083) prepared for the US Nuclear Regulatory Commission by Oak Ridge National Laboratory, Oak Ridge, TN (2008).

15. Axel Hoefer et al., "Proposal for Benchmark Phase IV Role of Integral Experiment Covariance Data for Criticality Safety," Benchmark Proposal, OECD/NEA (2015).

16. W. J. Marshall, B. T. Rearden, and R. E. Pevey, "Determination of Critical Experiment Correlations for Experiments Involving Arrays of Low-Enriched Fuel Rods," Proceedings of NCSD 2017: Criticality Safety - pushing boundaries by modernizing and integrating data, methods, and regulations, Carlsbad, NM (2017).

17. V. Sobes, B. T. Rearden, D. E. Mueller, W. J. Marshall, J. M. Scaglione, and M. E. Dunn, "Upper Subcritical Limit Calculations Based on Correlated Experimental Data," International Conference on Nuclear Criticality Safety (ICNC 2015), Charlotte, NC (2015).

18. M. B. Chadwick et al., "ENDF/B-VII.1 Nuclear Data for Science and Technology: Cross Sections, Covariances, Fission Product Yields, and Decay Data," Nucl. Data Sheets 112(12), 2887-2996 (2011).

19. W. J. Marshall and B. T. Rearden, The SCALE Verified, Archived Library of Inputs and Data - VALID, ANS Nuclear Criticality Safety Division Topical Meetings (NCSD2013), Wilmington, NC (2013).

20. I. Hill, J. Gulliford, J. B. Briggs, B. T. Rearden, and T. Ivanova, "Generation of 1800 New Sensitivity Data Files for ICSBEP Using SCALE 6.0," Trans. of the American Nuclear Society 109(1), pp. 867-869 (2013).

21. R. Little, T. Kawano, G. D. Hale, M. T. Pigni, M. Herman, P. Oblozinsky, M. L. Williams, M. E. Dunn, G. Arbanas, D. Wiarda, R. D. McKnight, J. N. McKamy, and J. R. Felty, "LowFidelity Covariance Project," Nucl. Data Sheets 109(12), pp. 2828-2833 (2008).

22. M. Salvatores and R. Jacqmin, Uncertainty and Target Accuracy Assessment for Innovative Systems Using Recent Covariance Data Evaluations, NEA/WPEC-26, Nuclear Energy Agency (2008).

23. K. Shibata, O. Iwamoto, T. Nakagawa, N. Iwamoto, A. Ichihara, S. Kunieda, S. Chiba, K. Furutaka, N. Otuka, T. Ohsawa, T. Murata, H. Matsunobu, A. Zukeran, S. Kamada, and J. Katakura: "JENDL-4.0: A New Library for Nuclear Science and Engineering," J. Nucl. Sci. Technol. . 48(1), pp. 1-30 (2011).

24. W. J. Marshall, M. L. Williams, D. Wiarda, B. T. Rearden, M. E. Dunn, D. E. Mueller, J. B. Clarity, and E. L. Jones, "Development and Testing of Neutron Cross Section Covariance Data for SCALE 6.2," Proceedings of International Conference on Nuclear Criticality Safety, Charlotte, NC (2015).

25. SCALE: A Comprehensive Modeling and Simulation Suite for Nuclear Safety Analysis and Design, ORNL/TM-2005/39, Version 6.1, Oak Ridge National Laboratory, (2011). 
26. K. Shibata, T. Kawano, T. Nakagawa, O. Iwamoto, J. Katakura, T. Fukahori, S. Chiba, A. Hasegawa, T. Murata, H. Matsunobu, T. Ohsawa, Y. Nakajima, T. Yoshida, A. Zukeran, M. Kawai, M. Baba, M. Ishikawa, T. Asami, T. Watanabe, Y. Watanabe, M. Igashira, N. Yamamuro, H. Kitazawa, N. Yamano and H. Takano: "Japanese Evaluated Nuclear Data Library Version 3 Revision-3: JENDL-3.3," J. Nucl. Sci. Technol. 39, 1125 (2002).

27. B. L. Broadhead and J. J. Wagschal, "The Fission Spectrum Uncertainty," 95821.pdf in Proc. of PHYSOR 2004-The Physics of Fuel Cycles and Advanced Nuclear Systems: Global Developments, Chicago, IL (2004).

28. Validation of Neutron Transport Methods for Nuclear Criticality Safety Calculations, ANSI/ANS-8.24-2017, American Nuclear Society, La Grange Park, IL (2017).

29. Standard Review Plan for Spent Fuel Dry Storage Systems at a General License Facility, NUREG-1536, Revision 1, US Nuclear Regulatory Commission, Washington, DC (2010).

30. D. A. Brown et al., "ENDF/B-VIII.0: The $8^{\text {th }}$ Major Release of the Nuclear Reaction Data Library with CIELO-project Cross Sections, New Standards and Thermal Scattering Data," Nucl. Data Sheets 148, pp. 1-142 (2018).

31. C. M. Perfetti, B. T. Rearden, and W. R. Martin, "SCALE Continuous-Energy Eigenvalue Sensitivity Coefficient Calculations," Nucl. Sci. Eng., 182, 3, 332-353 (2016).

32. E. L. Jones, User Perspective and Analysis of the Continuous-Energy Sensitivity Methods in SCALE 6.2 using TSUNAMI-3D, M.S. Thesis, University of Tennessee-Knoxville (2015).

33. W. J. Marshall, E. L. Jones, B. T. Rearden, and M. E. Dunn, "A Case Study in the Application of TSUNAMI-3D - Part 1, Multigroup," Trans. Am. Nucl. Soc. 115, 673-676 (2016). 



\section{APPENDIX A ASSESSMENT OF INTEGRAL PARAMETER E}





\section{APPENDIX A ASSESSMENT OF INTEGRAL PARAMETER E}

Historically, $c_{k}$ (see Section 2.1.2) has been the integral parameter used for S/U based validation of computational methods for criticality safety. The calculation of $c_{k}$ is performed by combining the sensitivity profiles of the application of interest with the profiles of each experiment considered in the validation study and weighting both sensitivity profiles with the neutron cross section covariance data. Combining the sensitivity data with the covariance data produces a measure of the correlation of the nuclear data-induced uncertainty in $k_{\text {eff }}$ between each experiment and application. Theoretically, cross sections with the greatest uncertainty are most likely to contribute to the calculational bias of a system, providing a justification for using $c_{k}$ values to select representative experiments (Sections 3.1 and 5) and as the independent variable in trending analysis (Sections 3.2.3 and 6).

Neutron cross section covariance data has become an area of interest only in the past 20 years for the validation of criticality safety computational methods and is therefore maturing much more rapidly than the underlying cross section data. An update to the covariance data was performed as part of the release of SCALE 6.2. A subsequent assessment of the updated covariance data performed by Marshall et al. [24] showed that the values of $c_{k}$ using the new data had changed significantly for PWR and BWR BUC systems compared to values generated with the previous version of the covariance library. This topic is discussed extensively in Section 3 with respect to the validation of peak reactivity BWR BUC.

Another approach that has been discussed is the development of alternative integral indices that use weighting functions that are independent of the covariance data. One of the simplest approaches is to consider the unweighted overlap in the sensitivity profiles. The integral parameter $E$ is calculated by combining the sensitivity for the application with the experiments without including a weighting function. Just as $c_{k}$ represents the fraction of uncertainty in $k_{\text {eff }}$ that is shared between an application and an experiment, E represents the fraction of the sensitivity coefficients that is shared between an application and an experiment. The definition of $E$ is provided in Equation $A-1$, where $S_{a}$ is the nuclide- and energy-dependent sensitivity profile for the applications, and $S_{e}$ is the sensitivity profile for the experiment. Like $c_{k}, E$ is calculated by the TSUNAMI-IP module available in SCALE.

$$
E=\frac{S_{a}^{T} S_{e}}{\left|S_{a}\right|\left|S_{e}\right|}
$$

This appendix begins to examine the potential application of $E$ as a validation parameter. The analysis of the integral parameter $E$ compared to $c_{k}$ is divided in two segments. The first segment examines the general trends in the parameters for each of the four applications used for the extended BUC validation study. The second segment analyzes the individual differences in sensitives and nuclear data-induced uncertainties for the application cases and selected critical experiments.

This appendix documents an initial investigation into the use of $E$ and should not be construed as an endorsement or indictment of the use of $E$ as an experimental selection or trending parameter for validation. $E$ is used along with $c_{k}$ in Section 4.3 to compare different methods of sensitivity profile generation. It is appropriate for this purpose because it is simply being used to show the aggregate equivalence of two methods being used with the same system rather than as a metric of demonstrating the neutronic similarity of two systems. 


\section{A.1 General Trend Analysis}

Similarity of the critical experiments is assessed for each of the four extended BUC cases using the $E$ integral parameter. Figures A-1 through A-4 are plots of $E$ that are directly comparable to the plots in Section 5 which used $c_{k}$ as the parameter of interest:

- Figure A-1 presents the values of E found for the $25 \mathrm{GWd} / \mathrm{MTU}$ AO case and is directly comparable to Figure 5-1.

- Figure A-2 presents the values of $E$ for the $25 \mathrm{GWd} / \mathrm{MTU}$ AFP case is and directly comparable to Figure 5-3.

- Figure A-3 presents the values of E for the $50 \mathrm{GWd} / \mathrm{MTU}$ AO case and is directly comparable to Figure 5-5.

- Figure A-4 presents values of $E$ for the $50 \mathrm{GWd} / \mathrm{MTU}$ case and is directly comparable to Figure 5-7.

A red line corresponding to an $E$ value of 0.8 in each figure provides perspective to the Section 5 plots. While guidance is available on what values of $c_{k}$ should be used as a cutoff of the inclusion in a validation study, such guidance is essentially nonexistent for $E$. Rearden et al. [11] state that "[b]cause of the similarity of $c_{k}$ and $E$, the same limits developed for $c_{k}$ should be applicable to the use of the E parameter."

The average and standard deviation of $E, c_{k}$, and the difference between $E$ and $c_{k}$ are tabulated in Table A-1. The experimental types included in Table A-1 are limited to the LCT, MCT, and HTC types. This data reduction is introduced because the LEU-MISC-THERM and LEU-SOL-THERM experiments behave in a manner similar to that of the LEU-COMP-THERM experiments, and the MIX-SOL-THERM experiments behave in a manner similar to that of the MIX-COMP-THERM.

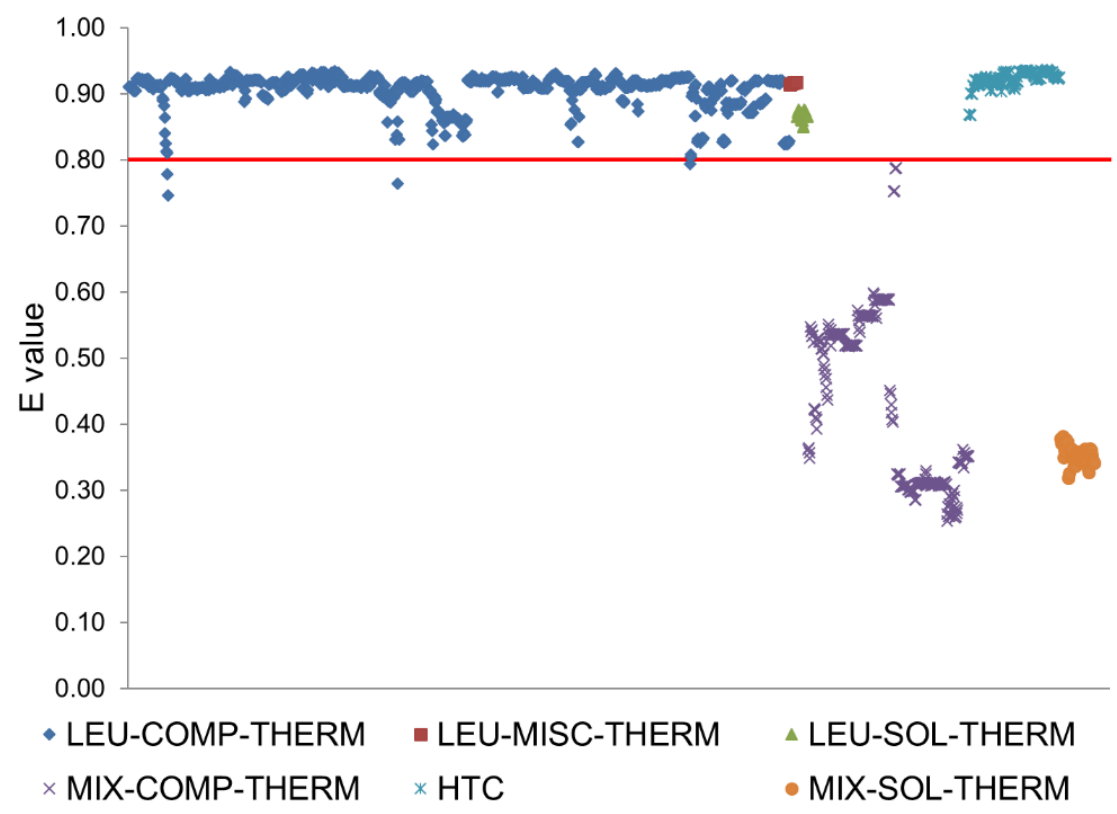

Figure A-1 E Values for Critical Experiments Compared to GBC-68 with Fuel at a Burnup of $25 \mathrm{GWd} / \mathrm{MTU}$ and the AO Isotope Set 


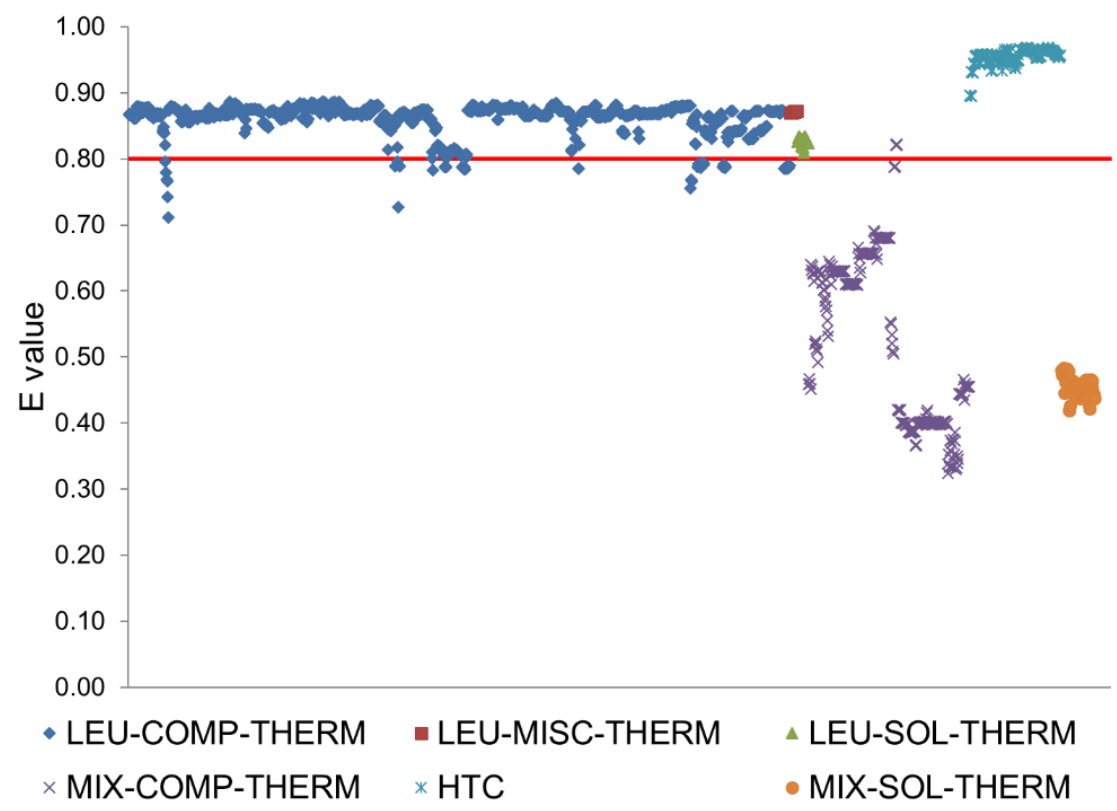

Figure A-2 E Values for Critical Experiments Compared to GBC-68 with Fuel at a Burnup of $25 \mathrm{GWd} / \mathrm{MTU}$ and the AFP Isotope Set

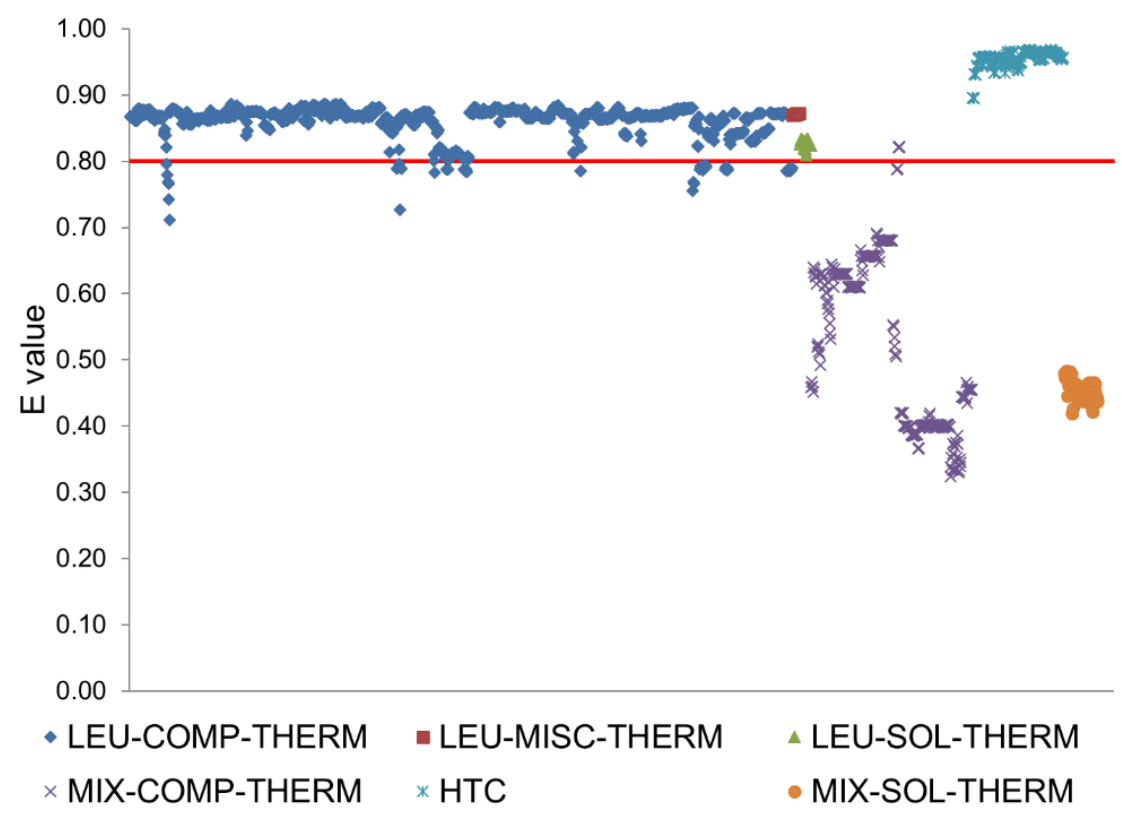

Figure A-3 E Values for Critical Experiments Compared to GBC-68 with Fuel at a Burnup of $50 \mathrm{GWd} / \mathrm{MTU}$ and the AO Isotope Set 


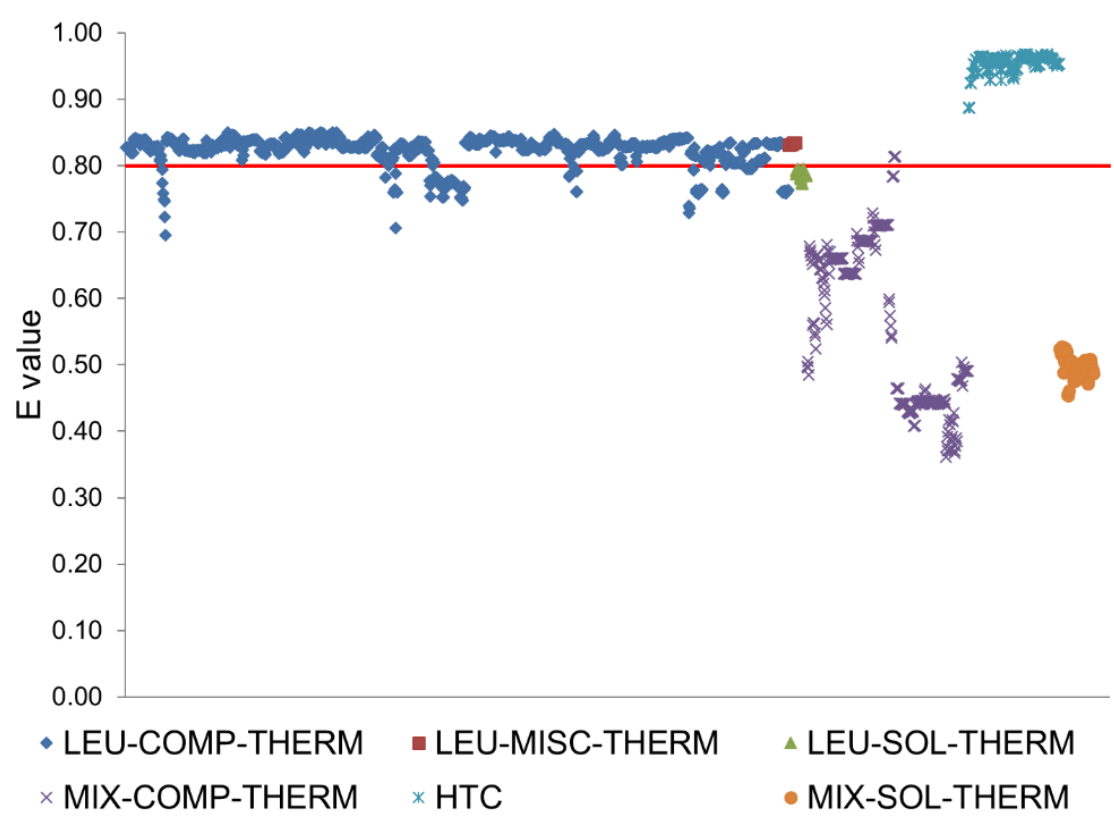

Figure A-4 E Values for Critical Experiments Compared to GBC-68 with Fuel at a Burnup of $50 \mathrm{GWd} / \mathrm{MTU}$ and the AFP Isotope Set

Table A-1 Summary Statistics Associated with Difference Between $E$ and $c_{k}$ for the Four Extended BUC Applications Examined in Sections 5-7

\begin{tabular}{|c|c|c|c|c|c|c|}
\hline \multirow[b]{2}{*}{$\begin{array}{l}\text { Experiment } \\
\text { Set }\end{array}$} & \multicolumn{3}{|c|}{$25 \mathrm{GWd} / \mathrm{MTU}$ AO } & \multicolumn{3}{|c|}{$25 \mathrm{GWd} / \mathrm{MTU}$ AFP } \\
\hline & $\mathrm{E}$ & $c_{k}$ & $\mathrm{E}-\mathrm{C}_{\mathrm{k}}$ & $E$ & $c_{k}$ & $\mathrm{E}-\mathrm{C}_{\mathrm{k}}$ \\
\hline LCT & $0.907 \pm 0.024$ & $0.674 \pm 0.079$ & $0.233 \pm 0.078$ & $0.853 \pm 0.022$ & $0.560 \pm 0.088$ & $0.294 \pm 0.086$ \\
\hline MCT & $0.436 \pm 0.127$ & $0.491 \pm 0.103$ & $-0.055 \pm 0.057$ & $0.514 \pm 0.118$ & $0.526 \pm 0.089$ & $-0.012 \pm 0.065$ \\
\hline HTC & $0.923 \pm 0.011$ & $0.808 \pm 0.037$ & $0.116 \pm 0.033$ & $0.942 \pm 0.013$ & $0.782 \pm 0.038$ & $0.160 \pm 0.035$ \\
\hline \multicolumn{4}{|c|}{$50 \mathrm{GWd} / \mathrm{MTU}$ AO } & \multicolumn{3}{|c|}{$50 \mathrm{GWd} / \mathrm{MTU}$ AFP } \\
\hline LCT & $0.861 \pm 0.024$ & $0.670 \pm 0.065$ & $0.191 \pm 0.063$ & $0.824 \pm 0.022$ & $0.592 \pm 0.070$ & $0.232 \pm 0.069$ \\
\hline MCT & $0.527 \pm 0.126$ & $0.584 \pm 0.110$ & $-0.058 \pm 0.054$ & $0.562 \pm 0.119$ & $0.592 \pm 0.098$ & $-0.030 \pm 0.059$ \\
\hline HTC & $0.955 \pm 0.012$ & $0.869 \pm 0.038$ & $0.086 \pm 0.034$ & $0.954 \pm 0.014$ & $0.837 \pm 0.037$ & $0.117 \pm 0.034$ \\
\hline
\end{tabular}

Figures A-1 through A-4 and Table A-1 show that the values of the integral parameter $E$ vary substantially for each of the four application cases when compared to the values of $c_{k}$. The average values of $E$ for the LCT experiments range between 0.907 and 0.824 for each of four cases of the extended BUC cases, with a consistent standard deviation of approximately 0.024 . This represents an increase of the integral parameter ranging from 0.191 to 0.294 between $c_{k}$ and $\mathrm{E}$. The $\mathrm{E}$ values for the LCT experiments are greater for the $25 \mathrm{GWd} / \mathrm{MTU}$ cases than they are for 
the $50 \mathrm{GWd} / \mathrm{MTU}$ cases, and they are also higher for the AO cases than they are for the AFP cases. The $\mathrm{E}$ values are higher for the $25 \mathrm{GWd} / \mathrm{MTU}$ cases because the fuel composition in the $25 \mathrm{GWd} / \mathrm{MTU}$ cases more closely resembles fresh fuel than the fuel composition in the 50 $\mathrm{GWd} / \mathrm{MTU}$ case. The $\mathrm{E}$ values are higher for the AO cases than the AFP cases because the AFP cases include a number of fission products that do not have any sensitivity profiles associated with them in the LCT critical experiments. Also, there is a substantial amount of ${ }^{155} \mathrm{Gd} \mathrm{BA}$ remaining in the AFP cases. The remaining ${ }^{155} \mathrm{Gd}$ is preferentially located in the upper portion of the fuel assemblies in the fuel with lower burnup, causing the flux distribution to be shifted lower in the fuel assembly to nodes with higher burnup. The fuel assembly thus appears more heavily burned with the AFP isotope set than with the AO set. A plot of the relative fission density as a function of axial elevation is given in Figure A-5. Figure A-5 shows that the middle of the fuel assembly, which has higher relative burnups, is more important for the AFP cases than for the AO cases, with the effect being significantly more pronounced for the $25 \mathrm{GWd} / \mathrm{MTU}$ case than the 50 GWd/MTU case. It is also noted that the standard deviation of the $E$ values is about one quarter of the standard deviation of the $c_{k}$ values for each of the cases considered. It is noted that a similar trend with burnup and isotope set was observed for the $c_{k}$ values.

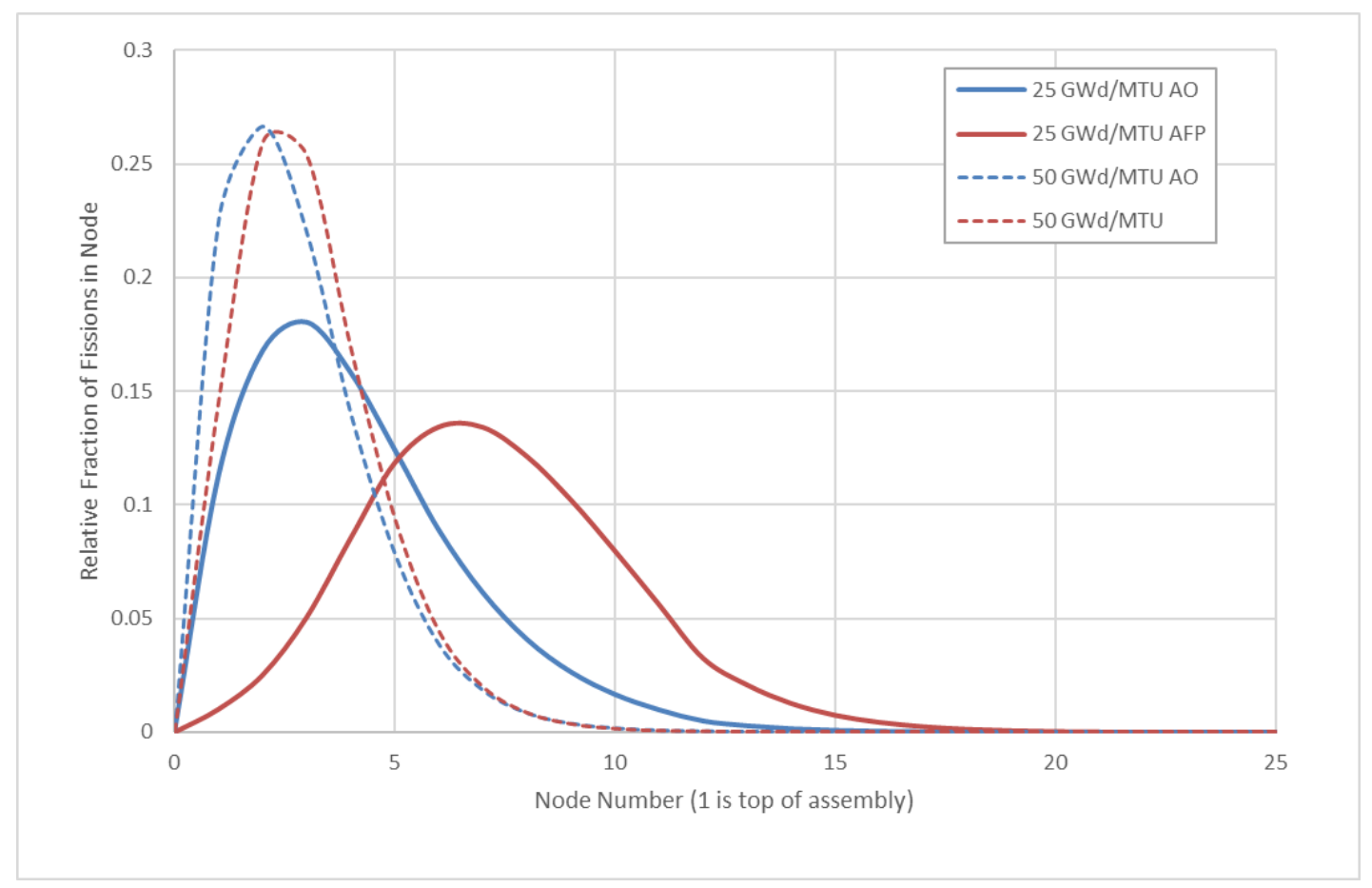

\section{Figure A-5 E Values for Critical Experiments Compared to GBC-68 with Fuel at a Burnup of $50 \mathrm{GWd} / \mathrm{MTU}$ and the AFP Isotope Set}

The MCT experiments were also examined. Figures A-1 through A-4 and Table A-1 show that the MCT cases have the lowest similarity to the application cases, with the values of $E$ ranging from 0.436 for the $25 \mathrm{GWd}$ /MTU AO case to 0.562 for the $50 \mathrm{GWd} / \mathrm{MTU}$ AFP case. The AFP cases show greater similarity to the MCT cases than the AO cases, and the $50 \mathrm{GWd} / \mathrm{MTU}$ cases show a higher similarity to the MCT cases than the $25 \mathrm{GWd} / \mathrm{MTU}$ cases. This is consistent with the increased dependence of the $k_{\text {eff }}$ of the system on the plutonium cross sections with increased burnup of the assembly. The $E$ and $c_{k}$ values for each of the cases are relatively close, with the difference ranging from -0.012 to -0.058 . Of the three types of experiments considered in this work, the MCT experiments are the only ones for which the value of $E$ is consistently below the 
value of $c_{k}$, indicating that removal of the covariance weighting results in lower assessed similarity. The low similarity in terms of both integral indices is not surprising given the nearly complete lack of ${ }^{235} \mathrm{U}$ in the MCT cases and the modest burnup of the upper nodes of the fuel assembly in the cask models.

The HTC cases were also examined. Figures A-1 through A-4 and Table A-1 show that the HTC cases have average values of $E$ ranging 0.923 to 0.955 . The values of $E$ are generally high, and they increase from the $25 \mathrm{GWd} / \mathrm{MTU}$ cases to the $50 \mathrm{GWd} / \mathrm{MTU}$ cases, as would be expected given that the HTCs are intended to mimic the actinide composition of $4.5 \mathrm{wt} \%$ enriched fuel, with a burnup of $37.5 \mathrm{GWd} / \mathrm{MTU}$. The axial fission density weighted burnups of the cases correspond to $16.9 \mathrm{GWd} / \mathrm{MTU}$ and $23.3 \mathrm{GWd} / \mathrm{MTU}$ for the $25 \mathrm{GWd} / \mathrm{MTU} \mathrm{AO}$ and AFP cases, and 26.4 and 28.6 for the $50 \mathrm{GWd} / \mathrm{MTU}$ AO and AFP cases. The values of $E$ are higher for the AFP isotope set than for the AO isotope set for the $25 \mathrm{GWd} / \mathrm{MTU}$, but they were essentially the same for the 50 $\mathrm{GWd} / \mathrm{MTU}$ cases. $E$ was higher than $c_{k}$ for both of the isotope sets at both burnups. It is also noted that the standard deviation of the values of $E$ is about one third of the standard deviation of the $c_{k}$ values.

\section{A.2 Detailed Analysis of Selected Experiments}

It is clear that there are substantial changes in the values of $E$ and $c_{k}$ based on the general trends of those parameters with respect to the four extended BUC cases investigated. To gain better insight into what is causing the differences between $E$ and $c_{k}$, a more detailed examination must be made of one experiment for each of the LCT, MCT, and HTC sets. As discussed earlier, $\mathrm{c}_{\mathrm{k}}$ is a measure of the amount of nuclear data-induced uncertainty that is shared between the application and experiment. The shared uncertainty is calculated by weighting the shared sensitivity of the application and experiment by the covariance data. The $\mathrm{E}$ parameter is the unweighted shared sensitivity between the two experiments. To identify areas where $E$ and $c_{k}$ differ, a comparison of the sensitivities and nuclear data induced uncertainties was performed.

The test cases identified to examine the differences between $c_{k}$ and $E$ were LCT-002-004, MCT-001-004, and HTC-2B-009. The E and $c_{k}$ values for the selected experiments are provided in Table A-2 for comparison. Among all of the experiments considered, LCT-002-004 has a largerthan-average change between $c_{k}$ and $E$ when compared to other LCT experiments, MCT-001-004 has a representative change between $C_{k}$ and $E$ when compared to other MCT experiments and HTC-2B-009 has a smaller-than-average change when compared to other experiments. 
Table A-2 Comparison of $E$ and $c_{k}$ Values for the Experiments Selected for Detailed Analysis

\begin{tabular}{|cc|c|cc|c|} 
Experiment & Parameter & $\begin{array}{c}25 \mathrm{GWd} / \mathrm{MTU} \\
\mathrm{AO}\end{array}$ & $\begin{array}{c}25 \mathrm{GWd} / \mathrm{MTU} \\
\mathrm{AFP}\end{array}$ & $\begin{array}{c}50 \mathrm{GWd} / \mathrm{MTU} \\
\mathrm{AO}\end{array}$ & $\begin{array}{c}50 \mathrm{GWd} / \mathrm{MTU} \\
\mathrm{AFP}\end{array}$ \\
\hline \multirow{2}{*}{ LCT-002-004 } & $\mathrm{C}_{\mathrm{k}}$ & 0.59620 & 0.47090 & 0.60790 & 0.52010 \\
& $\mathrm{E}$ & 0.90570 & 0.84870 & 0.86200 & 0.82010 \\
MCT-001-004 & $\mathrm{C}_{\mathrm{k}}$ & 0.43340 & 0.47820 & 0.52970 & 0.54370 \\
& $\mathrm{E}$ & 0.34870 & 0.42790 & 0.45120 & 0.48510 \\
HTC-2B-009 & $\mathrm{C}_{k}$ & 0.86620 & 0.85910 & 0.92020 & 0.90130 \\
& $\mathrm{E}$ & 0.92140 & 0.94530 & 0.95320 & 0.95660 \\
\hline
\end{tabular}

Tables A-3 and A-4 show the total sensitivities and nuclear data-induced uncertainties, respectively, for the nuclides important to BWR BUC applications, including ${ }^{235} \mathrm{U},{ }^{238} \mathrm{U},{ }^{239} \mathrm{Pu},{ }^{1} \mathrm{H}$, ${ }^{10} \mathrm{~B}$, and ${ }^{155} \mathrm{Gd}$. Analysis of the similarities and differences between an application and the experiments should improve understanding of the practical differences between $E$ and $c_{k}$.

Table A-3 Comparison of Total Sensitivities for Major BUC Nuclides for the Applications and Selected Experiments

\begin{tabular}{|c|c|c|c|c|c|c|c|}
\hline Nuclide & $\begin{array}{c}25 \\
\text { GWd/MTU } \\
\text { AO }\end{array}$ & $\begin{array}{c}25 \\
\text { GWd/MTU } \\
\text { AFP }\end{array}$ & $\begin{array}{c}50 \\
\text { GWd/MTU } \\
\text { AO }\end{array}$ & $\begin{array}{c}50 \\
\text { GWd/MTU } \\
\text { AFP }\end{array}$ & $\begin{array}{l}\text { LCT-002- } \\
004\end{array}$ & $\begin{array}{c}\text { HTC- } \\
\text { 2B-009 }\end{array}$ & $\begin{array}{c}\text { MCT- } \\
001-004\end{array}$ \\
\hline $235 U$ & 0.1884 & 0.2077 & 0.1793 & 0.2054 & 0.2038 & 0.1630 & 0.0025 \\
\hline${ }^{238} U$ & -0.0818 & -0.0758 & -0.0795 & -0.0684 & -0.0588 & -0.0971 & -0.0052 \\
\hline${ }^{239} \mathrm{Pu}$ & 0.0643 & 0.0991 & 0.0901 & 0.1174 & - & 0.1238 & 0.1221 \\
\hline${ }^{1} \mathrm{H}$ & 0.1938 & 0.1933 & 0.2150 & 0.2225 & 0.1715 & 0.1224 & 0.1930 \\
\hline${ }^{10} \mathrm{~B}$ & -0.0507 & -0.0509 & -0.0501 & -0.0502 & - & -0.1190 & - \\
\hline${ }^{155} \mathrm{Gd}$ & - & -0.0144 & - & -0.0142 & - & - & - \\
\hline
\end{tabular}


Table A-4 Comparison of Total Uncertainties for Major BUC Nuclides for the Applications and Selected Experiments

\begin{tabular}{|lcccccccc} 
Nuclide & $\begin{array}{c}25 \\
\text { GWd/MTU } \\
\text { AO }\end{array}$ & $\begin{array}{c}25 \\
\text { GWd/MTU } \\
\text { AFP }\end{array}$ & $\begin{array}{c}50 \\
\text { GWd/MTU } \\
\text { AO }\end{array}$ & $\begin{array}{c}50 \\
\text { GWd/MTU } \\
\text { AO }\end{array}$ & $\begin{array}{c}\text { LCT- } \\
002-004\end{array}$ & $\begin{array}{c}\text { HTC- } \\
2 B-009\end{array}$ & $\begin{array}{c}\text { MCT- } \\
001-004\end{array}$ \\
\hline${ }^{235} \mathrm{U}$ & 0.3010 & 0.2698 & 0.2644 & 0.2477 & 0.6089 & 0.2202 & 0.0142 \\
${ }^{238} \mathrm{U}$ & 0.1830 & 0.1823 & 0.1923 & 0.1837 & 0.3113 & 0.2400 & 0.0858 \\
${ }^{239} \mathrm{Pu}$ & 0.1596 & 0.2011 & 0.2003 & 0.2216 & - & 0.2627 & 0.6610 \\
${ }^{1} \mathrm{H}$ & 0.1066 & 0.0987 & 0.1175 & 0.1081 & 0.2583 & 0.1257 & 0.2635 \\
${ }^{10} \mathrm{~B}$ & 0.0087 & 0.0089 & 0.0085 & 0.0086 & - & 0.0099 & - \\
${ }^{155} \mathrm{Gd}$ & - & 0.0485 & - & 0.0471 & - & - & - \\
\hline
\end{tabular}

The ${ }^{235} \mathrm{U}$ total sensitivities range between 0.1793 and 0.2077 for each of the application cases, and the nuclear data induced uncertainty ranges between 0.2477 and 0.3010 . Both the total sensitivity and uncertainty for ${ }^{235} \mathrm{U}$ are within relatively narrow bands, though the sensitivity and uncertainty do not increase and decrease together. The values of ${ }^{235} \mathrm{U}$ sensitivity appear to be similar among the application cases and are also similar between the LCT experiment $(0.2038)$ and the HTC experiment $(0.1630)$. This is also true of the nuclear data-induced uncertainty in the $\mathrm{HTC}$ experiment, with its value falling slightly below the range of the application cases. The smaller sensitivities and uncertainties for the HTC case are logical, given that the applications behave as though they are less burned than the HTC experiment and therefore have higher contributions from ${ }^{235} \mathrm{U}$ than shown in the experiment. Despite having a similar ${ }^{235} \mathrm{U}$ sensitivity to the applications, the LCT experiment has a nuclear data-induced uncertainty of 0.6089 , which is more than twice the application cases. A more detailed inspection of the LCT experiment uncertainty output revealed that there is a much larger sensitivity of the LCT experiment to the energy dependence of the neutrons emerging from fission $(X)$, which has a high degree of uncertainty compared to other reactions. The contribution to data-induced uncertainty from $X$ for the application cases is virtually zero. Discussions with M. L. Williams indicated that large uncertainties are associated with geometrically small systems in which leakage plays an important role. Examining the underlying sensitivity revealed that the sensitivity is 500 times greater in the LCT experiment than in the applications. The LCT experiment is a reasonably small geometry relative to the application case. It is noted that this conclusion is in conflict with the results from the HTC case, which is a similar size system to the LCT case but does not have a large $x$ uncertainty. This topic needs further investigation to be fully understood. The MCT case contains very little ${ }^{235} \mathrm{U}$ and therefore does not have a substantial sensitivity or nuclear data-induced uncertainty associated with ${ }^{235} \mathrm{U}$.

The ${ }^{238} \mathrm{U}$ total sensitivities range from -0.0684 to -0.0818 , and the nuclear data-induced uncertainties range from 0.1823 to 0.1923 for all the application cases. For the HTC experiment, both the sensitivity and nuclear data-induced uncertainty are larger than in any of the application cases. The LCT experiment has a smaller total sensitivity to ${ }^{238} \mathrm{U}$ than any of the application cases, but the nuclear data-induced uncertainty is nearly twice that of any of the application cases. The ${ }^{238} \mathrm{U}$ uncertainty is driven by a large contribution from inelastic scattering for the LCT experiment. This contribution to the uncertainty is much smaller for the application cases, which derive most of their sensitivity and uncertainty from radiative capture. The MCT experiment has 
relatively little uranium present, so it does not have a substantial sensitivity to the ${ }^{238} \mathrm{U}$ cross sections; the uncertainty contributed is approximately half that of the application cases. The disproportionately high contribution of uncertainty is present because inelastic scattering is the primary contributor among the ${ }^{238} \mathrm{U}$ reactions for the MCT experiment.

The ${ }^{239} \mathrm{Pu}$ total cross section sensitivities range from 0.0643 to 0.1174 , and the nuclear datainduced uncertainties ranged from 0.1596 to 0.2216 for each of the applications cases. The LCT experiment considered has no Pu present, and therefore it has no sensitivity or nuclear datainduced uncertainty due to the Pu cross sections. The HTC experiment considered has a slightly higher sensitivity and nuclear data-induced uncertainty than any of the application cases. This is because the HTC cases are designed to have the actinide composition of fuel that is slightly more burned than the fission density weighted burnup of the applications used in the analysis.

Furthermore, the nuclear data-induced uncertainty increase for the HTC cases compared to the applications is approximately proportional to the increased sensitivity. The total sensitivity to ${ }^{239} \mathrm{Pu}$ is approximately the same for the MCT case as it is for the HTC case, which is slightly elevated compared to the application cases. However, the nuclear data-induced uncertainty for the MCT case is more than three times that of any of the applications. The contributions to nuclear data uncertainty for fission and radiative capture are about three times higher for the MCT case than for the application cases, and an additional contribution to uncertainty from $X$ is also present, which is not in the application cases. Therefore, it appears that the sensitivity of the MCT cases is small since it is a sum of large negative and positive contributions which both increase the nuclear data induced uncertainty but cancel in the sum of sensitivities.

The sensitivities to ${ }^{1} \mathrm{H}$ range between 0.1933 and 0.2225 , and the nuclear data-induced uncertainties range between 0.0987 and 0.1175 for each of the application cases. The ${ }^{1} \mathrm{H}$ total sensitivities are in good agreement with the experimental cases. The nuclear data uncertainty due to ${ }^{1} \mathrm{H}$ for the LCT and MCT cases is about twice the value for the applications. Differences in nuclear data-induced uncertainty are due to how they influence the other reactions in the problem. A plot of the energy-dependent ${ }^{1} \mathrm{H}$ total sensitivity is provided in Figure A-6, which shows the $50 \mathrm{GWd} / \mathrm{MTU}$ application case and HTC experiment have relatively flat sensitivity profiles when compared to the MCT and LCT experiments. The LCT and MCT experiments have strong positive sensitivities in the fast region and strong negative sensitivities in the thermal region, while the HTC and application have lesser contributions in both regions. The large sensitivities in the MCT and LCT fast region are likely the cause of the increased uncertainty due to the large cross section uncertainties in that energy range.

In the AFP cases, the absorbers in the application case included ${ }^{10} \mathrm{~B}$ in the absorber panels and ${ }^{155} \mathrm{Gd}$ in the fuel. Despite the moderate sensitivity of the boron in the absorber plates, there is very little contribution to total uncertainty due to the low small cross section uncertainty. The ${ }^{155} \mathrm{Gd}$ contribution to the nuclear data-induced uncertainty is modest considering that it has a relatively small sensitivity. 


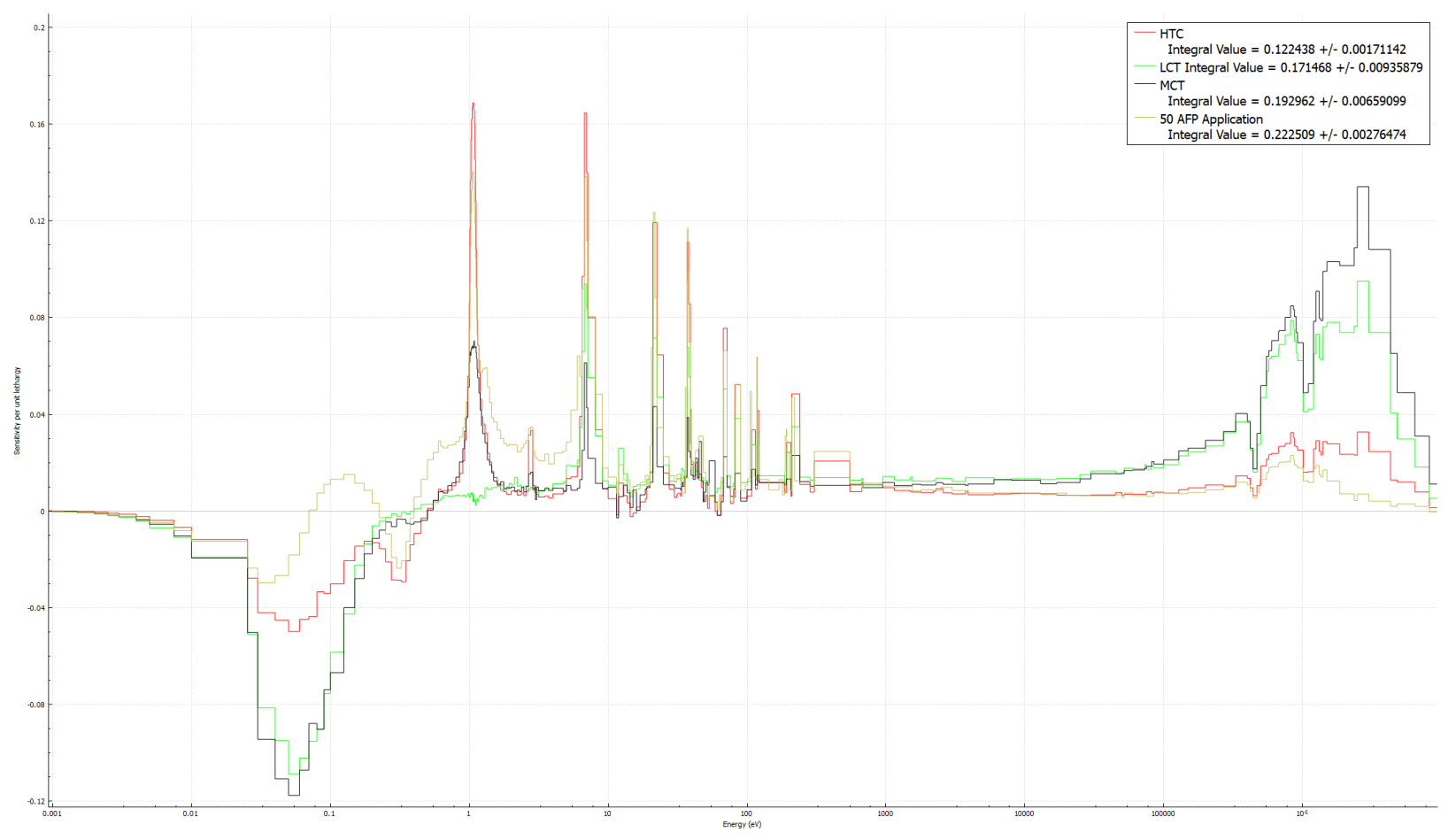

Figure A-6 Comparison of Energy Dependent ${ }^{1} \mathrm{H}$ Sensitivities for the $50 \mathrm{GWd} / \mathrm{MTU}$ AFP Case and the LCT, HTC, and MTC Experiments 


\section{APPENDIX B LIST OF CRITICAL BENCHMARK EXPERIMENTS CONSIDERED}





\section{APPENDIX B LIST OF CRITICAL BENCHMARK EXPERIMENTS CONSIDERED}

Table B-1 of this appendix contains the full list of critical benchmark experiments considered as candidates for use in criticality code validation. This list was compiled from the three sources discussed in Section 2.3.2 and contains data from 1,643 unique critical experiments.

Table B-1 Critical Benchmark Experiments Considered

\begin{tabular}{|c|c|c|}
\hline LEU-COMP-THERM-001-001 & LEU-COMP-THERM-033-025 & LEU-COMP-THERM-090-007 \\
\hline LEU-COMP-THERM-001-002 & LEU-COMP-THERM-033-026 & LEU-COMP-THERM-090-008 \\
\hline LEU-COMP-THERM-001-003 & LEU-COMP-THERM-033-027 & LEU-COMP-THERM-090-009 \\
\hline LEU-COMP-THERM-001-004 & LEU-COMP-THERM-033-028 & LEU-COMP-THERM-091-001 \\
\hline LEU-COMP-THERM-001-005 & LEU-COMP-THERM-033-029 & LEU-COMP-THERM-091-002 \\
\hline LEU-COMP-THERM-001-006 & LEU-COMP-THERM-033-030 & LEU-COMP-THERM-091-003 \\
\hline LEU-COMP-THERM-001-007 & LEU-COMP-THERM-033-031 & LEU-COMP-THERM-091-004 \\
\hline LEU-COMP-THERM-001-008 & LEU-COMP-THERM-033-032 & LEU-COMP-THERM-091-005 \\
\hline LEU-COMP-THERM-002-001 & LEU-COMP-THERM-033-033 & LEU-COMP-THERM-091-006 \\
\hline LEU-COMP-THERM-002-002 & LEU-COMP-THERM-033-034 & LEU-COMP-THERM-091-007 \\
\hline LEU-COMP-THERM-002-003 & LEU-COMP-THERM-033-035 & LEU-COMP-THERM-091-008 \\
\hline LEU-COMP-THERM-002-004 & LEU-COMP-THERM-033-036 & LEU-COMP-THERM-091-009 \\
\hline LEU-COMP-THERM-002-005 & LEU-COMP-THERM-033-037 & LEU-COMP-THERM-092-001 \\
\hline LEU-COMP-THERM-003-001 & LEU-COMP-THERM-033-038 & LEU-COMP-THERM-092-002 \\
\hline LEU-COMP-THERM-003-002 & LEU-COMP-THERM-033-039 & LEU-COMP-THERM-092-003 \\
\hline LEU-COMP-THERM-003-003 & LEU-COMP-THERM-033-040 & LEU-COMP-THERM-092-004 \\
\hline LEU-COMP-THERM-003-004 & LEU-COMP-THERM-033-041 & LEU-COMP-THERM-092-005 \\
\hline LEU-COMP-THERM-003-005 & LEU-COMP-THERM-033-042 & LEU-COMP-THERM-092-006 \\
\hline LEU-COMP-THERM-003-006 & LEU-COMP-THERM-033-043 & LEU-COMP-THERM-094-001 \\
\hline LEU-COMP-THERM-003-007 & LEU-COMP-THERM-033-044 & LEU-COMP-THERM-094-002 \\
\hline LEU-COMP-THERM-003-008 & LEU-COMP-THERM-033-045 & LEU-COMP-THERM-094-003 \\
\hline LEU-COMP-THERM-003-009 & LEU-COMP-THERM-033-046 & LEU-COMP-THERM-094-004 \\
\hline LEU-COMP-THERM-003-010 & LEU-COMP-THERM-033-047 & LEU-COMP-THERM-094-005 \\
\hline LEU-COMP-THERM-003-011 & LEU-COMP-THERM-033-048 & LEU-COMP-THERM-094-006 \\
\hline LEU-COMP-THERM-003-012 & LEU-COMP-THERM-033-049 & LEU-COMP-THERM-094-007 \\
\hline LEU-COMP-THERM-003-013 & LEU-COMP-THERM-033-050 & LEU-COMP-THERM-094-008 \\
\hline LEU-COMP-THERM-003-014 & LEU-COMP-THERM-033-051 & LEU-COMP-THERM-094-009 \\
\hline LEU-COMP-THERM-003-015 & LEU-COMP-THERM-033-052 & LEU-COMP-THERM-094-010 \\
\hline LEU-COMP-THERM-003-016 & LEU-COMP-THERM-034-001 & LEU-COMP-THERM-094-011 \\
\hline LEU-COMP-THERM-003-017 & LEU-COMP-THERM-034-002 & LEU-MISC-THERM-005-001 \\
\hline LEU-COMP-THERM-003-018 & LEU-COMP-THERM-034-003 & LEU-MISC-THERM-005-002 \\
\hline LEU-COMP-THERM-003-019 & LEU-COMP-THERM-034-004 & LEU-MISC-THERM-005-003 \\
\hline LEU-COMP-THERM-003-020 & LEU-COMP-THERM-034-005 & LEU-MISC-THERM-005-004 \\
\hline LEU-COMP-THERM-003-021 & LEU-COMP-THERM-034-006 & LEU-MISC-THERM-005-005 \\
\hline LEU-COMP-THERM-003-022 & LEU-COMP-THERM-034-007 & LEU-MISC-THERM-005-006 \\
\hline LEU-COMP-THERM-004-001 & LEU-COMP-THERM-034-008 & LEU-MISC-THERM-005-007 \\
\hline LEU-COMP-THERM-004-002 & LEU-COMP-THERM-034-009 & LEU-MISC-THERM-005-008 \\
\hline LEU-COMP-THERM-004-003 & LEU-COMP-THERM-034-010 & LEU-MISC-THERM-005-009 \\
\hline LEU-COMP-THERM-004-004 & LEU-COMP-THERM-034-011 & LEU-MISC-THERM-005-010 \\
\hline LEU-COMP-THERM-004-005 & LEU-COMP-THERM-034-012 & LEU-MISC-THERM-005-011 \\
\hline LEU-COMP-THERM-004-006 & LEU-COMP-THERM-034-013 & LEU-MISC-THERM-005-012 \\
\hline LEU-COMP-THERM-004-007 & LEU-COMP-THERM-034-014 & LEU-SOL-THERM-002-001 \\
\hline LEU-COMP-THERM-004-008 & LEU-COMP-THERM-034-015 & LEU-SOL-THERM-002-002 \\
\hline
\end{tabular}


List of critical benchmark experiments considered

LEU-COMP-THERM-004-009 LEU-COMP-THERM-034-016

LEU-COMP-THERM-004-010

LEU-COMP-THERM-004-011

LEU-COMP-THERM-004-012

LEU-COMP-THERM-004-013

LEU-COMP-THERM-004-014

LEU-COMP-THERM-004-015

LEU-COMP-THERM-004-016

LEU-COMP-THERM-004-017

LEU-COMP-THERM-004-018

LEU-COMP-THERM-004-019

LEU-COMP-THERM-004-020

LEU-COMP-THERM-005-001

LEU-COMP-THERM-005-002

LEU-COMP-THERM-005-003

LEU-COMP-THERM-005-004

LEU-COMP-THERM-005-005

LEU-COMP-THERM-005-006

LEU-COMP-THERM-005-007

LEU-COMP-THERM-005-008

LEU-COMP-THERM-005-009

LEU-COMP-THERM-005-010

LEU-COMP-THERM-005-011

LEU-COMP-THERM-005-012

LEU-COMP-THERM-005-013

LEU-COMP-THERM-005-014

LEU-COMP-THERM-005-015

LEU-COMP-THERM-005-016

LEU-COMP-THERM-006-001

LEU-COMP-THERM-006-002

LEU-COMP-THERM-006-003

LEU-COMP-THERM-006-004

LEU-COMP-THERM-006-005

LEU-COMP-THERM-006-006

LEU-COMP-THERM-006-007

LEU-COMP-THERM-006-008

LEU-COMP-THERM-006-009

LEU-COMP-THERM-006-010

LEU-COMP-THERM-006-011

LEU-COMP-THERM-006-012

LEU-COMP-THERM-006-013

LEU-COMP-THERM-006-014

LEU-COMP-THERM-006-015

LEU-COMP-THERM-006-016

LEU-COMP-THERM-006-017

LEU-COMP-THERM-006-018

LEU-COMP-THERM-008-001

LEU-COMP-THERM-008-002

LEU-COMP-THERM-008-003

LEU-COMP-THERM-008-004
LEU-COMP-THERM-034-017

LEU-COMP-THERM-034-018

LEU-COMP-THERM-034-019

LEU-COMP-THERM-034-020

LEU-COMP-THERM-034-021

LEU-COMP-THERM-034-022

LEU-COMP-THERM-034-023

LEU-COMP-THERM-034-024

LEU-COMP-THERM-035-001

LEU-COMP-THERM-035-002

LEU-COMP-THERM-035-003

LEU-COMP-THERM-036-001

LEU-COMP-THERM-036-002

LEU-COMP-THERM-036-003

LEU-COMP-THERM-036-004

LEU-COMP-THERM-036-005

LEU-COMP-THERM-036-006

LEU-COMP-THERM-036-007

LEU-COMP-THERM-036-008

LEU-COMP-THERM-036-009

LEU-COMP-THERM-036-010

LEU-COMP-THERM-036-011

LEU-COMP-THERM-036-012

LEU-COMP-THERM-036-013

LEU-COMP-THERM-036-014

LEU-COMP-THERM-036-015

LEU-COMP-THERM-036-016

LEU-COMP-THERM-036-017

LEU-COMP-THERM-036-018

LEU-COMP-THERM-036-019

LEU-COMP-THERM-036-020

LEU-COMP-THERM-036-021

LEU-COMP-THERM-036-022

LEU-COMP-THERM-036-023

LEU-COMP-THERM-036-024

LEU-COMP-THERM-036-025

LEU-COMP-THERM-036-026

LEU-COMP-THERM-036-027

LEU-COMP-THERM-036-028

LEU-COMP-THERM-036-029

LEU-COMP-THERM-036-030

LEU-COMP-THERM-036-031

LEU-COMP-THERM-036-032

LEU-COMP-THERM-036-033

LEU-COMP-THERM-036-034

LEU-COMP-THERM-036-035

LEU-COMP-THERM-036-036

LEU-COMP-THERM-036-037

LEU-COMP-THERM-036-038
LEU-SOL-THERM-002-003

LEU-SOL-THERM-003-001

LEU-SOL-THERM-003-002

LEU-SOL-THERM-003-003

LEU-SOL-THERM-003-004

LEU-SOL-THERM-003-005

LEU-SOL-THERM-003-006

LEU-SOL-THERM-003-007

LEU-SOL-THERM-003-008

LEU-SOL-THERM-003-009

LEU-SOL-THERM-004-001

LEU-SOL-THERM-004-002

LEU-SOL-THERM-004-003

LEU-SOL-THERM-004-004

LEU-SOL-THERM-004-005

LEU-SOL-THERM-004-006

LEU-SOL-THERM-004-007

MIX-COMP-THERM-001-001

MIX-COMP-THERM-001-002

MIX-COMP-THERM-001-003

MIX-COMP-THERM-001-004

MIX-COMP-THERM-002-001S

MIX-COMP-THERM-002-002S

MIX-COMP-THERM-002-003S

MIX-COMP-THERM-002-004S

MIX-COMP-THERM-002-005S

MIX-COMP-THERM-002-006S

MIX-COMP-THERM-003-001

MIX-COMP-THERM-003-002

MIX-COMP-THERM-003-003

MIX-COMP-THERM-003-004

MIX-COMP-THERM-003-005

MIX-COMP-THERM-003-006

MIX-COMP-THERM-004-001

MIX-COMP-THERM-004-002

MIX-COMP-THERM-004-003

MIX-COMP-THERM-004-004

MIX-COMP-THERM-004-005

MIX-COMP-THERM-004-006

MIX-COMP-THERM-004-007

MIX-COMP-THERM-004-008

MIX-COMP-THERM-004-009

MIX-COMP-THERM-004-010

MIX-COMP-THERM-004-011

MIX-COMP-THERM-005-01

MIX-COMP-THERM-005-02

MIX-COMP-THERM-005-03

MIX-COMP-THERM-005-04

MIX-COMP-THERM-005-05

MIX-COMP-THERM-005-06 
List of critical benchmark experiments considered

LEU-COMP-THERM-008-005

LEU-COMP-THERM-008-006

LEU-COMP-THERM-008-007

LEU-COMP-THERM-008-008

LEU-COMP-THERM-008-009

LEU-COMP-THERM-008-010

LEU-COMP-THERM-008-011

LEU-COMP-THERM-008-012

LEU-COMP-THERM-008-013

LEU-COMP-THERM-008-014

LEU-COMP-THERM-008-015

LEU-COMP-THERM-008-016

LEU-COMP-THERM-008-017

LEU-COMP-THERM-009-001

LEU-COMP-THERM-009-002

LEU-COMP-THERM-009-003

LEU-COMP-THERM-009-004

LEU-COMP-THERM-009-005

LEU-COMP-THERM-009-006

LEU-COMP-THERM-009-007

LEU-COMP-THERM-009-008

LEU-COMP-THERM-009-009

LEU-COMP-THERM-009-010

LEU-COMP-THERM-009-011

LEU-COMP-THERM-009-012

LEU-COMP-THERM-009-013

LEU-COMP-THERM-009-014

LEU-COMP-THERM-009-015

LEU-COMP-THERM-009-016

LEU-COMP-THERM-009-017

LEU-COMP-THERM-009-018

LEU-COMP-THERM-009-019

LEU-COMP-THERM-009-020

LEU-COMP-THERM-009-021

LEU-COMP-THERM-009-022

LEU-COMP-THERM-009-023

LEU-COMP-THERM-009-024

LEU-COMP-THERM-009-025

LEU-COMP-THERM-009-026

LEU-COMP-THERM-009-027

LEU-COMP-THERM-010-001

LEU-COMP-THERM-010-002

LEU-COMP-THERM-010-003

LEU-COMP-THERM-010-004

LEU-COMP-THERM-010-005

LEU-COMP-THERM-010-006

LEU-COMP-THERM-010-007

LEU-COMP-THERM-010-008

LEU-COMP-THERM-010-009

LEU-COMP-THERM-010-010
LEU-COMP-THERM-036-039

LEU-COMP-THERM-036-040

LEU-COMP-THERM-036-041

LEU-COMP-THERM-036-042

LEU-COMP-THERM-036-043

LEU-COMP-THERM-036-044

LEU-COMP-THERM-036-045

LEU-COMP-THERM-036-046

LEU-COMP-THERM-036-047

LEU-COMP-THERM-036-048

LEU-COMP-THERM-036-049

LEU-COMP-THERM-036-050

LEU-COMP-THERM-036-051

LEU-COMP-THERM-036-052

LEU-COMP-THERM-036-053

LEU-COMP-THERM-036-054

LEU-COMP-THERM-036-055

LEU-COMP-THERM-036-056

LEU-COMP-THERM-036-057

LEU-COMP-THERM-036-058

LEU-COMP-THERM-036-059

LEU-COMP-THERM-036-060

LEU-COMP-THERM-036-061

LEU-COMP-THERM-036-062

LEU-COMP-THERM-036-063

LEU-COMP-THERM-036-064

LEU-COMP-THERM-036-065

LEU-COMP-THERM-036-066

LEU-COMP-THERM-036-067

LEU-COMP-THERM-036-068

LEU-COMP-THERM-036-069

LEU-COMP-THERM-037-001

LEU-COMP-THERM-037-002

LEU-COMP-THERM-037-003

LEU-COMP-THERM-037-004

LEU-COMP-THERM-037-005

LEU-COMP-THERM-037-006

LEU-COMP-THERM-037-007

LEU-COMP-THERM-037-008

LEU-COMP-THERM-037-009

LEU-COMP-THERM-037-010

LEU-COMP-THERM-037-011

LEU-COMP-THERM-038-001

LEU-COMP-THERM-038-002

LEU-COMP-THERM-038-003

LEU-COMP-THERM-038-004

LEU-COMP-THERM-038-005

LEU-COMP-THERM-038-006

LEU-COMP-THERM-038-007

LEU-COMP-THERM-038-008
MIX-COMP-THERM-005-07

MIX-COMP-THERM-006-001

MIX-COMP-THERM-006-002

MIX-COMP-THERM-006-003

MIX-COMP-THERM-006-004

MIX-COMP-THERM-006-005

MIX-COMP-THERM-006-006

MIX-COMP-THERM-006-007

MIX-COMP-THERM-006-008

MIX-COMP-THERM-006-009

MIX-COMP-THERM-006-010

MIX-COMP-THERM-006-011

MIX-COMP-THERM-006-012

MIX-COMP-THERM-006-013

MIX-COMP-THERM-006-014

MIX-COMP-THERM-006-015

MIX-COMP-THERM-006-016

MIX-COMP-THERM-006-017

MIX-COMP-THERM-006-018

MIX-COMP-THERM-006-019

MIX-COMP-THERM-006-020

MIX-COMP-THERM-006-021

MIX-COMP-THERM-006-022

MIX-COMP-THERM-006-023

MIX-COMP-THERM-006-024

MIX-COMP-THERM-006-025

MIX-COMP-THERM-006-026

MIX-COMP-THERM-006-027

MIX-COMP-THERM-006-028

MIX-COMP-THERM-006-029

MIX-COMP-THERM-006-030

MIX-COMP-THERM-006-031

MIX-COMP-THERM-006-032

MIX-COMP-THERM-006-033

MIX-COMP-THERM-006-034

MIX-COMP-THERM-006-035

MIX-COMP-THERM-006-036

MIX-COMP-THERM-006-037

MIX-COMP-THERM-006-038

MIX-COMP-THERM-006-039

MIX-COMP-THERM-006-040

MIX-COMP-THERM-006-041

MIX-COMP-THERM-006-042

MIX-COMP-THERM-006-043

MIX-COMP-THERM-006-044

MIX-COMP-THERM-006-045

MIX-COMP-THERM-006-046

MIX-COMP-THERM-006-047

MIX-COMP-THERM-006-048

MIX-COMP-THERM-006-049 
List of critical benchmark experiments considered

LEU-COMP-THERM-010-011 LEU-COMP-THERM-038-009

LEU-COMP-THERM-010-012 LEU-COMP-THERM-038-010

LEU-COMP-THERM-010-013 LEU-COMP-THERM-038-011

LEU-COMP-THERM-010-014 LEU-COMP-THERM-038-012

LEU-COMP-THERM-010-015

LEU-COMP-THERM-010-016

LEU-COMP-THERM-038-013

LEU-COMP-THERM-038-014

LEU-COMP-THERM-010-017

LEU-COMP-THERM-039-001

LEU-COMP-THERM-010-018

LEU-COMP-THERM-039-002

LEU-COMP-THERM-010-019

LEU-COMP-THERM-039-003

LEU-COMP-THERM-010-020

LEU-COMP-THERM-039-004

LEU-COMP-THERM-010-021

LEU-COMP-THERM-039-005

LEU-COMP-THERM-010-022

LEU-COMP-THERM-039-006

LEU-COMP-THERM-010-023

LEU-COMP-THERM-010-024

LEU-COMP-THERM-039-007

LEU-COMP-THERM-039-008

LEU-COMP-THERM-010-025

LEU-COMP-THERM-039-009

LEU-COMP-THERM-010-026

LEU-COMP-THERM-039-010

LEU-COMP-THERM-010-027

LEU-COMP-THERM-039-011

LEU-COMP-THERM-010-028

LEU-COMP-THERM-039-012

LEU-COMP-THERM-010-029

LEU-COMP-THERM-039-013

LEU-COMP-THERM-010-030

LEU-COMP-THERM-039-014

LEU-COMP-THERM-011-001

LEU-COMP-THERM-011-002

LEU-COMP-THERM-039-015

LEU-COMP-THERM-039-016

LEU-COMP-THERM-011-003

LEU-COMP-THERM-039-017

LEU-COMP-THERM-011-004

LEU-COMP-THERM-011-005

LEU-COMP-THERM-040-001

LEU-COMP-THERM-040-002

LEU-COMP-THERM-040-003

LEU-COMP-THERM-011-006

LEU-COMP-THERM-011-007

LEU-COMP-THERM-011-008

LEU-COMP-THERM-040-004

LEU-COMP-THERM-040-005

LEU-COMP-THERM-011-009

LEU-COMP-THERM-011-010

LEU-COMP-THERM-011-011

LEU-COMP-THERM-011-012

LEU-COMP-THERM-011-013

LEU-COMP-THERM-011-014

LEU-COMP-THERM-011-015

LEU-COMP-THERM-012-001

LEU-COMP-THERM-012-002

LEU-COMP-THERM-012-003

LEU-COMP-THERM-012-004

LEU-COMP-THERM-012-005

LEU-COMP-THERM-040-006

LEU-COMP-THERM-040-007

LEU-COMP-THERM-040-008

LEU-COMP-THERM-040-009

LEU-COMP-THERM-040-010

LEU-COMP-THERM-042-001

LEU-COMP-THERM-042-002

LEU-COMP-THERM-042-003

LEU-COMP-THERM-042-004

LEU-COMP-THERM-042-005

LEU-COMP-THERM-042-006

LEU-COMP-THERM-042-007

LEU-COMP-THERM-012-006

LEU-COMP-THERM-012-007

LEU-COMP-THERM-043-001

LEU-COMP-THERM-043-002

LEU-COMP-THERM-012-008

LEU-COMP-THERM-012-009

LEU-COMP-THERM-043-003

LEU-COMP-THERM-043-004

LEU-COMP-THERM-012-010

LEU-COMP-THERM-013-001

LEU-COMP-THERM-043-005

LEU-COMP-THERM-043-006

LEU-COMP-THERM-013-002

LEU-COMP-THERM-013-003

LEU-COMP-THERM-043-007

LEU-COMP-THERM-043-008

MIX-COMP-THERM-006-050

MIX-COMP-THERM-007-001

MIX-COMP-THERM-007-002

MIX-COMP-THERM-007-003

MIX-COMP-THERM-007-004

MIX-COMP-THERM-007-005

MIX-COMP-THERM-007-006

MIX-COMP-THERM-007-007

MIX-COMP-THERM-007-008

MIX-COMP-THERM-007-009

MIX-COMP-THERM-007-010

MIX-COMP-THERM-007-011

MIX-COMP-THERM-007-012

MIX-COMP-THERM-007-013

MIX-COMP-THERM-007-014

MIX-COMP-THERM-007-015

MIX-COMP-THERM-007-016

MIX-COMP-THERM-007-017

MIX-COMP-THERM-007-018

MIX-COMP-THERM-007-019

MIX-COMP-THERM-007-020

MIX-COMP-THERM-007-021

MIX-COMP-THERM-007-022

MIX-COMP-THERM-007-023

MIX-COMP-THERM-007-024

MIX-COMP-THERM-007-025

MIX-COMP-THERM-007-026

MIX-COMP-THERM-007-027

MIX-COMP-THERM-008-001

MIX-COMP-THERM-008-002

MIX-COMP-THERM-008-003

MIX-COMP-THERM-008-004

MIX-COMP-THERM-008-005

MIX-COMP-THERM-008-006

MIX-COMP-THERM-008-007

MIX-COMP-THERM-008-008

MIX-COMP-THERM-008-009

MIX-COMP-THERM-008-010

MIX-COMP-THERM-008-011

MIX-COMP-THERM-008-012

MIX-COMP-THERM-008-013

MIX-COMP-THERM-008-014

MIX-COMP-THERM-008-015

MIX-COMP-THERM-008-016

MIX-COMP-THERM-008-017

MIX-COMP-THERM-008-018

MIX-COMP-THERM-008-019

MIX-COMP-THERM-008-020

LEU-COMP-THERM-043-009

MIX-COMP-THERM-008-021

MIX-COMP-THERM-008-022 
List of critical benchmark experiments considered

LEU-COMP-THERM-013-006 LEU-COMP-THERM-044-002

LEU-COMP-THERM-013-007

LEU-COMP-THERM-014-001

LEU-COMP-THERM-014-002

LEU-COMP-THERM-014-005

LEU-COMP-THERM-014-006

LEU-COMP-THERM-014-007

LEU-COMP-THERM-015-001

LEU-COMP-THERM-015-002

LEU-COMP-THERM-015-003

LEU-COMP-THERM-015-004

LEU-COMP-THERM-015-005

LEU-COMP-THERM-015-006

LEU-COMP-THERM-015-007

LEU-COMP-THERM-015-008

LEU-COMP-THERM-015-009

LEU-COMP-THERM-015-010

LEU-COMP-THERM-015-011

LEU-COMP-THERM-015-012

LEU-COMP-THERM-015-013

LEU-COMP-THERM-015-014

LEU-COMP-THERM-015-015

LEU-COMP-THERM-015-016

LEU-COMP-THERM-015-017

LEU-COMP-THERM-015-018

LEU-COMP-THERM-015-019

LEU-COMP-THERM-015-020

LEU-COMP-THERM-015-021

LEU-COMP-THERM-015-022

LEU-COMP-THERM-015-023

LEU-COMP-THERM-015-024

LEU-COMP-THERM-015-025

LEU-COMP-THERM-015-026

LEU-COMP-THERM-015-027

LEU-COMP-THERM-015-028

LEU-COMP-THERM-015-029

LEU-COMP-THERM-015-030

LEU-COMP-THERM-015-031

LEU-COMP-THERM-015-032

LEU-COMP-THERM-015-033

LEU-COMP-THERM-015-034

LEU-COMP-THERM-015-035

LEU-COMP-THERM-015-036

LEU-COMP-THERM-015-037

LEU-COMP-THERM-015-038

LEU-COMP-THERM-015-039

LEU-COMP-THERM-015-040

LEU-COMP-THERM-015-041

LEU-COMP-THERM-015-042

LEU-COMP-THERM-015-043
LEU-COMP-THERM-044-003

LEU-COMP-THERM-044-004

LEU-COMP-THERM-044-005

LEU-COMP-THERM-044-006

LEU-COMP-THERM-044-007

LEU-COMP-THERM-044-008

LEU-COMP-THERM-044-009

LEU-COMP-THERM-044-010

LEU-COMP-THERM-045-001

LEU-COMP-THERM-045-002

LEU-COMP-THERM-045-003

LEU-COMP-THERM-045-004

LEU-COMP-THERM-045-005

LEU-COMP-THERM-045-006

LEU-COMP-THERM-045-007

LEU-COMP-THERM-045-008

LEU-COMP-THERM-045-009

LEU-COMP-THERM-045-010

LEU-COMP-THERM-045-011

LEU-COMP-THERM-045-012

LEU-COMP-THERM-045-013

LEU-COMP-THERM-045-014

LEU-COMP-THERM-045-015

LEU-COMP-THERM-045-016

LEU-COMP-THERM-045-017

LEU-COMP-THERM-045-018

LEU-COMP-THERM-045-019

LEU-COMP-THERM-045-020

LEU-COMP-THERM-045-021

LEU-COMP-THERM-046-001

LEU-COMP-THERM-046-002

LEU-COMP-THERM-046-003

LEU-COMP-THERM-046-004

LEU-COMP-THERM-046-005

LEU-COMP-THERM-046-006

LEU-COMP-THERM-046-007

LEU-COMP-THERM-046-008

LEU-COMP-THERM-046-009

LEU-COMP-THERM-046-010

LEU-COMP-THERM-046-011

LEU-COMP-THERM-046-012

LEU-COMP-THERM-046-013

LEU-COMP-THERM-046-014

LEU-COMP-THERM-046-015

LEU-COMP-THERM-046-016

LEU-COMP-THERM-046-017

LEU-COMP-THERM-046-018

LEU-COMP-THERM-046-019

LEU-COMP-THERM-046-020
MIX-COMP-THERM-008-023

MIX-COMP-THERM-008-024

MIX-COMP-THERM-008-025

MIX-COMP-THERM-008-026

MIX-COMP-THERM-008-027

MIX-COMP-THERM-008-028

MIX-COMP-THERM-009-01

MIX-COMP-THERM-009-02

MIX-COMP-THERM-009-03

MIX-COMP-THERM-009-04

MIX-COMP-THERM-009-05

MIX-COMP-THERM-009-06

MIX-COMP-THERM-011-01

MIX-COMP-THERM-011-02

MIX-COMP-THERM-011-03

MIX-COMP-THERM-011-04

MIX-COMP-THERM-011-05

MIX-COMP-THERM-011-06

MIX-COMP-THERM-012-001

MIX-COMP-THERM-012-002

MIX-COMP-THERM-012-003

MIX-COMP-THERM-012-004

MIX-COMP-THERM-012-005

MIX-COMP-THERM-012-006

MIX-COMP-THERM-012-007

MIX-COMP-THERM-012-008

MIX-COMP-THERM-012-009

MIX-COMP-THERM-012-010

MIX-COMP-THERM-012-011

MIX-COMP-THERM-012-012

MIX-COMP-THERM-012-013

MIX-COMP-THERM-012-014

MIX-COMP-THERM-012-015

MIX-COMP-THERM-012-016

MIX-COMP-THERM-012-017

MIX-COMP-THERM-012-018

MIX-COMP-THERM-012-019

MIX-COMP-THERM-012-020

MIX-COMP-THERM-012-021

MIX-COMP-THERM-012-022

MIX-COMP-THERM-012-023

MIX-COMP-THERM-012-024

MIX-COMP-THERM-012-025

MIX-COMP-THERM-012-026

MIX-COMP-THERM-012-027

MIX-COMP-THERM-012-028

MIX-COMP-THERM-012-029

MIX-COMP-THERM-012-030

MIX-COMP-THERM-012-031

MIX-COMP-THERM-012-032 
List of critical benchmark experiments considered

LEU-COMP-THERM-015-044 LEU-COMP-THERM-046-021

LEU-COMP-THERM-015-045 LEU-COMP-THERM-046-022

LEU-COMP-THERM-015-046

LEU-COMP-THERM-015-047

LEU-COMP-THERM-015-048

LEU-COMP-THERM-015-049

LEU-COMP-THERM-015-050

LEU-COMP-THERM-015-051

LEU-COMP-THERM-015-052

LEU-COMP-THERM-015-053

LEU-COMP-THERM-015-054

LEU-COMP-THERM-015-055

LEU-COMP-THERM-015-056

LEU-COMP-THERM-015-057

LEU-COMP-THERM-015-058

LEU-COMP-THERM-015-059

LEU-COMP-THERM-015-060

LEU-COMP-THERM-015-061

LEU-COMP-THERM-015-062

LEU-COMP-THERM-015-063

LEU-COMP-THERM-015-064

LEU-COMP-THERM-015-065

LEU-COMP-THERM-015-066

LEU-COMP-THERM-015-067

LEU-COMP-THERM-015-068

LEU-COMP-THERM-015-069

LEU-COMP-THERM-015-070

LEU-COMP-THERM-015-071

LEU-COMP-THERM-015-072

LEU-COMP-THERM-015-073

LEU-COMP-THERM-015-074

LEU-COMP-THERM-015-075

LEU-COMP-THERM-015-076

LEU-COMP-THERM-015-077

LEU-COMP-THERM-015-078

LEU-COMP-THERM-015-079

LEU-COMP-THERM-015-080

LEU-COMP-THERM-015-081

LEU-COMP-THERM-015-082

LEU-COMP-THERM-015-083

LEU-COMP-THERM-015-084

LEU-COMP-THERM-015-085

LEU-COMP-THERM-015-086

LEU-COMP-THERM-015-087

LEU-COMP-THERM-015-088

LEU-COMP-THERM-015-089

LEU-COMP-THERM-015-090

LEU-COMP-THERM-015-091

LEU-COMP-THERM-015-092

LEU-COMP-THERM-015-093
LEU-COMP-THERM-047-001

LEU-COMP-THERM-047-002

LEU-COMP-THERM-047-003

LEU-COMP-THERM-048-001

LEU-COMP-THERM-048-002

LEU-COMP-THERM-048-003

LEU-COMP-THERM-048-004

LEU-COMP-THERM-048-005

LEU-COMP-THERM-050-001

LEU-COMP-THERM-050-002

LEU-COMP-THERM-050-003

LEU-COMP-THERM-050-004

LEU-COMP-THERM-050-005

LEU-COMP-THERM-050-006

LEU-COMP-THERM-050-007

LEU-COMP-THERM-050-008

LEU-COMP-THERM-050-009

LEU-COMP-THERM-050-010

LEU-COMP-THERM-050-011

LEU-COMP-THERM-050-012

LEU-COMP-THERM-050-013

LEU-COMP-THERM-050-014

LEU-COMP-THERM-050-015

LEU-COMP-THERM-050-016

LEU-COMP-THERM-050-017

LEU-COMP-THERM-050-018

LEU-COMP-THERM-051-001

LEU-COMP-THERM-051-002

LEU-COMP-THERM-051-003

LEU-COMP-THERM-051-004

LEU-COMP-THERM-051-005

LEU-COMP-THERM-051-006

LEU-COMP-THERM-051-007

LEU-COMP-THERM-051-008

LEU-COMP-THERM-051-009

LEU-COMP-THERM-051-010

LEU-COMP-THERM-051-011

LEU-COMP-THERM-051-012

LEU-COMP-THERM-051-013

LEU-COMP-THERM-051-014

LEU-COMP-THERM-051-015

LEU-COMP-THERM-051-016

LEU-COMP-THERM-051-017

LEU-COMP-THERM-051-018

LEU-COMP-THERM-051-019

LEU-COMP-THERM-052-001

LEU-COMP-THERM-052-002

LEU-COMP-THERM-052-003
MIX-COMP-THERM-012-033

MIX-COMP-THERM-013-001

MIX-COMP-THERM-013-002

MIX-COMP-THERM-013-003

MIX-COMP-THERM-013-004

MIX-COMP-THERM-013-005

MIX-COMP-THERM-013-006

MIX-COMP-THERM-013-007

MIX-COMP-THERM-013-008

MIX-COMP-THERM-013-009

MIX-COMP-THERM-013-010

MIX-COMP-THERM-013-011

MIX-COMP-THERM-013-012

MIX-COMP-THERM-013-013

MIX-COMP-THERM-013-014

MIX-COMP-THERM-013-015

MIX-COMP-THERM-013-016

MIX-COMP-THERM-013-017

MIX-COMP-THERM-013-018

MIX-COMP-THERM-013-019

MIX-COMP-THERM-013-020

MIX-COMP-THERM-013-021

MIX-COMP-THERM-013-022

MIX-COMP-THERM-013-023

MIX-COMP-THERM-013-024

MIX-COMP-THERM-013-025

MIX-COMP-THERM-013-026

MIX-COMP-THERM-013-027

MIX-COMP-THERM-013-028

MIX-COMP-THERM-013-029

MIX-COMP-THERM-013-030

MIX-COMP-THERM-014-001

MIX-COMP-THERM-014-002

MIX-COMP-THERM-014-003

MIX-COMP-THERM-014-004

MIX-COMP-THERM-014-005

MIX-COMP-THERM-014-006

MIX-COMP-THERM-014-007

MIX-COMP-THERM-014-008

MIX-COMP-THERM-014-009

MIX-COMP-THERM-014-010

MIX-COMP-THERM-014-011

MIX-COMP-THERM-014-012

MIX-COMP-THERM-014-013

MIX-COMP-THERM-014-014

MIX-COMP-THERM-014-015

MIX-COMP-THERM-014-016

MIX-COMP-THERM-014-017

MIX-COMP-THERM-014-018

MIX-COMP-THERM-014-019 
List of critical benchmark experiments considered

LEU-COMP-THERM-015-094 LEU-COMP-THERM-052-004

LEU-COMP-THERM-015-095

LEU-COMP-THERM-015-096

LEU-COMP-THERM-015-097

LEU-COMP-THERM-015-098

LEU-COMP-THERM-015-099

LEU-COMP-THERM-015-100

LEU-COMP-THERM-015-101

LEU-COMP-THERM-015-102

LEU-COMP-THERM-015-103

LEU-COMP-THERM-015-104

LEU-COMP-THERM-015-105

LEU-COMP-THERM-015-106

LEU-COMP-THERM-015-107

LEU-COMP-THERM-015-108

LEU-COMP-THERM-015-109

LEU-COMP-THERM-015-110

LEU-COMP-THERM-015-111

LEU-COMP-THERM-015-112

LEU-COMP-THERM-015-113

LEU-COMP-THERM-015-114

LEU-COMP-THERM-015-115

LEU-COMP-THERM-015-116

LEU-COMP-THERM-015-117

LEU-COMP-THERM-015-118

LEU-COMP-THERM-015-119

LEU-COMP-THERM-015-120

LEU-COMP-THERM-015-121

LEU-COMP-THERM-015-122

LEU-COMP-THERM-015-123

LEU-COMP-THERM-015-124

LEU-COMP-THERM-015-125

LEU-COMP-THERM-015-126

LEU-COMP-THERM-015-127

LEU-COMP-THERM-015-128

LEU-COMP-THERM-015-129

LEU-COMP-THERM-015-130

LEU-COMP-THERM-015-131

LEU-COMP-THERM-015-132

LEU-COMP-THERM-015-133

LEU-COMP-THERM-015-134

LEU-COMP-THERM-015-135

LEU-COMP-THERM-015-136

LEU-COMP-THERM-015-137

LEU-COMP-THERM-015-138

LEU-COMP-THERM-015-139

LEU-COMP-THERM-015-140

LEU-COMP-THERM-015-141

LEU-COMP-THERM-015-142

LEU-COMP-THERM-015-143
LEU-COMP-THERM-052-005

LEU-COMP-THERM-052-006

LEU-COMP-THERM-053-001

LEU-COMP-THERM-053-002

LEU-COMP-THERM-053-003

LEU-COMP-THERM-053-004

LEU-COMP-THERM-053-005

LEU-COMP-THERM-053-006

LEU-COMP-THERM-053-007

LEU-COMP-THERM-053-008

LEU-COMP-THERM-053-009

LEU-COMP-THERM-053-010

LEU-COMP-THERM-053-011

LEU-COMP-THERM-053-012

LEU-COMP-THERM-053-013

LEU-COMP-THERM-053-014

LEU-COMP-THERM-054-001

LEU-COMP-THERM-054-002

LEU-COMP-THERM-054-003

LEU-COMP-THERM-054-004

LEU-COMP-THERM-054-005

LEU-COMP-THERM-054-006

LEU-COMP-THERM-054-007

LEU-COMP-THERM-054-008

LEU-COMP-THERM-055-001

LEU-COMP-THERM-055-002

LEU-COMP-THERM-057-001

LEU-COMP-THERM-057-002

LEU-COMP-THERM-057-003

LEU-COMP-THERM-057-004

LEU-COMP-THERM-057-005

LEU-COMP-THERM-057-006

LEU-COMP-THERM-057-007

LEU-COMP-THERM-057-008

LEU-COMP-THERM-057-009

LEU-COMP-THERM-057-010

LEU-COMP-THERM-057-011

LEU-COMP-THERM-057-012

LEU-COMP-THERM-057-013

LEU-COMP-THERM-057-014

LEU-COMP-THERM-057-015

LEU-COMP-THERM-057-016

LEU-COMP-THERM-057-017

LEU-COMP-THERM-057-018

LEU-COMP-THERM-057-019

LEU-COMP-THERM-057-020

LEU-COMP-THERM-057-021

LEU-COMP-THERM-057-022

LEU-COMP-THERM-057-023
MIX-COMP-THERM-014-020

MIX-COMP-THERM-014-021

MIX-COMP-THERM-014-022

MIX-COMP-THERM-016-001

MIX-COMP-THERM-016-002

MIX-COMP-THERM-016-003

MIX-COMP-THERM-016-004

MIX-COMP-THERM-016-005

MIX-COMP-THERM-016-006

MIX-COMP-THERM-016-007

MIX-COMP-THERM-016-008

MIX-COMP-THERM-016-009

MIX-COMP-THERM-016-010

MIX-COMP-THERM-016-011

MIX-COMP-THERM-016-012

MIX-COMP-THERM-016-013

MIX-COMP-THERM-016-014

MIX-COMP-THERM-016-015

MIX-COMP-THERM-016-016

MIX-COMP-THERM-016-017

MIX-COMP-THERM-016-018

MIX-COMP-THERM-016-019

MIX-COMP-THERM-017-001

MIX-COMP-THERM-017-002

MIX-COMP-THERM-017-003

MIX-COMP-THERM-017-004

MIX-COMP-THERM-017-005

MIX-COMP-THERM-017-006

MIX-COMP-THERM-017-007

MIX-COMP-THERM-017-008

MIX-COMP-THERM-017-009

MIX-COMP-THERM-017-010

MIX-COMP-THERM-017-011

MIX-COMP-THERM-017-012

MIX-COMP-THERM-017-013

MIX-COMP-THERM-017-014

MIX-COMP-THERM-017-015

MIX-COMP-THERM-017-016

MIX-COMP-THERM-017-017

MIX-COMP-THERM-017-018

MIX-COMP-THERM-017-019

HTC1 001

HTC1_002

HTC1_003

HTC1_004

HTC1_005

HTC1_006

HTC1_007

HTC1 008

HTC1_009 
List of critical benchmark experiments considered

LEU-COMP-THERM-015-144 LEU-COMP-THERM-057-024

LEU-COMP-THERM-015-145

LEU-COMP-THERM-015-146

LEU-COMP-THERM-015-147

LEU-COMP-THERM-015-148

LEU-COMP-THERM-015-149

LEU-COMP-THERM-015-150

LEU-COMP-THERM-015-151

LEU-COMP-THERM-015-152

LEU-COMP-THERM-015-153

LEU-COMP-THERM-015-154

LEU-COMP-THERM-015-155

LEU-COMP-THERM-015-156

LEU-COMP-THERM-015-157

LEU-COMP-THERM-015-158

LEU-COMP-THERM-015-159

LEU-COMP-THERM-015-160

LEU-COMP-THERM-015-161

LEU-COMP-THERM-015-162

LEU-COMP-THERM-015-163

LEU-COMP-THERM-015-164

LEU-COMP-THERM-015-165

LEU-COMP-THERM-016-001

LEU-COMP-THERM-016-002

LEU-COMP-THERM-016-003

LEU-COMP-THERM-016-004

LEU-COMP-THERM-016-005

LEU-COMP-THERM-016-006

LEU-COMP-THERM-016-007

LEU-COMP-THERM-016-008

LEU-COMP-THERM-016-009

LEU-COMP-THERM-016-010

LEU-COMP-THERM-016-011

LEU-COMP-THERM-016-012

LEU-COMP-THERM-016-013

LEU-COMP-THERM-016-014

LEU-COMP-THERM-016-015

LEU-COMP-THERM-016-016

LEU-COMP-THERM-016-017

LEU-COMP-THERM-016-018

LEU-COMP-THERM-016-019

LEU-COMP-THERM-016-020

LEU-COMP-THERM-016-021

LEU-COMP-THERM-016-022

LEU-COMP-THERM-016-023

LEU-COMP-THERM-016-024

LEU-COMP-THERM-016-025

LEU-COMP-THERM-016-026

LEU-COMP-THERM-016-027

LEU-COMP-THERM-016-028
LEU-COMP-THERM-057-025

LEU-COMP-THERM-057-026

LEU-COMP-THERM-057-027

LEU-COMP-THERM-057-028

LEU-COMP-THERM-057-029

LEU-COMP-THERM-057-030

LEU-COMP-THERM-057-031

LEU-COMP-THERM-057-032

LEU-COMP-THERM-057-033

LEU-COMP-THERM-057-034

LEU-COMP-THERM-057-035

LEU-COMP-THERM-057-036

LEU-COMP-THERM-058-001

LEU-COMP-THERM-058-002

LEU-COMP-THERM-058-003

LEU-COMP-THERM-058-004

LEU-COMP-THERM-058-005

LEU-COMP-THERM-058-006

LEU-COMP-THERM-058-007

LEU-COMP-THERM-058-008

LEU-COMP-THERM-058-009

LEU-COMP-THERM-061-001

LEU-COMP-THERM-061-002

LEU-COMP-THERM-061-003

LEU-COMP-THERM-061-004

LEU-COMP-THERM-061-005

LEU-COMP-THERM-061-006

LEU-COMP-THERM-061-007

LEU-COMP-THERM-061-008

LEU-COMP-THERM-061-009

LEU-COMP-THERM-061-010

LEU-COMP-THERM-062-001

LEU-COMP-THERM-062-002

LEU-COMP-THERM-062-003

LEU-COMP-THERM-062-004

LEU-COMP-THERM-062-005

LEU-COMP-THERM-062-006

LEU-COMP-THERM-062-007

LEU-COMP-THERM-062-008

LEU-COMP-THERM-062-009

LEU-COMP-THERM-062-010

LEU-COMP-THERM-062-011

LEU-COMP-THERM-062-012

LEU-COMP-THERM-062-013

LEU-COMP-THERM-062-014

LEU-COMP-THERM-062-015

LEU-COMP-THERM-065-001

LEU-COMP-THERM-065-002

LEU-COMP-THERM-065-003
HTC1_010

HTC1_011

HTC1_012

HTC1_013

HTC1_014

HTC1_015

HTC1_016

HTC1_017

HTC1 018

HTC2B 001

HTC2B 002

HTC2B 003

HTC2B 004

HTC2B_005

HTC2B 006

HTC2B_007

HTC2B 008

HTC2B_009

HTC2B 010

HTC2B_011

HTC2B 012

HTC2B 014

HTC2B 015

HTC2B_016

HTC2B 017

HTC2B_018

HTC2B_019

HTC2B_020

HTC2B_021

HTC2G_001

HTC2G_002

HTC2G_003

HTC2G_004

HTC2G_005

HTC2G_006

HTC2G_007

HTC2G_008

HTC2G_009

HTC2G_010

HTC2G_011

HTC2G 012

HTC2G_013

HTC2G 014

HTC2G 015

HTC2G 016

HTC2G 017

HTC2G 018

HTC2G_019

HTC2G 020

HTC3_001 
List of critical benchmark experiments considered

LEU-COMP-THERM-016-029 LEU-COMP-THERM-065-004

LEU-COMP-THERM-016-030 LEU-COMP-THERM-065-005

LEU-COMP-THERM-016-031 LEU-COMP-THERM-065-006

LEU-COMP-THERM-016-032 LEU-COMP-THERM-065-007

LEU-COMP-THERM-017-001 LEU-COMP-THERM-065-008

LEU-COMP-THERM-017-002 LEU-COMP-THERM-065-009

LEU-COMP-THERM-017-003

LEU-COMP-THERM-065-010

LEU-COMP-THERM-017-004

LEU-COMP-THERM-065-011

LEU-COMP-THERM-017-005

LEU-COMP-THERM-065-012

LEU-COMP-THERM-017-006

LEU-COMP-THERM-065-013

LEU-COMP-THERM-065-014

LEU-COMP-THERM-017-007

LEU-COMP-THERM-065-015

LEU-COMP-THERM-017-008

LEU-COMP-THERM-065-016

LEU-COMP-THERM-017-009

LEU-COMP-THERM-065-017

LEU-COMP-THERM-017-010

LEU-COMP-THERM-066-004

LEU-COMP-THERM-017-011

LEU-COMP-THERM-066-005

LEU-COMP-THERM-017-012

LEU-COMP-THERM-017-013

LEU-COMP-THERM-066-006

LEU-COMP-THERM-066-007

LEU-COMP-THERM-017-014

LEU-COMP-THERM-017-015

LEU-COMP-THERM-066-008

LEU-COMP-THERM-066-009

LEU-COMP-THERM-017-016

LEU-COMP-THERM-017-017

LEU-COMP-THERM-017-018

LEU-COMP-THERM-017-019

LEU-COMP-THERM-017-020

LEU-COMP-THERM-017-021

LEU-COMP-THERM-017-022

LEU-COMP-THERM-017-023

LEU-COMP-THERM-017-024

LEU-COMP-THERM-017-025

LEU-COMP-THERM-017-026

LEU-COMP-THERM-017-027

LEU-COMP-THERM-017-028

LEU-COMP-THERM-017-029

LEU-COMP-THERM-018-001

LEU-COMP-THERM-020-001

LEU-COMP-THERM-020-002

LEU-COMP-THERM-020-003

LEU-COMP-THERM-020-004

LEU-COMP-THERM-020-005

LEU-COMP-THERM-020-006

LEU-COMP-THERM-020-007

LEU-COMP-THERM-021-001

LEU-COMP-THERM-021-002

LEU-COMP-THERM-021-003

LEU-COMP-THERM-066-010

LEU-COMP-THERM-069-001

LEU-COMP-THERM-069-002

LEU-COMP-THERM-069-003

LEU-COMP-THERM-069-004

LEU-COMP-THERM-069-005

LEU-COMP-THERM-070-001

LEU-COMP-THERM-070-002

LEU-COMP-THERM-070-003

LEU-COMP-THERM-070-004

LEU-COMP-THERM-070-005

LEU-COMP-THERM-070-006

LEU-COMP-THERM-070-007

LEU-COMP-THERM-070-008

LEU-COMP-THERM-070-009

LEU-COMP-THERM-070-010

LEU-COMP-THERM-070-011

LEU-COMP-THERM-070-012

LEU-COMP-THERM-071-001

LEU-COMP-THERM-071-002

LEU-COMP-THERM-071-003

LEU-COMP-THERM-071-004

LEU-COMP-THERM-072-001

LEU-COMP-THERM-072-002

LEU-COMP-THERM-021-004

LEU-COMP-THERM-021-005

LEU-COMP-THERM-072-003

LEU-COMP-THERM-072-004

LEU-COMP-THERM-021-006

LEU-COMP-THERM-022-001

LEU-COMP-THERM-072-005

LEU-COMP-THERM-072-006

HTC3_002

HTC3_003

HTC3 004

HTC3_005

HTC3_006

HTC3_007

HTC3 008

HTC3_009

HTC3 010

HTC3 011

HTC3 012

HTC3 013

HTC3 014

HTC3_015

HTC3 016

HTC3_017

HTC3_018

HTC3_019

HTC3 020

HTC3_021

HTC3 022

HTC3 023

HTC3 024

HTC3_025

HTC3 026

HTC4FE_001

HTC4FE-002

HTC4FE_003

HTC4FE_004

HTC4FE_005

HTC4FE 006

HTC4FE_007

HTC4FE_008

HTC4FE_009

HTC4FE_010

HTC4FE_011

HTC4FE_012

HTC4FE_013

HTC4FE_014

HTC4FE_015

HTC4FE 016

HTC4FE 017

HTC4FE_018

HTC4FE_019

HTC4FE_020

HTC4FE_021

HTC4FE_022

HTC4FE 023

LEU-COMP-THERM-072-007

HTC4FE 024

LEU-COMP-THERM-022-002

LEU-COMP-THERM-072-008

HTC4FE_025 
List of critical benchmark experiments considered

LEU-COMP-THERM-022-004

LEU-COMP-THERM-022-005

LEU-COMP-THERM-022-006

LEU-COMP-THERM-022-007

LEU-COMP-THERM-023-001

LEU-COMP-THERM-023-002

LEU-COMP-THERM-023-003

LEU-COMP-THERM-023-004

LEU-COMP-THERM-023-005

LEU-COMP-THERM-023-006

LEU-COMP-THERM-024-001

LEU-COMP-THERM-024-002

LEU-COMP-THERM-026-001

LEU-COMP-THERM-026-002

LEU-COMP-THERM-026-003

LEU-COMP-THERM-026-004

LEU-COMP-THERM-026-005

LEU-COMP-THERM-026-006

LEU-COMP-THERM-027-001

LEU-COMP-THERM-027-002

LEU-COMP-THERM-027-003

LEU-COMP-THERM-027-004

LEU-COMP-THERM-028-001

LEU-COMP-THERM-028-002

LEU-COMP-THERM-028-003

LEU-COMP-THERM-028-004

LEU-COMP-THERM-028-005

LEU-COMP-THERM-028-006

LEU-COMP-THERM-028-007

LEU-COMP-THERM-028-008

LEU-COMP-THERM-028-009

LEU-COMP-THERM-028-010

LEU-COMP-THERM-028-011

LEU-COMP-THERM-028-012

LEU-COMP-THERM-028-013

LEU-COMP-THERM-028-014

LEU-COMP-THERM-028-015

LEU-COMP-THERM-028-016

LEU-COMP-THERM-028-017

LEU-COMP-THERM-028-018

LEU-COMP-THERM-028-019

LEU-COMP-THERM-028-020

LEU-COMP-THERM-029-001

LEU-COMP-THERM-029-002

LEU-COMP-THERM-029-003

LEU-COMP-THERM-029-004

LEU-COMP-THERM-029-005

LEU-COMP-THERM-029-006

LEU-COMP-THERM-029-007

LEU-COMP-THERM-029-008
LEU-COMP-THERM-072-009

LEU-COMP-THERM-073-001

LEU-COMP-THERM-073-002

LEU-COMP-THERM-073-003

LEU-COMP-THERM-073-004

LEU-COMP-THERM-073-005

LEU-COMP-THERM-073-006

LEU-COMP-THERM-073-007

LEU-COMP-THERM-073-008

LEU-COMP-THERM-073-009

LEU-COMP-THERM-073-010

LEU-COMP-THERM-073-011

LEU-COMP-THERM-073-012

LEU-COMP-THERM-073-013

LEU-COMP-THERM-073-014

LEU-COMP-THERM-074-001

LEU-COMP-THERM-074-002

LEU-COMP-THERM-074-003

LEU-COMP-THERM-074-004

LEU-COMP-THERM-075-001

LEU-COMP-THERM-075-002

LEU-COMP-THERM-075-003

LEU-COMP-THERM-075-004

LEU-COMP-THERM-075-005

LEU-COMP-THERM-075-006

LEU-COMP-THERM-076-001

LEU-COMP-THERM-076-002

LEU-COMP-THERM-076-003

LEU-COMP-THERM-076-004

LEU-COMP-THERM-076-005

LEU-COMP-THERM-076-006

LEU-COMP-THERM-076-007

LEU-COMP-THERM-077-001

LEU-COMP-THERM-077-002

LEU-COMP-THERM-077-003

LEU-COMP-THERM-077-004

LEU-COMP-THERM-077-005

LEU-COMP-THERM-078-001

LEU-COMP-THERM-078-002

LEU-COMP-THERM-078-003

LEU-COMP-THERM-078-004

LEU-COMP-THERM-078-005

LEU-COMP-THERM-078-006

LEU-COMP-THERM-078-007

LEU-COMP-THERM-078-008

LEU-COMP-THERM-078-009

LEU-COMP-THERM-078-010

LEU-COMP-THERM-078-011

LEU-COMP-THERM-078-012

LEU-COMP-THERM-078-013
HTC4FE_026

HTC4FE_027

HTC4FE_028

HTC4FE_029

HTC4FE_030

HTC4FE_031

HTC4FE_032

HTC4FE_033

HTC4PB_001

HTC4PB_002

HTC4PB 003

HTC4PB 004

HTC4PB 005

HTC4PB 006

HTC4PB 007

HTC4PB_008

HTC4PB_009

HTC4PB_010

HTC4PB_011

HTC4PB_012

HTC4PB 013

HTC4PB 014

HTC4PB 015

HTC4PB 016

HTC4PB 017

HTC4PB_018

HTC4PB 019

HTC4PB_020

HTC4PB_021

HTC4PB_022

HTC4PB_023

HTC4PB_024

HTC4PB_025

HTC4PB_026

HTC4PB_027

HTC4PB_028

HTC4PB 029

HTC4PB_030

HTC4PB_031

HTC4PB_032

HTC4PB 033

HTC4PB 034

HTC4PB_035

HTC4PB_036

HTC4PB 037

HTC4PB_038

MIX-SOL-THERM-001-001

MIX-SOL-THERM-001-002

MIX-SOL-THERM-001-003

MIX-SOL-THERM-001-004 
List of critical benchmark experiments considered

LEU-COMP-THERM-029-009 LEU-COMP-THERM-078-014

LEU-COMP-THERM-029-010 LEU-COMP-THERM-078-015

LEU-COMP-THERM-029-011

LEU-COMP-THERM-029-012

LEU-COMP-THERM-030-001

LEU-COMP-THERM-030-002

LEU-COMP-THERM-030-003

LEU-COMP-THERM-030-004

LEU-COMP-THERM-030-005

LEU-COMP-THERM-030-006

LEU-COMP-THERM-030-007

LEU-COMP-THERM-030-008

LEU-COMP-THERM-030-009

LEU-COMP-THERM-030-010

LEU-COMP-THERM-030-011

LEU-COMP-THERM-030-012

LEU-COMP-THERM-031-001

LEU-COMP-THERM-031-002

LEU-COMP-THERM-031-003

LEU-COMP-THERM-031-004

LEU-COMP-THERM-031-005

LEU-COMP-THERM-031-006

LEU-COMP-THERM-032-001

LEU-COMP-THERM-032-002

LEU-COMP-THERM-032-003

LEU-COMP-THERM-032-004

LEU-COMP-THERM-032-005

LEU-COMP-THERM-032-006

LEU-COMP-THERM-032-007

LEU-COMP-THERM-032-008

LEU-COMP-THERM-032-009

LEU-COMP-THERM-033-001

LEU-COMP-THERM-033-002

LEU-COMP-THERM-033-003

LEU-COMP-THERM-033-004

LEU-COMP-THERM-033-005

LEU-COMP-THERM-033-006

LEU-COMP-THERM-033-007

LEU-COMP-THERM-033-008

LEU-COMP-THERM-033-009

LEU-COMP-THERM-033-010

LEU-COMP-THERM-033-011

LEU-COMP-THERM-033-012

LEU-COMP-THERM-033-013

LEU-COMP-THERM-033-014

LEU-COMP-THERM-033-015

LEU-COMP-THERM-033-016

LEU-COMP-THERM-033-017

LEU-COMP-THERM-033-018

LEU-COMP-THERM-033-019
LEU-COMP-THERM-079-001

LEU-COMP-THERM-079-002

LEU-COMP-THERM-079-003

LEU-COMP-THERM-079-004

LEU-COMP-THERM-079-005

LEU-COMP-THERM-079-006

LEU-COMP-THERM-079-007

LEU-COMP-THERM-079-008

LEU-COMP-THERM-079-009

LEU-COMP-THERM-079-010

LEU-COMP-THERM-080-001

LEU-COMP-THERM-080-002

LEU-COMP-THERM-080-003

LEU-COMP-THERM-080-004

LEU-COMP-THERM-080-005

LEU-COMP-THERM-080-006

LEU-COMP-THERM-080-007

LEU-COMP-THERM-080-008

LEU-COMP-THERM-080-009

LEU-COMP-THERM-080-010

LEU-COMP-THERM-080-011

LEU-COMP-THERM-082-002

LEU-COMP-THERM-082-003

LEU-COMP-THERM-082-004

LEU-COMP-THERM-082-005

LEU-COMP-THERM-082-006

LEU-COMP-THERM-083-001

LEU-COMP-THERM-083-002

LEU-COMP-THERM-083-003

LEU-COMP-THERM-084-001

LEU-COMP-THERM-085-001

LEU-COMP-THERM-085-002

LEU-COMP-THERM-085-003

LEU-COMP-THERM-085-004

LEU-COMP-THERM-085-005

LEU-COMP-THERM-085-006

LEU-COMP-THERM-085-007

LEU-COMP-THERM-085-008

LEU-COMP-THERM-085-009

LEU-COMP-THERM-085-010

LEU-COMP-THERM-085-011

LEU-COMP-THERM-085-012

LEU-COMP-THERM-085-013

LEU-COMP-THERM-089-001

LEU-COMP-THERM-089-002

LEU-COMP-THERM-089-003

LEU-COMP-THERM-089-004

LEU-COMP-THERM-090-001
MIX-SOL-THERM-001-005

MIX-SOL-THERM-001-006

MIX-SOL-THERM-001-007

MIX-SOL-THERM-001-008

MIX-SOL-THERM-001-009

MIX-SOL-THERM-001-010

MIX-SOL-THERM-001-011

MIX-SOL-THERM-001-012

MIX-SOL-THERM-001-013

MIX-SOL-THERM-002-001

MIX-SOL-THERM-002-002

MIX-SOL-THERM-002-003

MIX-SOL-THERM-003-001

MIX-SOL-THERM-003-002

MIX-SOL-THERM-003-003

MIX-SOL-THERM-003-004

MIX-SOL-THERM-003-005

MIX-SOL-THERM-003-006

MIX-SOL-THERM-003-007

MIX-SOL-THERM-003-008

MIX-SOL-THERM-003-009

MIX-SOL-THERM-003-010

MIX-SOL-THERM-004-001

MIX-SOL-THERM-004-002

MIX-SOL-THERM-004-003

MIX-SOL-THERM-004-004

MIX-SOL-THERM-004-005

MIX-SOL-THERM-004-006

MIX-SOL-THERM-004-007

MIX-SOL-THERM-004-008

MIX-SOL-THERM-004-009

MIX-SOL-THERM-005-001

MIX-SOL-THERM-005-002

MIX-SOL-THERM-005-003

MIX-SOL-THERM-005-004

MIX-SOL-THERM-005-005

MIX-SOL-THERM-005-006

MIX-SOL-THERM-005-007

MIX-SOL-THERM-007-001

MIX-SOL-THERM-007-002

MIX-SOL-THERM-007-003

MIX-SOL-THERM-007-004

MIX-SOL-THERM-007-005

MIX-SOL-THERM-007-006

MIX-SOL-THERM-007-007

MIX-SOL-THERM-010-001

MIX-SOL-THERM-010-002

MIX-SOL-THERM-010-003

MIX-SOL-THERM-010-004

MIX-SOL-THERM-010-005 
List of critical benchmark experiments considered

LEU-COMP-THERM-033-020 LEU-COMP-THERM-090-002

MIX-SOL-THERM-010-006

LEU-COMP-THERM-033-021 LEU-COMP-THERM-090-003

LEU-COMP-THERM-033-022 LEU-COMP-THERM-090-004

MIX-SOL-THERM-010-007

LEU-COMP-THERM-033-023 LEU-COMP-THERM-090-005

MIX-SOL-THERM-010-008

LEU-COMP-THERM-033-024 LEU-COMP-THERM-090-006

MIX-SOL-THERM-010-009 
APPENDIX C EXPERIMENTS WITH $C_{K}$ VALUES OF AT LEAST 0.8 



\section{APPENDIX C EXPERIMENTS WITH $C_{K}$ VALUES OF AT LEAST 0.8}

This appendix provides the $c_{k}$ values of at least 0.8 for critical experiments compared to each of the 4 applications presented in Section 5. Table C-1 contains results for the GBC-68 cask containing fuel assemblies with a burnup of $25 \mathrm{GWd} / \mathrm{MTU}$ modeled with the AO isotope set. The results for the same fuel modeled with the AFP isotope set is provided in Table C-2. Table C-3 and Table C-4 contain the results for a burnup of $50 \mathrm{GWd} / \mathrm{MTU}$ modeled with the AO isotope set and the AFP isotope set, respectively.

Table C-1 $c_{k}$ Values of at Least 0.8 for Application 1

\begin{tabular}{|c|c|c|c|}
\hline Experiment & $\mathrm{C}_{\mathrm{k}}$ & Experiment & $c_{k}$ \\
\hline LEU-COMP-THERM-008-001 & 0.83910 & MIX-HTC3 001 & 0.82240 \\
\hline LEU-COMP-THERM-008-002 & 0.84590 & MIX-HTC3_002 & 0.82830 \\
\hline LEU-COMP-THERM-008-003 & 0.84660 & MIX-HTC3_003 & 0.83030 \\
\hline LEU-COMP-THERM-008-004 & 0.84770 & MIX-HTC3_004 & 0.82590 \\
\hline LEU-COMP-THERM-008-005 & 0.84740 & MIX-HTC3_005 & 0.83060 \\
\hline LEU-COMP-THERM-008-006 & 0.85060 & MIX-HTC3_006 & 0.83430 \\
\hline LEU-COMP-THERM-008-007 & 0.84940 & MIX-HTC3_007 & 0.82730 \\
\hline LEU-COMP-THERM-008-008 & 0.85740 & MIX-HTC3_008 & 0.83640 \\
\hline LEU-COMP-THERM-008-009 & 0.85740 & MIX-HTC3_009 & 0.83360 \\
\hline LEU-COMP-THERM-008-010 & 0.84600 & MIX-HTC3_010 & 0.83300 \\
\hline LEU-COMP-THERM-008-011 & 0.84560 & MIX-HTC3_011 & 0.83270 \\
\hline LEU-COMP-THERM-008-012 & 0.84620 & MIX-HTC3_016 & 0.80270 \\
\hline LEU-COMP-THERM-008-013 & 0.84630 & MIX-HTC3_017 & 0.80830 \\
\hline LEU-COMP-THERM-008-014 & 0.84390 & MIX-HTC3_018 & 0.81540 \\
\hline LEU-COMP-THERM-008-015 & 0.84500 & MIX-HTC3_019 & 0.81130 \\
\hline LEU-COMP-THERM-008-016 & 0.85040 & MIX-HTC3_020 & 0.81250 \\
\hline LEU-COMP-THERM-008-017 & 0.85770 & MIX-HTC3_025 & 0.80840 \\
\hline LEU-COMP-THERM-011-002 & 0.84700 & MIX-HTC4FE_001 & 0.83900 \\
\hline LEU-COMP-THERM-011-003 & 0.85410 & MIX-HTC4FE_002 & 0.83800 \\
\hline LEU-COMP-THERM-011-004 & 0.85510 & MIX-HTC4FE_003 & 0.83860 \\
\hline LEU-COMP-THERM-011-005 & 0.85380 & MIX-HTC4FE_004 & 0.83700 \\
\hline LEU-COMP-THERM-011-006 & 0.85330 & MIX-HTC4FE_005 & 0.83590 \\
\hline LEU-COMP-THERM-011-007 & 0.85080 & MIX-HTC4FE_006 & 0.83160 \\
\hline LEU-COMP-THERM-011-008 & 0.84810 & MIX-HTC4FE_007 & 0.82970 \\
\hline LEU-COMP-THERM-011-009 & 0.84640 & MIX-HTC4FE_008 & 0.83680 \\
\hline LEU-COMP-THERM-011-010 & 0.85090 & MIX-HTC4FE_009 & 0.83660 \\
\hline LEU-COMP-THERM-011-011 & 0.84670 & MIX-HTC4FE_010 & 0.83550 \\
\hline LEU-COMP-THERM-011-012 & 0.84090 & MIX-HTC4FE_011 & 0.83520 \\
\hline LEU-COMP-THERM-011-013 & 0.83810 & MIX-HTC4FE_012 & 0.84300 \\
\hline LEU-COMP-THERM-011-014 & 0.83150 & MIX-HTC4FE_013 & 0.84340 \\
\hline LEU-COMP-THERM-011-015 & 0.82120 & MIX-HTC4FE_014 & 0.84220 \\
\hline LEU-COMP-THERM-014-005 & 0.82880 & MIX-HTC4FE_015 & 0.83660 \\
\hline LEU-COMP-THERM-015-151 & 0.81620 & MIX-HTC4FE_016 & 0.83830 \\
\hline LEU-COMP-THERM-015-158 & 0.81130 & MIX-HTC4FE_017 & 0.84400 \\
\hline LEU-COMP-THERM-017-004 & 0.80260 & MIX-HTC4FE_018 & 0.84100 \\
\hline LEU-COMP-THERM-017-026 & 0.83020 & MIX-HTC4FE_019 & 0.83730 \\
\hline LEU-COMP-THERM-017-027 & 0.81680 & MIX-HTC4FE_020 & 0.83430 \\
\hline LEU-COMP-THERM-017-028 & 0.80900 & MIX-HTC4FE_021 & 0.83610 \\
\hline LEU-COMP-THERM-017-029 & 0.80200 & MIX-HTC4FE_022 & 0.83600 \\
\hline LEU-COMP-THERM-042-002 & 0.80540 & MIX-HTC4FE_023 & 0.83630 \\
\hline LEU-COMP-THERM-042-003 & 0.81190 & MIX-HTC4FE_024 & 0.83390 \\
\hline
\end{tabular}




\begin{tabular}{|c|c|c|c|}
\hline Experiment & $\mathrm{C}_{\mathrm{k}}$ & Experiment & $C_{k}$ \\
\hline LEU-COMP-THERM-042-004 & 0.81110 & MIX-HTC4FE_025 & 0.83150 \\
\hline LEU-COMP-THERM-042-005 & 0.81100 & MIX-HTC4FE_026 & 0.82980 \\
\hline LEU-COMP-THERM-042-007 & 0.80460 & MIX-HTC4FE_027 & 0.80190 \\
\hline LEU-COMP-THERM-047-001 & 0.84730 & MIX-HTC4FE_028 & 0.80540 \\
\hline LEU-COMP-THERM-051-001 & 0.83620 & MIX-HTC4FE_029 & 0.80960 \\
\hline LEU-COMP-THERM-051-002 & 0.86660 & MIX-HTC4FE_030 & 0.81880 \\
\hline LEU-COMP-THERM-051-003 & 0.86480 & MIX-HTC4FE_031 & 0.81820 \\
\hline LEU-COMP-THERM-051-004 & 0.86440 & MIX-HTC4FE_032 & 0.81220 \\
\hline LEU-COMP-THERM-051-005 & 0.86120 & MIX-HTC4FE_033 & 0.80420 \\
\hline LEU-COMP-THERM-051-006 & 0.86100 & MIX-HTC4PB_002 & 0.81030 \\
\hline LEU-COMP-THERM-051-007 & 0.86260 & MIX-HTC4PB_003 & 0.81060 \\
\hline LEU-COMP-THERM-051-008 & 0.85560 & MIX-HTC4PB_004 & 0.81000 \\
\hline LEU-COMP-THERM-051-009 & 0.86010 & MIX-HTC4PB_005 & 0.80970 \\
\hline LEU-COMP-THERM-051-010 & 0.84760 & MIX-HTC4PB_006 & 0.84550 \\
\hline LEU-COMP-THERM-051-011 & 0.84800 & MIX-HTC4PB_007 & 0.84470 \\
\hline LEU-COMP-THERM-051-012 & 0.84850 & MIX-HTC4PB_008 & 0.84590 \\
\hline LEU-COMP-THERM-051-013 & 0.84790 & MIX-HTC4PB_009 & 0.84520 \\
\hline LEU-COMP-THERM-051-014* & 0.84600 & MIX-HTC4PB_010 & 0.84340 \\
\hline LEU-COMP-THERM-051-015* & 0.84980 & MIX-HTC4PB_011 & 0.84420 \\
\hline LEU-COMP-THERM-051-016 & 0.84730 & MIX-HTC4PB_012 & 0.84190 \\
\hline LEU-COMP-THERM-051-017 & 0.84910 & MIX-HTC4PB_013 & 0.84100 \\
\hline LEU-COMP-THERM-051-018 & 0.84820 & MIX-HTC4PB_014 & 0.83900 \\
\hline LEU-COMP-THERM-051-019 & 0.83740 & MIX-HTC4PB_015 & 0.83990 \\
\hline LEU-COMP-THERM-055-001 & 0.81200 & MIX-HTC4PB_016 & 0.83840 \\
\hline LEU-COMP-THERM-055-002 & 0.80260 & MIX-HTC4PB_017 & 0.84600 \\
\hline LEU-COMP-THERM-076-001 & 0.81380 & MIX-HTC4PB_018 & 0.84210 \\
\hline LEU-COMP-THERM-076-002 & 0.81950 & MIX-HTC4PB_019 & 0.84980 \\
\hline LEU-COMP-THERM-076-003 & 0.81630 & MIX-HTC4PB_020 & 0.84730 \\
\hline LEU-COMP-THERM-076-004 & 0.80820 & MIX-HTC4PB_021 & 0.84380 \\
\hline LEU-COMP-THERM-076-005 & 0.82130 & MIX-HTC4PB_022 & 0.84180 \\
\hline LEU-COMP-THERM-076-006 & 0.81530 & MIX-HTC4PB_023 & 0.84080 \\
\hline LEU-COMP-THERM-076-007 & 0.82410 & MIX-HTC4PB_024 & 0.83880 \\
\hline MIX-HTC2B_004 & 0.80760 & MIX-HTC4PB_025 & 0.83700 \\
\hline MIX-HTC2B_005 & 0.82080 & MIX-HTC4PB_026 & 0.84120 \\
\hline MIX-HTC2B_006 & 0.81950 & MIX-HTC4PB_027 & 0.81210 \\
\hline MIX-HTC2B_007 & 0.83100 & MIX-HTC4PB_028 & 0.81460 \\
\hline MIX-HTC2B_008 & 0.84260 & MIX-HTC4PB_029 & 0.82080 \\
\hline MIX-HTC2B_009 & 0.86620 & MIX-HTC4PB_030 & 0.82070 \\
\hline MIX-HTC2B_010 & 0.85190 & MIX-HTC4PB_031 & 0.81940 \\
\hline MIX-HTC2B_011 & 0.83380 & MIX-HTC4PB_032 & 0.81880 \\
\hline MIX-HTC2B_012 & 0.81580 & MIX-HTC4PB_033 & 0.81730 \\
\hline MIX-HTC2B_016 & 0.81910 & MIX-HTC4PB_034 & 0.83150 \\
\hline MIX-HTC2B_017 & 0.84130 & MIX-HTC4PB_035 & 0.83360 \\
\hline MIX-HTC2B_018 & 0.86150 & MIX-HTC4PB_036 & 0.82950 \\
\hline MIX-HTC2B_020 & 0.83930 & MIX-HTC4PB_037 & 0.82370 \\
\hline MIX-HTC2B_021 & 0.81300 & MIX-HTC4PB_038 & 0.81790 \\
\hline
\end{tabular}


Table C-2 $\quad c_{k}$ Values of at Least $\mathbf{0 . 8}$ for Application 2

\begin{tabular}{|c|c|c|c|}
\hline Experiment & $C_{k}$ & Experiment & $C_{k}$ \\
\hline MIX-HTC2B_005 & 0.80170 & MIX-HTC4FE_017 & 0.82130 \\
\hline MIX-HTC2B_006 & 0.80000 & MIX-HTC4FE_018 & 0.81780 \\
\hline MIX-HTC2B_007 & 0.81610 & MIX-HTC4FE_019 & 0.81300 \\
\hline MIX-HTC2B_008 & 0.83290 & MIX-HTC4FE_020 & 0.80910 \\
\hline MIX-HTC2B_009 & 0.85910 & MIX-HTC4FE_021 & 0.81140 \\
\hline MIX-HTC2B_010 & 0.83750 & MIX-HTC4FE_022 & 0.81110 \\
\hline MIX-HTC2B_011 & 0.81220 & MIX-HTC4FE_023 & 0.81150 \\
\hline MIX-HTC2B_017 & 0.82240 & MIX-HTC4FE_024 & 0.80830 \\
\hline MIX-HTC2B_018 & 0.85270 & MIX-HTC4FE_025 & 0.80550 \\
\hline MIX-HTC2B_020 & 0.82620 & MIX-HTC4FE_026 & 0.80340 \\
\hline MIX-HTC3_002 & 0.80140 & MIX-HTC4PB_006 & 0.82360 \\
\hline MIX-HTC3_003 & 0.80430 & MIX-HTC4PB_007 & 0.82260 \\
\hline MIX-HTC3_005 & 0.80460 & MIX-HTC4PB_008 & 0.82420 \\
\hline MIX-HTC3_006 & 0.80940 & MIX-HTC4PB_009 & 0.82300 \\
\hline MIX-HTC3_008 & 0.81120 & MIX-HTC4PB_010 & 0.82070 \\
\hline MIX-HTC3_009 & 0.80780 & MIX-HTC4PB_011 & 0.82170 \\
\hline MIX-HTC3_010 & 0.80710 & MIX-HTC4PB_012 & 0.81880 \\
\hline MIX-HTC3_011 & 0.80650 & MIX-HTC4PB_013 & 0.81770 \\
\hline MIX-HTC4FE_001 & 0.81570 & MIX-HTC4PB_014 & 0.81510 \\
\hline MIX-HTC4FE_002 & 0.81440 & MIX-HTC4PB_015 & 0.81600 \\
\hline MIX-HTC4FE_003 & 0.81530 & MIX-HTC4PB_016 & 0.81400 \\
\hline MIX-HTC4FE_004 & 0.81320 & MIX-HTC4PB_017 & 0.82540 \\
\hline MIX-HTC4FE_005 & 0.81190 & MIX-HTC4PB_018 & 0.82020 \\
\hline MIX-HTC4FE_006 & 0.80640 & MIX-HTC4PB_019 & 0.82850 \\
\hline MIX-HTC4FE_007 & 0.80400 & MIX-HTC4PB_020 & 0.82530 \\
\hline MIX-HTC4FE_008 & 0.81310 & MIX-HTC4PB_021 & 0.82060 \\
\hline MIX-HTC4FE_009 & 0.81270 & MIX-HTC4PB_022 & 0.81810 \\
\hline MIX-HTC4FE_010 & 0.81120 & MIX-HTC4PB_023 & 0.81700 \\
\hline MIX-HTC4FE_011 & 0.81080 & MIX-HTC4PB_024 & 0.81450 \\
\hline MIX-HTC4FE_012 & 0.82120 & MIX-HTC4PB_025 & 0.81220 \\
\hline MIX-HTC4FE_013 & 0.82180 & MIX-HTC4PB_026 & 0.81720 \\
\hline MIX-HTC4FE_014 & 0.82010 & MIX-HTC4PB_034 & 0.80430 \\
\hline MIX-HTC4FE_015 & 0.81280 & MIX-HTC4PB_035 & 0.80700 \\
\hline MIX-HTC4FE_016 & 0.81510 & MIX-HTC4PB_036 & 0.80130 \\
\hline
\end{tabular}


Table C-3 $\quad c_{k}$ Values of at Least $\mathbf{0 . 8}$ for Application 3

\begin{tabular}{|c|c|c|c|}
\hline Experiment & $C_{k}$ & Experiment & $c_{k}$ \\
\hline LEU-COMP-THERM-011-003 & 0.80370 & MIX-HTC3_011 & 0.89500 \\
\hline LEU-COMP-THERM-011-004 & 0.80400 & MIX-HTC3_012 & 0.84200 \\
\hline LEU-COMP-THERM-011-005 & 0.80340 & MIX-HTC3_013 & 0.84840 \\
\hline LEU-COMP-THERM-011-006 & 0.80350 & MIX-HTC3_014 & 0.85920 \\
\hline LEU-COMP-THERM-011-007 & 0.80280 & MIX-HTC3_015 & 0.86280 \\
\hline LEU-COMP-THERM-011-008 & 0.80180 & MIX-HTC3_016 & 0.86660 \\
\hline LEU-COMP-THERM-011-009 & 0.80130 & MIX-HTC3_017 & 0.87090 \\
\hline LEU-COMP-THERM-011-010 & 0.80460 & MIX-HTC3_018 & 0.87560 \\
\hline LEU-COMP-THERM-011-011 & 0.80330 & MIX-HTC3_019 & 0.87150 \\
\hline LEU-COMP-THERM-011-012 & 0.80060 & MIX-HTC3_020 & 0.87220 \\
\hline LEU-COMP-THERM-047-001 & 0.80660 & MIX-HTC3_021 & 0.85290 \\
\hline LEU-COMP-THERM-051-002 & 0.81770 & MIX-HTC3_022 & 0.84170 \\
\hline LEU-COMP-THERM-051-003 & 0.81700 & MIX-HTC3_023 & 0.83530 \\
\hline LEU-COMP-THERM-051-004 & 0.81710 & MIX-HTC3_024 & 0.85490 \\
\hline LEU-COMP-THERM-051-005 & 0.81580 & MIX-HTC3 025 & 0.87200 \\
\hline LEU-COMP-THERM-051-006 & 0.81600 & MIX-HTC3_026 & 0.86020 \\
\hline LEU-COMP-THERM-051-007 & 0.81670 & MIX-HTC4FE_001 & 0.89980 \\
\hline LEU-COMP-THERM-051-008 & 0.81360 & MIX-HTC4FE_002 & 0.89890 \\
\hline LEU-COMP-THERM-051-009 & 0.81610 & MIX-HTC4FE_003 & 0.89920 \\
\hline LEU-COMP-THERM-051-010 & 0.80150 & MIX-HTC4FE_004 & 0.89760 \\
\hline LEU-COMP-THERM-051-011 & 0.80160 & MIX-HTC4FE_005 & 0.89670 \\
\hline LEU-COMP-THERM-051-012 & 0.80150 & MIX-HTC4FE_006 & 0.89300 \\
\hline LEU-COMP-THERM-051-013* & 0.80000 & MIX-HTC4FE_007 & 0.89140 \\
\hline LEU-COMP-THERM-051-014* & 0.80150 & MIX-HTC4FE_008 & 0.89750 \\
\hline LEU-COMP-THERM-051-015 & 0.80060 & MIX-HTC4FE 009 & 0.89740 \\
\hline LEU-COMP-THERM-051-016 & 0.80190 & MIX-HTC4FE_010 & 0.89650 \\
\hline LEU-COMP-THERM-051-017 & 0.80020 & MIX-HTC4FE_011 & 0.89630 \\
\hline LEU-COMP-THERM-051-018 & 0.80200 & MIX-HTC4FE_012 & 0.90230 \\
\hline MIX-HTC1_001 & 0.83200 & MIX-HTC4FE_013 & 0.90260 \\
\hline MIX-HTC1_002 & 0.82930 & MIX-HTC4FE_014 & 0.90170 \\
\hline MIX-HTC1_003 & 0.82960 & MIX-HTC4FE_015 & 0.89720 \\
\hline MIX-HTC1_004 & 0.84180 & MIX-HTC4FE_016 & 0.89860 \\
\hline MIX-HTC1_005 & 0.84070 & MIX-HTC4FE_017 & 0.90410 \\
\hline MIX-HTC1_006 & 0.84070 & MIX-HTC4FE_018 & 0.90140 \\
\hline MIX-HTC1_007 & 0.83310 & MIX-HTC4FE_019 & 0.89810 \\
\hline MIX-HTC1_008 & 0.83190 & MIX-HTC4FE_020 & 0.89550 \\
\hline MIX-HTC1_009 & 0.83240 & MIX-HTC4FE_021 & 0.89730 \\
\hline MIX-HTC1 010 & 0.82410 & MIX-HTC4FE 022 & 0.89720 \\
\hline MIX-HTC1_011 & 0.82390 & MIX-HTC4FE_023 & 0.89750 \\
\hline MIX-HTC1_012 & 0.82480 & MIX-HTC4FE_024 & 0.89560 \\
\hline MIX-HTC1_013 & 0.83320 & MIX-HTC4FE_025 & 0.89330 \\
\hline MIX-HTC1_014 & 0.83130 & MIX-HTC4FE_026 & 0.89190 \\
\hline MIX-HTC1 015 & 0.83150 & MIX-HTC4FE 027 & 0.86820 \\
\hline MIX-HTC1_016 & 0.83880 & MIX-HTC4FE_028 & 0.87100 \\
\hline MIX-HTC1_017 & 0.84120 & MIX-HTC4FE_029 & 0.87410 \\
\hline MIX-HTC1_018 & 0.83520 & MIX-HTC4FE 030 & 0.88070 \\
\hline MIX-HTC2B_o01 & 0.84720 & MIX-HTC4FE_031 & 0.87980 \\
\hline MIX-HTC2B 002 & 0.84680 & MIX-HTC4FE 032 & 0.87490 \\
\hline
\end{tabular}




\begin{tabular}{|c|c|c|c|}
\hline Experiment & $\mathrm{C}_{\mathrm{k}}$ & Experiment & $\mathrm{C}_{\mathrm{k}}$ \\
\hline MIX-HTC2B_003 & 0.85850 & MIX-HTC4FE_033 & 0.86820 \\
\hline MIX-HTC2B_004 & 0.86970 & MIX-HTC4PB_001 & 0.86280 \\
\hline MIX-HTC2B_005 & 0.88050 & MIX-HTC4PB_002 & 0.87460 \\
\hline MIX-HTC2B_006 & 0.87950 & MIX-HTC4PB_003 & 0.87500 \\
\hline MIX-HTC2B_007 & 0.88870 & MIX-HTC4PB_004 & 0.87440 \\
\hline MIX-HTC2B_008 & 0.89770 & MIX-HTC4PB_005 & 0.87420 \\
\hline MIX-HTC2B_009 & 0.92020 & MIX-HTC4PB_006 & 0.90570 \\
\hline MIX-HTC2B_010 & 0.90980 & MIX-HTC4PB_007 & 0.90500 \\
\hline MIX-HTC2B_011 & 0.89530 & MIX-HTC4PB_008 & 0.90590 \\
\hline MIX-HTC2B_012 & 0.88010 & MIX-HTC4PB_009 & 0.90510 \\
\hline MIX-HTC2B_014 & 0.84660 & MIX-HTC4PB_010 & 0.90360 \\
\hline MIX-HTC2B_015 & 0.85980 & MIX-HTC4PB_011 & 0.90440 \\
\hline MIX-HTC2B_016 & 0.88130 & MIX-HTC4PB_012 & 0.90250 \\
\hline MIX-HTC2B_017 & 0.89960 & MIX-HTC4PB_013 & 0.90160 \\
\hline MIX-HTC2B_018 & 0.91490 & MIX-HTC4PB_014 & 0.89990 \\
\hline MIX-HTC2B_019 & 0.86420 & MIX-HTC4PB_015 & 0.90070 \\
\hline MIX-HTC2B_020 & 0.89240 & MIX-HTC4PB_016 & 0.89950 \\
\hline MIX-HTC2B_021 & 0.87160 & MIX-HTC4PB_017 & 0.90490 \\
\hline MIX-HTC2G_001 & 0.83990 & MIX-HTC4PB_018 & 0.90190 \\
\hline MIX-HTC2G_002 & 0.84000 & MIX-HTC4PB_019 & 0.90940 \\
\hline MIX-HTC2G_003 & 0.83100 & MIX-HTC4PB_020 & 0.90720 \\
\hline MIX-HTC2G_004 & 0.82990 & MIX-HTC4PB_021 & 0.90420 \\
\hline MIX-HTC2G_005 & 0.82940 & MIX-HTC4PB_022 & 0.90260 \\
\hline MIX-HTC2G_006 & 0.81110 & MIX-HTC4PB_023 & 0.90170 \\
\hline MIX-HTC2G_007 & 0.81000 & MIX-HTC4PB_024 & 0.90000 \\
\hline MIX-HTC2G_015 & 0.83040 & MIX-HTC4PB_025 & 0.89840 \\
\hline MIX-HTC2G_016 & 0.83000 & MIX-HTC4PB_026 & 0.90210 \\
\hline MIX-HTC2G_017 & 0.82630 & MIX-HTC4PB_027 & 0.87770 \\
\hline MIX-HTC2G_018 & 0.80960 & MIX-HTC4PB_028 & 0.87970 \\
\hline MIX-HTC2G_020 & 0.82850 & MIX-HTC4PB_029 & 0.88460 \\
\hline MIX-HTC3_001 & 0.88540 & MIX-HTC4PB_030 & 0.88450 \\
\hline MIX-HTC3_002 & 0.89100 & MIX-HTC4PB_031 & 0.88340 \\
\hline MIX-HTC3_003 & 0.89220 & MIX-HTC4PB_032 & 0.88290 \\
\hline MIX-HTC3_004 & 0.88840 & MIX-HTC4PB_033 & 0.88150 \\
\hline MIX-HTC3_005 & 0.89280 & MIX-HTC4PB_034 & 0.89280 \\
\hline MIX-HTC3_006 & 0.89530 & MIX-HTC4PB_035 & 0.89450 \\
\hline MIX-HTC3_007 & 0.89010 & MIX-HTC4PB_036 & 0.89170 \\
\hline MIX-HTC3_008 & 0.89820 & MIX-HTC4PB_037 & 0.88720 \\
\hline MIX-HTC3_009 & 0.89550 & MIX-HTC4PB_038 & 0.88250 \\
\hline MIX-HTC3_010 & 0.89490 & & \\
\hline
\end{tabular}


Table C-4 $\quad c_{k}$ Values of at Least $\mathbf{0 . 8}$ for Application 4

\begin{tabular}{|c|c|c|c|}
\hline Experiment & $c_{k}$ & Experiment & $C_{k}$ \\
\hline MIX-HTC1_001 & 0.80900 & MIX-HTC4FE_009 & 0.86620 \\
\hline MIX-HTC1_002 & 0.80590 & MIX-HTC4FE_010 & 0.86510 \\
\hline MIX-HTC1_003 & 0.80640 & MIX-HTC4FE_011 & 0.86490 \\
\hline MIX-HTC1_004 & 0.80290 & MIX-HTC4FE_012 & 0.87260 \\
\hline MIX-HTC1_005 & 0.80170 & MIX-HTC4FE_013 & 0.87300 \\
\hline MIX-HTC1_006 & 0.80170 & MIX-HTC4FE_014 & 0.87170 \\
\hline MIX-HTC2B_o01 & 0.81200 & MIX-HTC4FE_015 & 0.86600 \\
\hline MIX-HTC2B_002 & 0.81170 & MIX-HTC4FE_016 & 0.86790 \\
\hline MIX-HTC2B_003 & 0.82620 & MIX-HTC4FE_017 & 0.87390 \\
\hline MIX-HTC2B_004 & 0.84020 & MIX-HTC4FE_018 & 0.87070 \\
\hline MIX-HTC2B_005 & 0.85430 & MIX-HTC4FE_019 & 0.86660 \\
\hline MIX-HTC2B_006 & 0.85300 & MIX-HTC4FE_020 & 0.86350 \\
\hline MIX-HTC2B_007 & 0.86520 & MIX-HTC4FE_021 & 0.86550 \\
\hline MIX-HTC2B_008 & 0.87780 & MIX-HTC4FE_022 & 0.86540 \\
\hline MIX-HTC2B-009 & 0.90130 & MIX-HTC4FE 023 & 0.86580 \\
\hline MIX-HTC2B_010 & 0.88600 & MIX-HTC4FE_024 & 0.86340 \\
\hline MIX-HTC2B_011 & 0.86660 & MIX-HTC4FE_025 & 0.86070 \\
\hline MIX-HTC2B_012 & 0.84720 & MIX-HTC4FE_026 & 0.85890 \\
\hline MIX-HTC2B_014 & 0.80620 & MIX-HTC4FE_027 & 0.82970 \\
\hline MIX-HTC2B_015 & 0.82150 & MIX-HTC4FE_028 & 0.83300 \\
\hline MIX-HTC2B_016 & 0.84820 & MIX-HTC4FE_029 & 0.83690 \\
\hline MIX-HTC2B_017 & 0.87200 & MIX-HTC4FE_030 & 0.84560 \\
\hline MIX-HTC2B_018 & 0.89430 & MIX-HTC4FE_031 & 0.84480 \\
\hline MIX-HTC2B_019 & 0.82680 & MIX-HTC4FE_032 & 0.83890 \\
\hline MIX-HTC2B_020 & 0.86830 & MIX-HTC4FE_033 & 0.83100 \\
\hline MIX-HTC2B_021 & 0.83980 & MIX-HTC4PB_001 & 0.82460 \\
\hline MIX-HTC2G_001 & 0.80970 & MIX-HTC4PB_002 & 0.83750 \\
\hline MIX-HTC2G_002 & 0.80980 & MIX-HTC4PB_003 & 0.83790 \\
\hline MIX-HTC2G_003 & 0.80850 & MIX-HTC4PB_004 & 0.83720 \\
\hline MIX-HTC2G_004 & 0.80700 & MIX-HTC4PB_005 & 0.83690 \\
\hline MIX-HTC2G_005 & 0.80650 & MIX-HTC4PB_006 & 0.87620 \\
\hline MIX-HTC2G_020 & 0.80170 & MIX-HTC4PB_007 & 0.87530 \\
\hline MIX-HTC3_001 & 0.85140 & MIX-HTC4PB_008 & 0.87650 \\
\hline MIX-HTC3_002 & 0.85820 & MIX-HTC4PB_009 & 0.87540 \\
\hline MIX-HTC3_003 & 0.85980 & MIX-HTC4PB_010 & 0.87350 \\
\hline MIX-HTC3_004 & 0.85500 & MIX-HTC4PB_011 & 0.87440 \\
\hline MIX-HTC3_005 & 0.86040 & MIX-HTC4PB_012 & 0.87200 \\
\hline MIX-HTC3_006 & 0.86370 & MIX-HTC4PB_013 & 0.87100 \\
\hline MIX-HTC3_007 & 0.85650 & MIX-HTC4PB_014 & 0.86890 \\
\hline MIX-HTC3_008 & 0.86640 & MIX-HTC4PB_015 & 0.86980 \\
\hline MIX-HTC3_009 & 0.86330 & MIX-HTC4PB_016 & 0.86820 \\
\hline MIX-HTC3_010 & 0.86260 & MIX-HTC4PB_017 & 0.87620 \\
\hline MIX-HTC3_011 & 0.86260 & MIX-HTC4PB_018 & 0.87220 \\
\hline MIX-HTC3_013 & 0.80700 & MIX-HTC4PB_019 & 0.88030 \\
\hline MIX-HTC3_014 & 0.81970 & MIX-HTC4PB_020 & 0.87760 \\
\hline MIX-HTC3 015 & 0.82400 & MIX-HTC4PB_021 & 0.87380 \\
\hline MIX-HTC3_016 & 0.82880 & MIX-HTC4PB_022 & 0.87170 \\
\hline MIX-HTC3_017 & 0.83420 & MIX-HTC4PB_023 & 0.87070 \\
\hline
\end{tabular}




\begin{tabular}{|lclc|}
\hline Experiment & $C_{k}$ & Experiment & $C_{k}$ \\
\hline MIX-HTC3_018 & 0.84080 & MIX-HTC4PB_024 & 0.86870 \\
MIX-HTC3_019 & 0.83640 & MIX-HTC4PB_025 & 0.86670 \\
MIX-HTC3_020 & 0.83760 & MIX-HTC4PB_026 & 0.87110 \\
MIX-HTC3_021 & 0.81300 & MIX-HTC4PB_027 & 0.84070 \\
MIX-HTC3_024 & 0.81410 & MIX-HTC4PB_028 & 0.84310 \\
MIX-HTC3_025 & 0.83470 & MIX-HTC4PB_029 & 0.84890 \\
MIX-HTC3_026 & 0.82080 & MIX-HTC4PB_030 & 0.84880 \\
MIX-HTC4FE_001 & 0.86910 & MIX-HTC4PB_031 & 0.84750 \\
MIX-HTC4FE_002 & 0.86800 & MIX-HTC4PB_032 & 0.84690 \\
MIX-HTC4FE_003 & 0.86850 & MIX-HTC4PB_033 & 0.84520 \\
MIX-HTC4FE_004 & 0.86660 & MIX-HTC4PB_034 & 0.85920 \\
MIX-HTC4FE_005 & 0.86550 & MIX-HTC4PB_035 & 0.86130 \\
MIX-HTC4FE_006 & 0.86090 & MIX-HTC4PB_036 & 0.85740 \\
MIX-HTC4FE_007 & 0.85890 & MIX-HTC4PB_037 & 0.85180 \\
MIX-HTC4FE_008 & 0.86650 & MIX-HTC4PB_038 & 0.84600 \\
\hline
\end{tabular}





\section{APPENDIX D VALIDATION DATA FOR LCT EXPERIMENTS}





\section{APPENDIX D VALIDATION DATA FOR LCT EXPERIMENTS}

The relevant critical experiment parameters used for the example validations provided in Section 6 are provided in Table D-1 for the LCT experiments. No data are provided here for the HTC experiments because the data are proprietary.

Table D-1 Critical Experiment Parameters Used for Validation

\begin{tabular}{|c|c|c|c|c|}
\hline Experiment & $\mathrm{C} / \mathrm{E}$ & $\begin{array}{c}\mathrm{C} / \mathrm{E} \\
\text { Uncertainty }\end{array}$ & $\begin{array}{c}\text { Enrichment } \\
\left.\text { (wt\% }{ }^{235} \mathrm{U}\right)\end{array}$ & $\begin{array}{c}\text { EALF } \\
(\mathrm{eV})\end{array}$ \\
\hline LEU-COMP-THERM-008-001 & 0.99893 & 0.00120 & 2.46 & 0.279 \\
\hline LEU-COMP-THERM-008-002 & 0.99956 & 0.00120 & 2.46 & 0.246 \\
\hline LEU-COMP-THERM-008-003 & 1.00019 & 0.00120 & 2.46 & 0.246 \\
\hline LEU-COMP-THERM-008-004 & 0.99957 & 0.00120 & 2.46 & 0.247 \\
\hline LEU-COMP-THERM-008-005 & 0.99882 & 0.00120 & 2.46 & 0.247 \\
\hline LEU-COMP-THERM-008-006 & 0.99970 & 0.00120 & 2.46 & 0.246 \\
\hline LEU-COMP-THERM-008-007 & 0.99884 & 0.00120 & 2.46 & 0.246 \\
\hline LEU-COMP-THERM-008-008 & 0.99829 & 0.00120 & 2.46 & 0.244 \\
\hline LEU-COMP-THERM-008-009 & 0.99877 & 0.00120 & 2.46 & 0.244 \\
\hline LEU-COMP-THERM-008-010 & 0.99938 & 0.00120 & 2.46 & 0.249 \\
\hline LEU-COMP-THERM-008-011 & 1.00001 & 0.00120 & 2.46 & 0.255 \\
\hline LEU-COMP-THERM-008-012 & 0.99956 & 0.00120 & 2.46 & 0.249 \\
\hline LEU-COMP-THERM-008-013 & 0.99977 & 0.00120 & 2.46 & 0.248 \\
\hline LEU-COMP-THERM-008-014 & 0.99942 & 0.00120 & 2.46 & 0.251 \\
\hline LEU-COMP-THERM-008-015 & 0.99939 & 0.00120 & 2.46 & 0.250 \\
\hline LEU-COMP-THERM-008-016 & 0.99950 & 0.00120 & 2.46 & 0.228 \\
\hline LEU-COMP-THERM-008-017 & 0.99867 & 0.00120 & 2.46 & 0.199 \\
\hline LEU-COMP-THERM-011-002 & 0.99749 & 0.00319 & 2.46 & 0.248 \\
\hline LEU-COMP-THERM-011-003 & 0.99775 & 0.00319 & 2.46 & 0.195 \\
\hline LEU-COMP-THERM-011-004 & 0.99827 & 0.00319 & 2.46 & 0.195 \\
\hline LEU-COMP-THERM-011-005 & 0.99807 & 0.00319 & 2.46 & 0.196 \\
\hline LEU-COMP-THERM-011-006 & 0.99789 & 0.00319 & 2.46 & 0.197 \\
\hline LEU-COMP-THERM-011-007 & 0.99786 & 0.00319 & 2.46 & 0.198 \\
\hline LEU-COMP-THERM-011-008 & 0.99825 & 0.00319 & 2.46 & 0.199 \\
\hline LEU-COMP-THERM-011-009 & 0.99794 & 0.00319 & 2.46 & 0.200 \\
\hline LEU-COMP-THERM-011-010 & 0.99415 & 0.00169 & 2.46 & 0.189 \\
\hline LEU-COMP-THERM-011-011 & 0.99416 & 0.00169 & 2.46 & 0.165 \\
\hline LEU-COMP-THERM-011-012 & 0.99398 & 0.00169 & 2.46 & 0.170 \\
\hline LEU-COMP-THERM-011-013 & 0.99524 & 0.00169 & 2.46 & 0.149 \\
\hline LEU-COMP-THERM-011-014 & 0.99505 & 0.00169 & 2.46 & 0.153 \\
\hline LEU-COMP-THERM-011-015 & 0.99689 & 0.00180 & 2.46 & 0.140 \\
\hline LEU-COMP-THERM-014-005 & 1.00333 & 0.00692 & 4.31 & 0.586 \\
\hline LEU-COMP-THERM-015-151 & 0.99951 & 0.00300 & 3.56 & 0.178 \\
\hline LEU-COMP-THERM-015-158 & 0.99797 & 0.00300 & 3.56 & 0.211 \\
\hline LEU-COMP-THERM-017-004 & 0.99764 & 0.00309 & 2.35 & 0.205 \\
\hline LEU-COMP-THERM-017-026 & 0.99588 & 0.00279 & 2.35 & 0.376 \\
\hline LEU-COMP-THERM-017-027 & 0.99797 & 0.00280 & 2.35 & 0.323 \\
\hline LEU-COMP-THERM-017-028 & 0.99858 & 0.00280 & 2.35 & 0.282 \\
\hline LEU-COMP-THERM-017-029 & 0.99854 & 0.00280 & 2.35 & 0.254 \\
\hline LEU-COMP-THERM-042-002 & 0.99771 & 0.00160 & 2.35 & 0.178 \\
\hline LEU-COMP-THERM-042-003 & 0.99851 & 0.00160 & 2.35 & 0.185 \\
\hline LEU-COMP-THERM-042-004 & 0.99930 & 0.00170 & 2.35 & 0.183 \\
\hline LEU-COMP-THERM-042-005 & 0.99922 & 0.00330 & 2.35 & 0.180 \\
\hline
\end{tabular}




\begin{tabular}{|c|c|c|c|c|}
\hline Experiment & $\mathrm{C} / \mathrm{E}$ & $\begin{array}{c}\mathrm{C} / \mathrm{E} \\
\text { Uncertainty }\end{array}$ & $\begin{array}{l}\text { Enrichment } \\
\left.\text { (wt\% }{ }^{235} \mathrm{U}\right)\end{array}$ & $\begin{array}{c}\text { EALF } \\
(\mathrm{eV})\end{array}$ \\
\hline LEU-COMP-THERM-042-007 & 0.99752 & 0.00180 & 2.35 & 0.176 \\
\hline LEU-COMP-THERM-047-001 & 1.00043 & 0.00200 & 3.01 & 0.168 \\
\hline LEU-COMP-THERM-051-001 & 0.99782 & 0.00200 & 2.46 & 0.149 \\
\hline LEU-COMP-THERM-051-002 & 0.99818 & 0.00240 & 2.46 & 0.196 \\
\hline LEU-COMP-THERM-051-003 & 0.99817 & 0.00240 & 2.46 & 0.196 \\
\hline LEU-COMP-THERM-051-004 & 0.99795 & 0.00239 & 2.46 & 0.198 \\
\hline LEU-COMP-THERM-051-005 & 0.99765 & 0.00239 & 2.46 & 0.198 \\
\hline LEU-COMP-THERM-051-006 & 0.99778 & 0.00239 & 2.46 & 0.199 \\
\hline LEU-COMP-THERM-051-007 & 0.99743 & 0.00239 & 2.46 & 0.200 \\
\hline LEU-COMP-THERM-051-008 & 0.99776 & 0.00239 & 2.46 & 0.201 \\
\hline LEU-COMP-THERM-051-009 & 0.99709 & 0.00190 & 2.46 & 0.167 \\
\hline LEU-COMP-THERM-051-010 & 0.99680 & 0.00189 & 2.46 & 0.192 \\
\hline LEU-COMP-THERM-051-011 & 0.99409 & 0.00189 & 2.46 & 0.193 \\
\hline LEU-COMP-THERM-051-012 & 0.99285 & 0.00189 & 2.46 & 0.195 \\
\hline LEU-COMP-THERM-051-015 & 0.99206 & 0.00238 & 2.46 & 0.200 \\
\hline LEU-COMP-THERM-051-016 & 0.99167 & 0.00198 & 2.46 & 0.169 \\
\hline LEU-COMP-THERM-051-017 & 0.99348 & 0.00268 & 2.46 & 0.201 \\
\hline LEU-COMP-THERM-051-018 & 0.99323 & 0.00209 & 2.46 & 0.169 \\
\hline LEU-COMP-THERM-051-019 & 0.99313 & 0.00189 & 2.46 & 0.150 \\
\hline LEU-COMP-THERM-055-001 & 0.99948 & 0.00250 & 3.01 & 1.217 \\
\hline LEU-COMP-THERM-055-002 & 0.99906 & 0.00250 & 3.01 & 1.482 \\
\hline LEU-COMP-THERM-076-001 & 0.99847 & 0.00250 & 3.00 & 1.485 \\
\hline LEU-COMP-THERM-076-002 & 0.99847 & 0.00250 & 3.00 & 1.485 \\
\hline LEU-COMP-THERM-076-003 & 0.99850 & 0.00250 & 3.00 & 1.403 \\
\hline LEU-COMP-THERM-076-004 & 0.99779 & 0.00250 & 3.00 & 1.483 \\
\hline LEU-COMP-THERM-076-005 & 1.00171 & 0.00251 & 3.00 & 1.480 \\
\hline LEU-COMP-THERM-076-006 & 0.99949 & 0.00250 & 3.00 & 1.496 \\
\hline LEU-COMP-THERM-076-007 & 1.00325 & 0.00251 & 3.00 & 1.368 \\
\hline
\end{tabular}


NRC FORM 335

$(12-2010)$

NRCMD 3.7
U.S. NUCLEAR REGULATORY COMMISSION

BIBLIOGRAPHIC DATA SHEET

(See instructions on the reverse)
NUREG/CR-7252

ORNL/TM-2018/797

3. DATE REPORT PUBLISHED

Validation of keff Calculations for Extended BWR Burnup Credit

December $\quad 2018$

4. FIN OR GRANT NUMBER

6. TYPE OF REPORT

Technical

W.J. Marshall

J.B. Clarity

S.M. Bowman

7. PERIOD COVERED (Inclusive Dates)

8. PERFORMING ORGANIZATION - NAME AND ADDRESS (If NRC, provide Division, Office or Region, U. S. Nuclear Regulatory Commission, and mailing address; if contractor, provide name and mailing address.)

Oak Ridge National Laboratory

Managed by UT-Battelle, LLC

Oak Ridge, TN 37831-6170

9. SPONSORING ORGANIZATION - NAME AND ADDRESS (If NRC, type "Same as above", if contractor, provide NRC Division, Office or Region, U. S. Nuclear Regulatory Commission, and mailing address.)

Division of System Analysis and Regulatory Effectiveness

Office of Nuclear Regulatory Research

U.S. Nuclear Regulatory Commission

Washington, D.C. 20555-0001

10. SUPPLEMENTARY NOTES

\section{ABSTRACT (200 words or less)}

The validation of numerical methods used in criticality safety analyses is required by the Code of Federal Regulations. Validation requires the comparison of computational results with measurements of physical systems, and these systems must be similar to the safety analysis being performed. This document examines methods available to generate sensitivity data to facilitate the identification of similar systems. A large number of critical benchmark experiments are surveyed using sensitivity/uncertainty (S/U) techniques to assess their applicability to boiling-water reactor (BWR) burnup credit (BUC) beyond the burnup of peak reactivity. Multiple burnups of BWR assemblies are considered, as well as both the actinide-only (AO) and actinide and major fission product (AFP) isotope sets. Sample validations are completed for representative application models to demonstrate that appropriate validation is possible and to provide an indication of the bias and bias uncertainty values that should be expected for related applications.

12. KEY WORDS/DESCRIPTORS (List words or phrases that will assist researchers in locating the report.)

Validation

Burnup credit

Boiling-water reactor

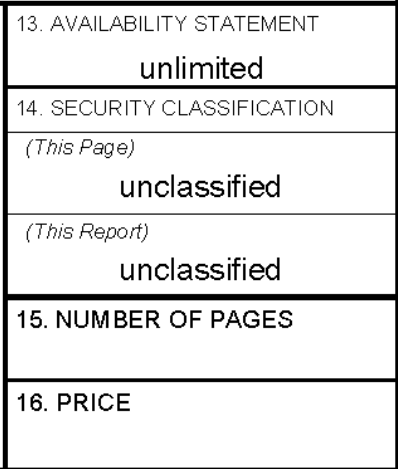


$\theta$ 



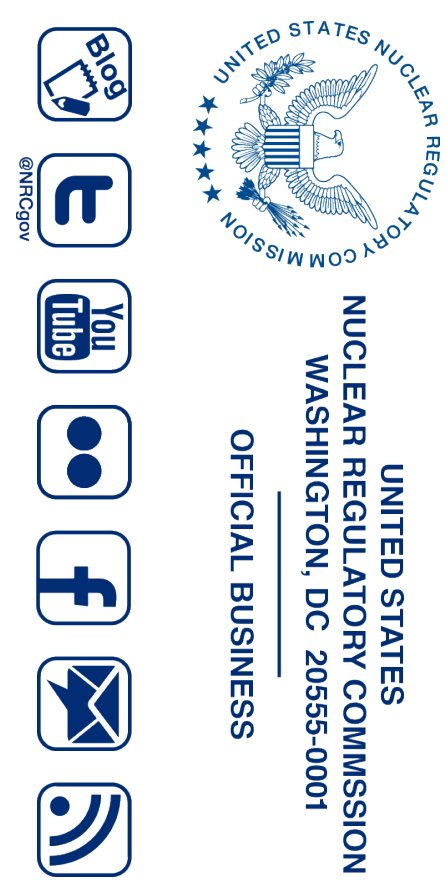




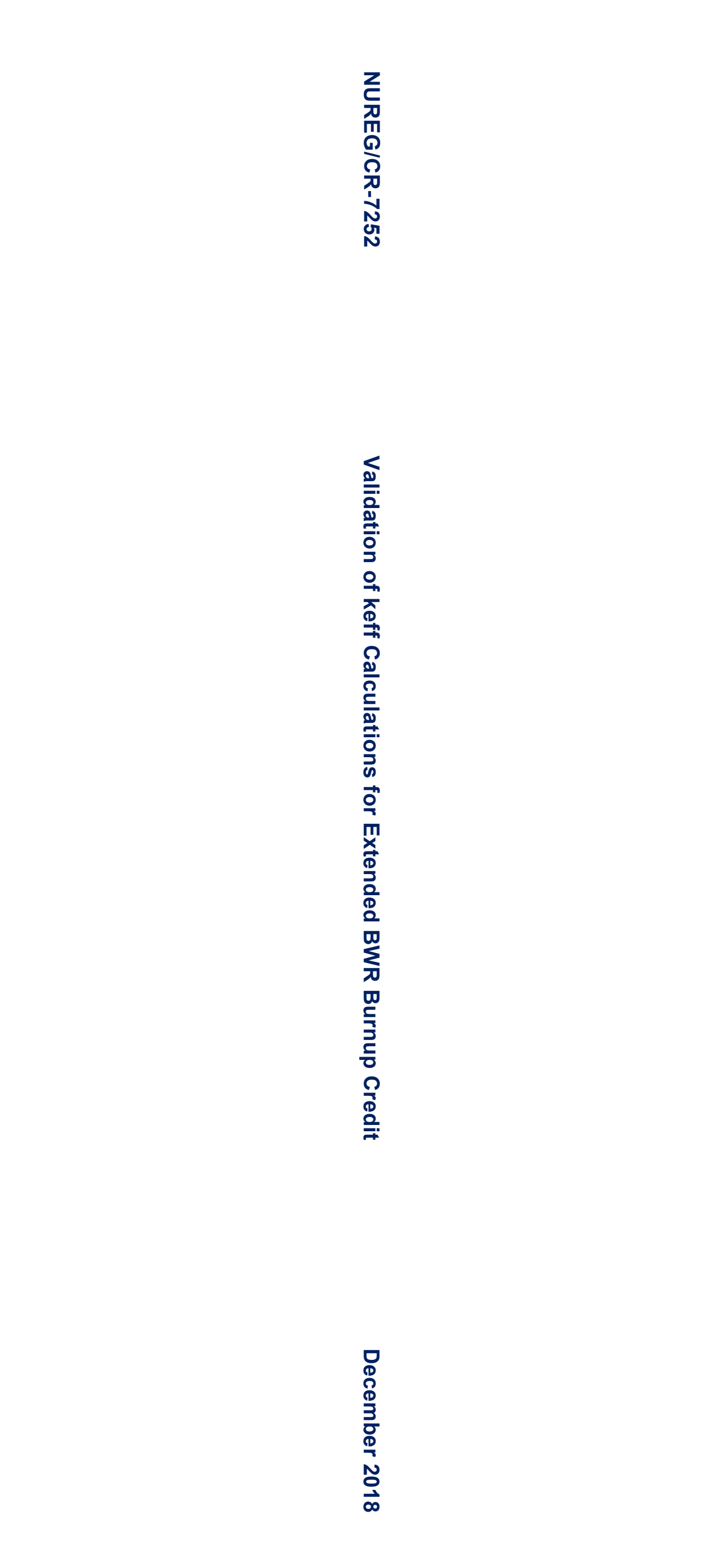

